\title{
Climate change projections using the IPSL-CM5 Earth System Model: from CMIP3 to CMIP5
}

\author{
J.-L. Dufresne $\cdot$ M.-A. Foujols $\cdot$ S. Denvil $\cdot$ A. Caubel $\cdot$ O. Marti $\cdot$ O. Aumont $\cdot$ Y. Balkanski $\cdot$ S. Bekki $\cdot$ \\ H. Bellenger $\cdot$ R. Benshila $\cdot$ S. Bony $\cdot$ L. Bopp $\cdot$ P. Braconnot $\cdot$ P. Brockmann $\cdot$ P. Cadule $\cdot$ F. Cheruy $\cdot$ \\ F. Codron $\cdot$ A. Cozic $\cdot$ D. Cugnet $\cdot$ N. de Noblet $\cdot$ J.-P. Duvel $\cdot$ C. Ethé $\cdot$ L. Fairhead $\cdot$ T. Fichefet $\cdot$ \\ S. Flavoni $\cdot$ P. Friedlingstein $\cdot$ J.-Y. Grandpeix $\cdot$ L. Guez $\cdot$ E. Guilyardi $\cdot$ D. Hauglustaine $\cdot$ F. Hourdin $\cdot$ \\ A. Idelkadi $\cdot$ J. Ghattas $\cdot$ S. Joussaume $\cdot$ M. Kageyama $\cdot$ G. Krinner $\cdot$ S. Labetoulle $\cdot$ A. Lahellec $\cdot$

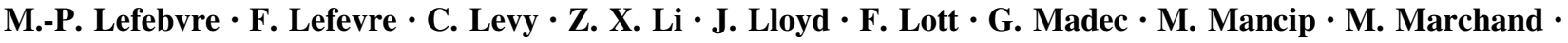 \\ S. Masson $\cdot$ Y. Meurdesoif $\cdot$ J. Mignot $\cdot$ I. Musat $\cdot$ S. Parouty $\cdot$ J. Polcher $\cdot$ C. Rio $\cdot$ M. Schulz $\cdot$ D. Swingedouw $\cdot$ \\ S. Szopa $\cdot$ C. Talandier $\cdot$ P. Terray $\cdot$ N. Viovy $\cdot$ N. Vuichard
}

Received: 14 November 2011 / Accepted: 15 December 2012/Published online: 24 February 2013

(c) The Author(s) 2013. This article is published with open access at Springerlink.com

\begin{abstract}
We present the global general circulation model IPSL-CM5 developed to study the long-term response of the climate system to natural and anthropogenic forcings as part of the 5th Phase of the Coupled Model Intercomparison Project (CMIP5). This model includes an interactive carbon cycle, a representation of tropospheric and stratospheric chemistry, and a comprehensive representation of aerosols. As it represents the principal dynamical, physical, and biogeochemical processes relevant to the climate system, it may be referred to as an Earth System Model. However, the IPSL-CM5 model may be used in a multitude of
\end{abstract}

This paper is a contribution to the special issue on the IPSL and CNRM global climate and Earth System Models, both developed in France and contributing to the 5th coupled model intercomparison project.

J.-L. Dufresne $(\bowtie) \cdot S$. Bony $\cdot$ F. Cheruy $\cdot$ F. Codron ·

J.-P. Duvel · L. Fairhead · J.-Y. Grandpeix · L. Guez ·

F. Hourdin · A. Idelkadi - A. Lahellec - M.-P. Lefebvre .

Z. X. Li · F. Lott · I. Musat · J. Polcher · C. Rio

Laboratoire de Météorologie Dynamique (LMD/IPSL), Centre

National de la Recherche Scientifique (CNRS), Ecole Normale

Supérieure (ENS), Ecole Polytechnique (EP), Université Pierre

et Marie Curie (UPMC), Paris, France

e-mail: Jean-Louis.Dufresne@1md.jussieu.fr

M.-A. Foujols · S. Denvil · P. Cadule · C. Ethé · J. Ghattas · M. Mancip

Institut Pierre Simon Laplace (IPSL), Centre National de la Recherche Scientifique (CNRS), Université de Versailles Saint-Quentin (UVSQ), Université Pierre et Marie Curie (UPMC), Commissariat à l'Energie Atomique (CEA), Institut de Recherche pour le Développement (IRD), Ecole Normale Supérieure (ENS), Ecole Polytechnique (EP), Université Denis Diderot, Université Paris-Est Créteil, Paris, France configurations associated with different boundary conditions and with a range of complexities in terms of processes and interactions. This paper presents an overview of the different model components and explains how they were coupled and used to simulate historical climate changes over the past 150 years and different scenarios of future climate change. A single version of the IPSL-CM5 model (IPSLCM5A-LR) was used to provide climate projections associated with different socio-economic scenarios, including the different Representative Concentration Pathways considered by CMIP5 and several scenarios from the Special Report on Emission Scenarios considered by CMIP3. Results suggest that the magnitude of global warming projections primarily depends on the socio-economic scenario considered, that there is potential for an aggressive mitigation policy to limit global warming to about two degrees, and

\footnotetext{
A. Caubel - O. Marti - Y. Balkanski - L. Bopp - P. Braconnot ·

P. Brockmann · A. Cozic $\cdot$ N. de Noblet $\cdot$ P. Friedlingstein ·

D. Hauglustaine $\cdot$ S. Joussaume $\cdot$ M. Kageyama .

Y. Meurdesoif $\cdot$ M. Schulz $\cdot$ D. Swingedouw $\cdot$ S. Szopa ·

N. Viovy $\cdot$ N. Vuichard

Laboratoire des Sciences du Climat et de l'Environnement

(LSCE/IPSL), Centre National de la Recherche Scientifique (CNRS), Commissariat à l'Energie Atomique (CEA),

Université de Versailles Saint-Quentin (UVSQ),

Gif-sur-Yvette, France

O. Aumont $\cdot$ C. Talandier

Laboratoire de Physique des Océans (LPO), Centre National de

la Recherche Scientifique (CNRS), Institut Français de

Recherche pour l'Exploitation de la Mer (Ifremer),

Institut de Recherche pour le Développement (IRD),

Université de Bretagne Occidentale (UBO),

Brest, France
} 
that the behavior of some components of the climate system such as the Arctic sea ice and the Atlantic Meridional Overturning Circulation may change drastically by the end of the twenty-first century in the case of a no climate policy scenario. Although the magnitude of regional temperature and precipitation changes depends fairly linearly on the magnitude of the projected global warming (and thus on the scenario considered), the geographical pattern of these changes is strikingly similar for the different scenarios. The representation of atmospheric physical processes in the model is shown to strongly influence the simulated climate variability and both the magnitude and pattern of the projected climate changes.

Keywords Climate Climate change Climate projections - Earth System Model - CMIP5 - CMIP3 . Greenhouse gases · Aerosols · Carbon cycle $\cdot$ Allowable emissions $\cdot$ RCP scenarios $\cdot$ Land use changes

\section{Introduction}

As climate change projections rely on climate model results, the scientific community organizes regular international projects to intercompare these models. Over the years, the various phases of the Coupled Model Intercomparison Project (CMIP) have grown steadily both in terms of participants' number and scientific impacts. The

S. Bekki - D. Cugnet · F. Lefevre · M. Marchand Laboratoire Atmosphères, Milieux, Observations Spatiales (LATMOS/IPSL), Centre National de la Recherche Scientifique (CNRS), Université de Versailles Saint-Quentin (UVSQ), Université Pierre et Marie Curie (UPMC), Paris, France

H. Bellenger · R. Benshila $\cdot$ S. Flavoni · E. Guilyardi . S. Labetoulle · C. Levy · J. Lloyd · G. Madec · S. Masson · J. Mignot $\cdot$ C. Talandier $\cdot$ P. Terray

Laboratoire d'Océanographie et du Climat: Expérimentation et Approches Numériques (LOCEAN/IPSL), Centre National de la Recherche Scientifique (CNRS), Université Pierre et Marie Curie (UPMC), Institut de Recherche pour le Développement (IRD), Museum National d'Histoire Naturelle (MNHM), Paris, France

\section{T. Fichefet}

Georges Lemaître Centre for Earth and Climate Research, Earth and Life Institute, Université Catholique de Louvain,

1348 Louvain-la-Neuve, Belgium

\section{P. Friedlingstein}

College of Engineering, Mathematics and Physical Sciences, University of Exeter, Exeter EX4 4QF, UK

G. Krinner · S. Parouty

Laboratoire de Glaciologie et Géophysique de l'Environnement (LGGE), Centre National de la Recherche Scientifique (CNRS), Université Joseph Fourier (UJF), Grenoble, France model outputs made available by the third phase of CMIP (CMIP3, Meehl et al. 2005; 2007a) have led to hundreds of publications and provided important inputs to the IPCC fourth assessment report (IPCC, 2007). The fifth phase, CMIP5 (Taylor et al. 2012), is also expected to serve the scientific community for many years and to provide major inputs to the forthcoming IPCC fifth assessment report.

The IPSL-CM4 model (Marti et al. 2010) developed at Institut Pierre Simon Laplace (IPSL) contributed to CMIP3. It is a classical climate model that couples an atmosphere-land surface model to a ocean-sea ice model. It has been used to simulate and to analyze tropical climate variability (Braconnot et al. 2007), climate change projections (Dufresne et al. 2005), paleo climates (Alkama et al. 2008; Marzin and Braconnot 2009), and the impact of Greenland ice sheet melting on the Atlantic meridional overturning circulation (Swingedouw et al. 2007b, 2009) among other studies. Using the same physical package, separate developments have been carried out to simulate tropospheric chemistry (Hauglustaine et al. 2004), tropospheric aerosols (Balkanski et al. 2010), stratospheric chemistry (Jourdain et al. 2008), and the carbon cycle (Friedlingstein et al. 2006; Cadule et al. 2009). The model with the carbon cycle (IPSL-CM4-LOOP) has been used to study feedbacks between climate and biogeochemical processes. For instance, Lenton et al. (2009) have shown that a change in stratospheric ozone may modify the carbon cycle through a modification of the atmospheric and oceanic circulations. Lengaigne et al. (2009) have suggested positive feedbacks between sea-ice extent and chlorophyll distribution in the Arctic region on a seasonal time scale.

The IPSL-CM5 model, which is presented here and contributes to CMIP5, is an Earth System Model (ESM) that includes all the previous developments. It is a platform that allows for a consistent suite of models with various degrees of complexity, various numbers of components and processes, and different resolutions. Similar approaches have been adopted in other climate modeling centers (e.g. Martin et al. 2011). This flexibility is difficult to implement and to keep up to date but it is useful for many studies. For instance, when studying the various feedbacks of the climate system, it is common to replace some components or processes by prescribed conditions.

When evaluating the performance of the aerosol and chemistry components in the atmosphere, one may want to nudge the global atmospheric circulation to the observed one. For more theoretical studies or to investigate the robustness of some climate features, one may wish to drastically simplify the system by simulating for instance an idealized aqua-planet.

It is very useful to have different versions of a model with different "physical packages", i.e. different sets of consistent parameterizations. First, it allows for the 
analysis of the role of some physical processes on the climate system such as deep convection (e.g. Braconnot et al. 2007). Second, it facilitates the developments of the ESM, which is an ongoing process. Indeed developing and adjusting the physical package requires time. As these developments strongly impact the characteristics of the biogeochemistry variables (e.g. aerosol concentration, chemistry composition,...), it is important that a frozen version of the physical package is used while the models including the other processes are being developed. In the previous IPSL-CM4 model, most of the chemistry and aerosol studies where first made using the LMDZ atmospheric model with the Tiedtke convective scheme (Tiedtke 1989) while the Emanuel convective scheme (Emanuel 1991) was included and developed to improve the characteristics of the simulated climate. However these two versions were not included in a single framework and have diverged over the years. Conversely, the new IPSL model includes two physical packages within the same framework. IPSL-CM5A is an improved extension of IPSL-CM4 and is now used as an ESM. IPSL-CM5B includes a brand new set of physical parameterizations in the atmospheric model (Hourdin et al. 2013b).

The following main priorities were given to IPSLCM5A in order to fulfill our scientific priorities. The first was to include all necessary processes to study climatechemistry and climate-biogeochemistry interactions. This was achieved by including and adapting the new components and improvements developed at the IPSL during the last 10 years, and by increasing the vertical resolution of the stratosphere to make the coupling with stratospheric chemistry possible. The second priority was to reduce the mid-latitude cold bias (Swingedouw et al. 2007a; Marti et al. 2010), and dedicated work on the impact of the atmospheric grid on this cold bias has been undertaken (Hourdin et al. 2013a). Finally, a rather coarse resolution for both the atmosphere and the ocean was favored to allow for long term simulations and ensembles simulations in a reasonable amount of computing time. For the IPSL-CM5B model, the objectives of developments were very different. The main objective was to test some major developments of the parameterizations of boundary layer, deep convection and clouds processes. Although this new version is expected to have some possibly important biases due to incomplete developments and lack of tuning, its should be considered as a prototype of the next model generation.

The outline of the paper is the following. The IPSLCM5 model and its components are briefly presented in Sect. 2. The different model configurations and the different forcings used to perform the CMIP5 long-term experiments are presented in Sect. 3. Among these experiments, climate change simulations of the twentieth century and projections for the twenty-first century are analyzed in
Sects. 4 and 5 . Then the climate variability and response to the same forcing are analyzed for different versions of the IPSL model (Sect. 6). Summary and conclusions are given in Sect. 7.

\section{The IPSL-CM5 model and its components}

\subsection{The platform}

The IPSL-CM5 ESM platform allows for a large range of model configurations, which aim at addressing different scientific questions. These configurations may differ in various ways: physical parameterizations, horizontal resolution, vertical resolution, number of components (atmosphere and land surface only, ocean and sea ice only, coupled atmosphere-land surface-ocean-sea ice) and number of processes (physical, chemistry, aerosols, carbon cycle) (Fig. 1).

The IPSL-CM5 model is built around a physical core that includes the atmosphere, land-surface, ocean and seaice components. It also includes biogeochemical processes through different models: stratospheric and tropospheric chemistry, aerosols, terrestrial and oceanic carbon cycle (Fig. 1a). To test specific hypotheses or feedback mechanisms, components of the model may be suppressed and replaced by prescribed boundary conditions or values (Sect. 3). A general overview of the various models included in the IPSL-CM5 model is given in the next subsections.

\subsection{Atmosphere}

\subsubsection{Atmospheric GCM: LMDZ5A and LMDZ5B}

LMDZ is an atmospheric general circulation model developed at the Laboratoire de Météorologie Dynamique. The dynamical part of the code is based on a finite-difference formulation of the primitive equations of meteorology (Sadourny and Laval 1984) on a staggered and stretchable longitude-latitude grid (the Z in LMDZ stands for zoom). Water vapor, liquid water and atmospheric trace species are advected with a monotonic second order finite volume scheme (Van Leer 1977; Hourdin and Armengaud 1999). The model uses a classical so-called hybrid $\sigma-p$ coordinate in the vertical. The number of layers has been increased from 19 to 39 compared to the previous LMDZ4 version, with 15 levels above $20 \mathrm{~km}$. The maximum altitude for the L39 discretization is about the same as for the stratospheric LMDZ4-L50 version (Lott et al. 2005). It is fine enough to resolve the mid-latitude waves propagation in the stratosphere and to produce sudden-stratospheric warmings. Two versions of LMDZ5, which differ by the 
(a)
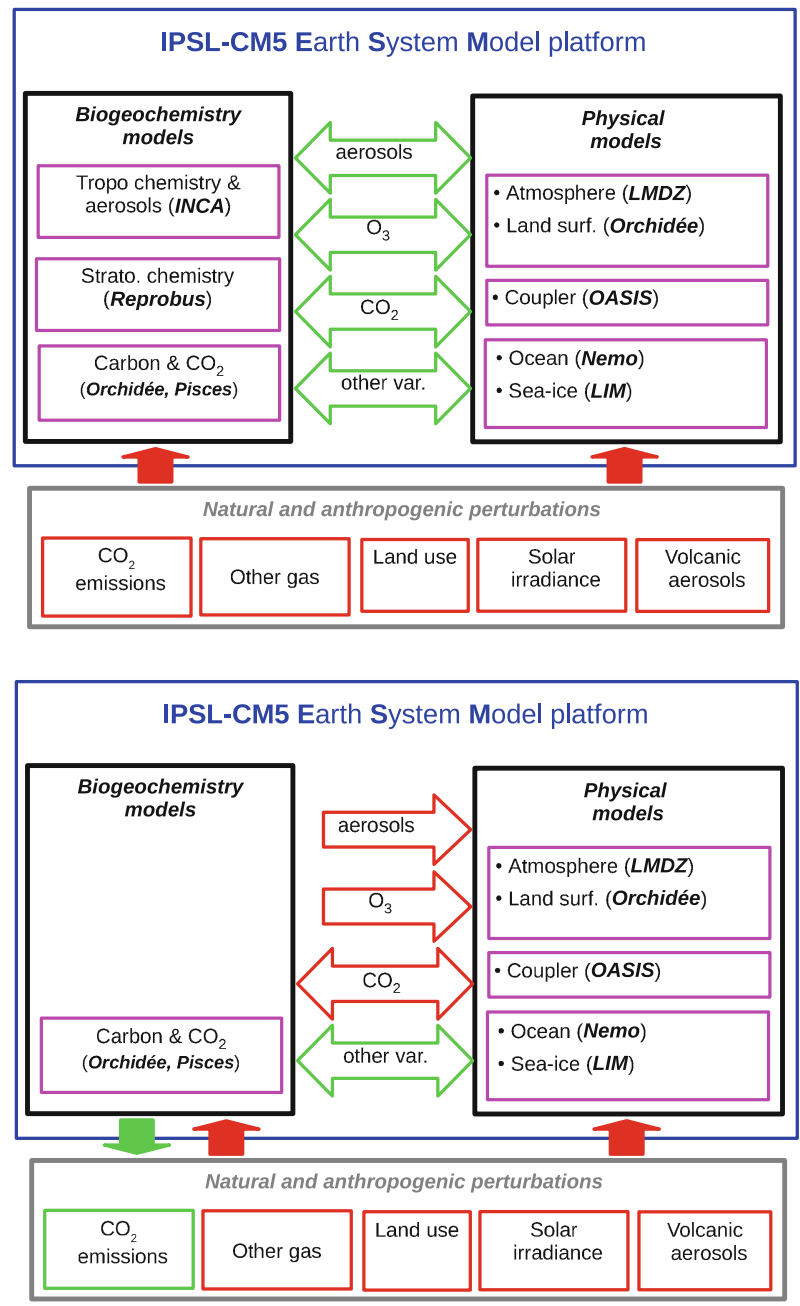

Fig. 1 Schematic of the IPSL-CM5 ESM platform. The individual models constituting the platform are in magenta boxes, the computed variables are in green boxes and the prescribed variables are in red boxes. The physical and biogeochemistry models exchange aerosol, ozone and $\mathrm{CO}_{2}$ concentrations, as detailed on the figure. They also exchange concentration of other constituents as well as many physical or dynamical variables, gathered in the "other var" label. In a, the "plain configuration" is shown with all the models being active. In $\mathbf{b}$, the "atmospheric chemistry configuration" is shown where the ocean

parameterization of turbulence, convection, and clouds can be used within IPSL-CM5.

In the LMDZ5A version, (Hourdin et al. 2013a) the physical parameterizations are very similar to that in the previous LMDZ4 version used for CMIP3 (Hourdin et al. 2006). The radiation scheme is inherited from the European Center for Medium-Range Weather Forecasts (Fouquart and Bonnel 1980; Morcrette et al. 1986). The dynamical effects of the subgrid-scale orography are parameterized according to Lott (1999). Turbulent transport in the planetary boundary layer is treated as a vertical eddy diffusion (Laval et al. 1981) with counter-gradient correction and dry convective adjustment. The surface boundary layer is treated according to Louis (1979). Cloud cover and cloud
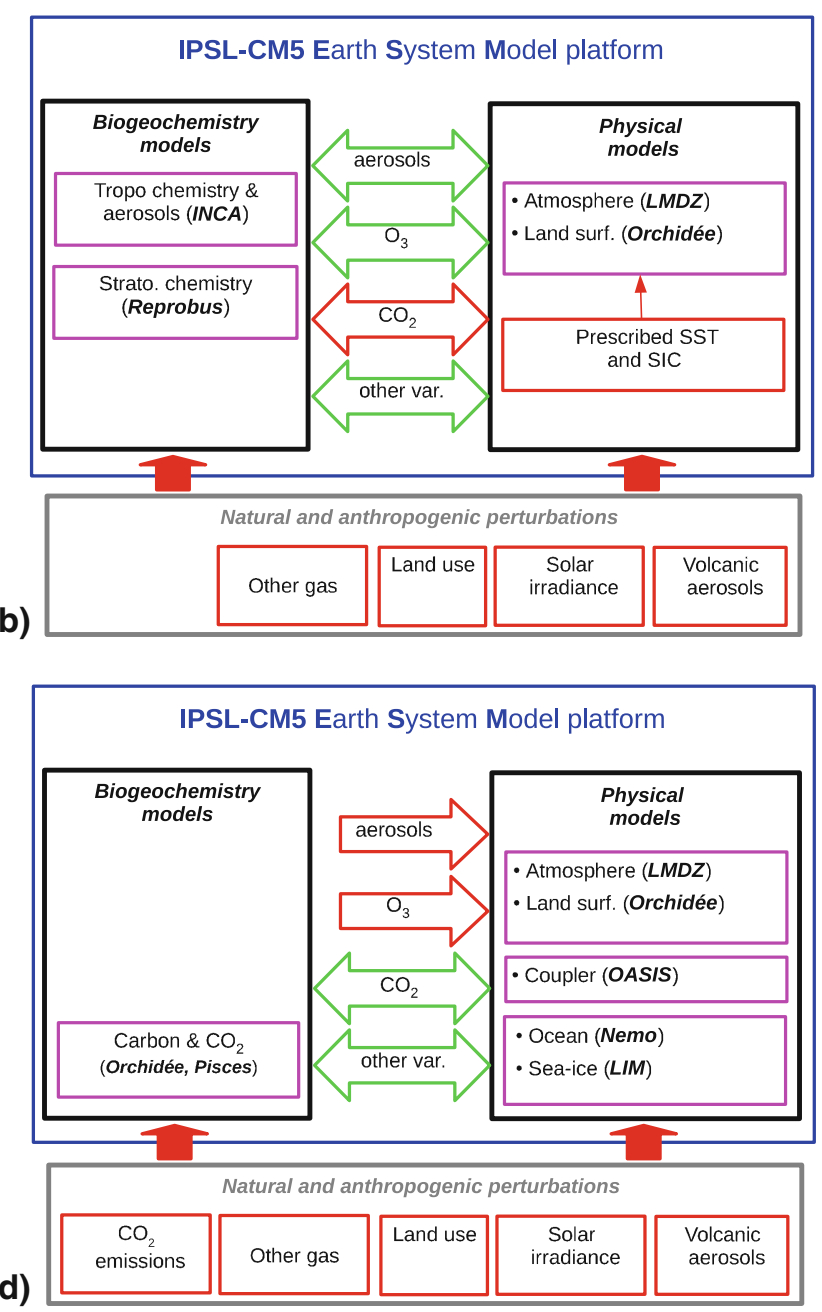

and the carbon cycle models have been replaced by prescribed boundary conditions: ocean surface temperature, sea-ice fraction and $\mathrm{CO}_{2}$ concentration. In $\mathbf{c}$, the "climate-carbon configuration" is shown where the chemistry and aerosol models have been replaced by prescribed conditions (ozone and aerosols 3D fields). The $\mathrm{CO}_{2}$ concentration is prescribed and the "implied $\mathrm{CO}_{2}$ emissions" are computed. In $\mathbf{d}$, the same configuration as in $\mathbf{c}$ is shown except that $\mathrm{CO}_{2}$ emissions are prescribed and $\mathrm{CO}_{2}$ concentration is computed

water content are computed using a statistical scheme (Bony and Emanuel 2001). For deep convection, the LMDZ5A version uses the "episodic mixing and buoyancy sorting" scheme originally developed by Emanuel (1991). LMDZ5A is used within the IPSL-CM5A model.

In the "New Physics" LMDZ5B version, (Hourdin et al. 2013b) the boundary layer is represented by a combined eddy-diffusion plus "thermal plume model" to represent the coherent structures of the convective boundary layer (Hourdin et al. 2002; Rio and Hourdin 2008; Rio et al. 2010). The cloud scheme is coupled to both the convection scheme (Bony and Emanuel 2001) and the boundary layer scheme (Jam et al. 2013) assuming that the subgrid scale distribution of total water can be represented by a 
generalized log-normal distribution in the first case, and by a bi-Gaussian distribution in the second case. In both cases, the statistical moments of the total water distribution are diagnosed as a function of both large-scale environmental variables and subgrid scale variables predicted by the convection or turbulence parameterizations. The triggering and the closure of the Emanuel (1991) convective scheme have been modified and are now based on the notions of Available Lifting Energy for the triggering and Available Lifting Power for the closure. A parameterization of the cold pools generated by the re-evaporation of convective rainfall has been introduced (Grandpeix and Lafore 2010; Grandpeix et al. 2010). The LMDZ5B version is characterized by a much better representation of the boundary layer and associated clouds, by a delay of several hours of the diurnal cycle of continental convection, and by a stronger and more realistic tropical variability. LMDZ5B is used within the IPSL-CM5B model.

\subsubsection{Stratospheric chemistry: REPROBUS}

The REPROBUS (Reactive Processes Ruling the Ozone Budget in the Stratosphere) module (Lefevre et al. 1994; 1998) coupled to a tracer transport scheme is used to interactively compute the global distribution of trace gases, aerosols, and clouds within the stratosphere in the LMDZ atmospheric model. The module is extensively described in Jourdain et al. (2008). It includes 55 chemical species, the associated stratospheric gas-phase, and heterogeneous chemical reactions. Absorption cross-sections and kinetics data are based on the latest Jet Propulsion Laboratory recommendations (Sander et al. 2006). The photolysis rates are calculated offline using a look-up table generated with the Tropospheric and Ultraviolet visible radiative model (Madronich and Flocke 1998). The heterogeneous chemistry component takes into account the reactions on sulfuric acid aerosols, and liquid (ternary solution) and solid (Nitric Acid Trihydrate particles, ice) Polar Stratospheric Clouds (PSCs). The gravitational sedimentation of PSCs is also simulated.

\subsubsection{Tropospheric chemistry and aerosol: INCA}

The INteraction with Chemistry and Aerosol (INCA) model simulates the distribution of aerosols and gaseous reactive species in the troposphere. The model accounts for surface and in-situ emissions (lightning, aircraft), scavenging processes and chemical transformations. LMDZINCA simulations are performed with a horizontal grid of $3.75^{\circ}$ in longitude and $1.9^{\circ}$ in latitude $(96 \times 95$ grid points). The vertical grid is based on the former LMDZ4 19 levels. Fundamentals for the gas phase chemistry are presented in Hauglustaine et al. (2004) and Folberth et al.
(2006). The tropospheric photochemistry is described through a total of 117 tracers including 22 tracers to represent aerosols and 82 reactive chemical tracers to represent tropospheric chemistry. The model includes 223 homogeneous chemical reactions, 43 photolytic reactions and 6 heterogeneous reactions including non-methane hydrocarbon oxidation pathways and aerosol formation. Biogenic surface emissions of organic compounds and soil emissions are provided from offline simulations with the ORCHIDEE land surface model as described by Lathière et al. (2005). In this tropospheric model, ozone concentrations are relaxed toward present-day observations at the uppermost model levels (altitudes higher than the $380 \mathrm{~K}$ potential temperature level). The changes in stratospheric ozone from pre-ozone hole conditions to the future are therefore not accounted for in the simulations.

The INCA module simulates the distribution of anthropogenic aerosols such as sulfates, black carbon (BC), particulate organic matter, as well as natural aerosols such as sea-salt and dust. The aerosol code keeps track of both the number concentration and the mass of aerosols using a modal approach to treat the size distribution, which is described by a superposition of log-normal modes (Schulz et al. 1998). Three size modes are considered: a submicronic (diameters less than $1 \mu \mathrm{m}$ ), a micronic (diameters between 1 and $10 \mu \mathrm{m}$ ) and a super-micronic (diameters $>10 \mu \mathrm{m})$. To account for the diversity in chemical composition, hygroscopicity, and mixing state, we distinguish between soluble and insoluble modes. Sea-salt, $\mathrm{SO}_{4}$, and methane sulfonic acid are treated as soluble components of the aerosol, dust is treated as insoluble species, whereas BC and particulate organic matter appear both in the soluble or insoluble fractions. The aging of primary insoluble carbonaceous particles transfers insoluble aerosol number and mass to soluble with a half-life time of 1.1 days. Details on the aerosol component of INCA can be found in Schulz (2007), Balkanski (2011).

The INCA model setup used to generate the aerosols and tropospheric ozone fields used in the CMIP5 simulations performed with IPSL-CM5 as well as the associated radiative forcings are described in detail by Szopa et al. (2013) (see also Sects. 3.5 and 3.7).

\subsubsection{Coupling between chemistry, aerosol, radiation and atmospheric circulation}

The radiative impact of dust, sea salt, BC and organic carbon aerosols was introduced in LMDZ as described in Déandreis (2008) and Balkanski (2011). The growth in aerosol size with increased relative humidity is computed using the method described by Schulz (2007). The effect of aerosol on cloud droplet radius without affecting cloud liquid water content (the so-called first indirect effect) is 
also accounted for. To parameterize this effect, the cloud droplet number concentration is computed from the total mass of soluble aerosol through the prognostic equation from Boucher and Lohmann (1995). The coefficient were taken from aerosol-cloud relationships derived from the Polder satellite measurements (Quaas and Boucher 2005). Both direct and first indirect aerosol radiative forcings are estimated through multiple calls to the radiative code.

The tropospheric chemistry and aerosols may be either computed or prescribed. When computed, the INCA and LMDZ models are coupled at each time step to account for interactions between chemistry, aerosol and climate. Otherwise, the aerosol concentration is usually prescribed from monthly mean values linearly interpolated for each day. Déandreis et al. (2012) have analyzed in detail the difference in results obtained with the online and offline setups for sulfate aerosols. They showed that the local effect of the aerosols on the surface temperature is larger for the online than for the offline simulations, although the global effect is very similar.

Similarly, the stratospheric chemistry and, in particular, ozone may be either computed or prescribed. When computed, the REPROBUS and LMDZ models are coupled at each time step to account for chemistry-climate interactions. When prescribed, LMDZ is forced by day-time and night-time ozone concentrations above the mid-stratosphere whereas it is forced by daily mean ozone fields below. Indeed, ozone concentration exhibits a strong diurnal cycle in the upper stratosphere and mesosphere. Neglecting these diurnal variations leads to an overestimation of the infra-red radiative cooling and therefore to a cold bias in the atmosphere.

\subsection{Land surface model: ORCHIDEE}

ORCHIDEE (ORganizing Carbon and Hydrology In Dynamic EcosystEms) is a land-surface model that simulates the energy and water cycles of soil and vegetation, the terrestrial carbon cycle, and the vegetation composition and distribution (Krinner et al. 2005). The land surface is described as a mosaic of twelve plant functional types (PFTs) and bare soil. The definition of PFT is based on ecological parameters such as plant physiognomy (tree or grass), leaves (needleleaf or broadleaf), phenology (evergreen, summergreen or raingreen) and photosynthesis pathways for crops and grasses (C3 or C4). Relevant biophysical and biogeochemical parameters are prescribed for each PFT.

Exchanges of energy (latent, sensible, and kinetic energy) and water, between the atmosphere and the biosphere are based on the work of Ducoudré et al. (1993) and de Rosnay and Polcher (1998) and they are computed with a 30-min time step together with the exchange of carbon during photosynthesis. The soil water budget in the standard version of ORCHIDEE is done with a two-layer bucket model (de Rosnay and Polcher 1998). The water that is not infiltrated or drained at the bottom of the soil is transported through rivers and aquifers (d'Orgeval et al. 2008). This routing scheme allows the re-evaporation of the water on its way to the ocean through floodplains or irrigation (de Rosnay et al. 2003).

The exchanges of water and energy at the land surface are interlinked with the exchange of carbon. The vegetation state (i.e. foliage density, interception capacity, soil-water stresses) is computed dynamically within ORCHIDEE (Krinner et al. 2005) and accounts for carbon assimilation, carbon allocation and senescence processes. Carbon exchange at the leaf level during photosynthesis is based on Farquhar et al. (1980) and Collatz et al. (1992) for C3 and C4 photosynthetic pathways, respectively. Concomitant water exchange through transpiration is linked to photosynthesis via the stomatal conductance, following the formulation of Ball et al (1987). Photosynthesis is computed with a 30-min time step while carbon allocation in the different soil-plant reservoirs is performed with a daily time step.

The PFT distribution is fully prescribed in the simulations presented in this article. The relative distribution of natural PFTs within each grid cell is prescribed by using PFT distribution maps where only the fractions of croplands and total natural lands per grid cell vary at a yearly time step. The elaboration of these maps is detailed in the Sect. 3.7 below.

When coupled, both LMDZ and ORCHIDEE models have the same spatial resolution and time step. The coupling procedure for heat and water fluxes uses an implicit approach as described in Marti et al. (2010).

\subsection{Ocean and sea-ice}

The ocean and sea-ice component is based on NEMOv3.2 (Nucleus for European Modelling of the Ocean, Madec 2008), which includes OPA for the dynamics of the ocean, PISCES for ocean biochemistry, and LIM for seaice dynamics and thermodynamics. The configuration is ORCA2 (Madec and Imbard 1996), which uses a tri-polar global grid and its associated physics. South of $40^{\circ} \mathrm{N}$, the grid is an isotropic Mercator grid with a nominal resolution of $2^{\circ}$. A latitudinal grid refinement of $0.5^{\circ}$ is used in the tropics. North of $40^{\circ} \mathrm{N}$ the grid is quasi-isotropic, the North Pole singularity being mapped onto a line between points in Canada and Siberia. In the vertical 31 depth levels are used (with thicknesses from $10 \mathrm{~m}$ near the surface to $500 \mathrm{~m}$ at 5,000 m). 


\subsubsection{Oceanic GCM: NEMO-OPA}

NEMOv3.2 takes advantage of several improvements over OPA8.2, which was used in IPSL-CM4. It uses a partial step formulation (Barnier et al. 2006), which ensures a better representation of bottom bathymetry and thus stream flow and friction at the bottom of the ocean. Advection of temperature and salinity is computed using a total variance dissipation scheme (Lévy et al. 2001; Cravatte et al. 2007). An energy and enstrophy conserving scheme is used in the momentum equation (Arakawa and Lamb 1981; Le Sommer et al. 2009). The mixed layer dynamics is parameterized using the Turbulent Kinetic Energy (TKE) closure scheme of Blanke and Delecluse (1993) improved by Madec (2008). Improvements include a double diffusion process (Merryfield et al. 1999), Langmuir cells (Axell 2002) and the contribution of surface wave breaking (Mellor and Blumberg 2004; Burchard and Rennau 2008). A parameterization of bottom intensified tidal-driven mixing similar to Simmons et al. (2004) is used in combination with a specific tidal mixing parameterization in the Indonesian region (Koch-Larrouy et al. 2007; 2010). NEMOv3.2 also includes representation of the interaction between incoming shortwave radiation into the ocean and the phytoplankton (Lengaigne et al. 2009).

The horizontal eddy viscosity coefficient (ahm) value is $4.10^{4} \mathrm{~m}^{2} . \mathrm{s}^{-1}$ and the lateral eddy diffusivity coefficient (aht) value is $10^{3} \mathrm{~m}^{2} \cdot \mathrm{s}^{-1}$. The coefficient ahm reduces to aht in the tropics, except along western boundaries. The tracer diffusion is along isoneutral surfaces. A Gent and Mcwilliams (1990) term is applied in the advective formulation. Its coefficient is computed from the local growth rate of baroclinic instability. It decreases in the $20 \mathrm{~S}-20 \mathrm{~N}$ band and vanishes at the equator. At the ocean floor, there is a linear bottom friction with a coefficient of $4.10^{-4}$, and a background bottom turbulent kinetic energy of $2.510^{-3}$ $\mathrm{m}^{2} . \mathrm{s}^{-2}$. The model has a Beckmann and Döscher (1997) diffusive bottom boundary layer scheme with a value of $10^{4} \mathrm{~m}^{2} . \mathrm{s}^{-1}$. A spatially varying geothermal flux is applied at the bottom of the ocean (Emile-Geay and Madec 2009) with a global mean value of $86.4 \mathrm{~mW} \cdot \mathrm{m}^{-2}$.

\subsubsection{Sea ice: NEMO-LIM2}

LIM2 (Louvain-la-Neuve Sea Ice Model, Version 2) is a two-level thermodynamic-dynamic sea ice model (Fichefet and Morales Maqueda 1997, 1999). Sensible heat storage and vertical heat conduction within snow and ice are determined by a three-layer model. The storage of latent heat inside the ice, which results from the trapping of shortwave radiation by brine pockets, is taken into account. The surface albedo is parameterized as a function of surface temperature and snow and ice thicknesses. Vertical and lateral growth/decay rates of ice are obtained from prognostic energy budgets at both the bottom and surface boundaries of the snow-ice cover and in leads. For the momentum balance, sea ice is considered as a twodimensional continuum in dynamical interaction with the atmosphere and ocean. The viscous-plastic constitutive law proposed by Hibler (1979) is used for computing the internal ice force. The ice strength is a function of ice thickness and compactness. The advected physical fields are the ice concentration, the snow and ice volume, enthalpy, and the brine reservoir. The sea ice and ocean models have the same horizontal grid.

\subsubsection{Ocean carbon cycle: NEMO-PISCES}

PISCES (Pelagic Interaction Scheme for Carbon and Ecosystem Studies) (Aumont and Bopp 2006) simulates the cycling of carbon, oxygen, and the major nutrients determining phytoplankton growth (phosphate, nitrate, ammonium, iron and silicic acid). The carbon chemistry of the model is based on the Ocean Carbon Model Intercomparison Project (OCMIP2) protocol (Najjar et al. 2007) and the parameterization proposed by Wanninkhof (1992) is used to compute air-sea gas exchange of $\mathrm{CO}_{2}$ and $\mathrm{O}_{2}$.

PISCES includes a simple representation of the marine ecosystem with two phytoplankton size classes representing nanophytoplankton and diatoms, as well as two zooplankton size classes representing microzooplankton and mesozooplankton. Phytoplankton growth is limited by the availability of nutrients, temperature, and light. There are three non-living components of organic carbon in the model: semi-labile dissolved organic carbon with a lifetime of several weeks to a few years, as well as large and small detrital particles, which are fuelled by mortality, aggregation, fecal pellet production and grazing. Biogenic silica and calcite particles are also included.

Nutrients and/or carbon are supplied to the ocean from three different sources: atmospheric deposition, rivers, and sediment mobilization. These sources are explicitly included but do not vary in time apart from a climatological seasonal cycle for the atmospheric input. Atmospheric deposition ( $\mathrm{Fe}, \mathrm{N}, \mathrm{P}$ and $\mathrm{Si}$ ) has been estimated from the INCA model (Aumont et al. 2008). River discharge of carbon and nutrients is taken from Ludwig et al. (1996). Iron input from sediment mobilization has been parameterized as in Aumont and Bopp (2006).

PISCES is used here to compute air-sea fluxes of carbon and also the effect of a biophysical coupling: the chlorophyll concentration produced by the biological component retroacts on the ocean heat budget by modulating the absorption of light as well as the oceanic heating rate (see Lengaigne et al. (2007) for a detailed description). 


\subsubsection{Atmosphere-Ocean-Sea ice coupling}

The Atmosphere/Ocean/Sea ice coupling in IPSL-CM5 is very similar yet improved compared to the coupling used in IPSL-CM4 (Marti et al. 2010). The atmospheric model has a fractional land-sea mask, each grid box being divided into four sub-surfaces corresponding to land surface, free ocean, sea ice and glaciers. The OASIS coupler (Valcke 2006) is used to interpolate and exchange the variables and to synchronize the models. Since a comprehensive model of glacier and land-ice is not yet included, the local snow mass is limited to $3,000 \mathrm{~kg} . \mathrm{m}^{2}$ to avoid infinite accumulation, and the snow mass above this limit is sent as "calving" to the ocean. The coupling and the interpolation procedures ensure local conservation of energy and water, avoiding the need of any transformation to conserve these global quantities. One improvement compared to Marti et al. (2010) consists in the daily mean velocity of the ocean surface being now sent to the atmosphere and used as boundary conditions for the atmospheric boundary layer scheme.

\subsection{Model tuning}

GCMs include many parameterizations, which are approximate descriptions of sub-grid processes. These parameterizations are formulated via a series of parameters that are usually not directly observable and must be tuned so that the parameterizations fit as well as possible the statistical behavior of the physical processes. Therefore the tuning process is a fundamental aspect of climate model development. It is usually performed at different stages: for individual parameterizations, for individual model components (atmosphere, ocean, land surface,...) and for the full coupled climate model. This tuning process is nonlinear. It includes iterations among these three stages and it inherits from successive tunings performed separately on the individual components or on coupled model along years of model development.

In coupled models with no flux adjustment, one important variable is the net heat budget of the Earth system, which has to be close to zero (i.e. within a few tenths of $\mathrm{Wm}^{-2}$ ) in order to avoid a major temperature drift. The observed present-day top of the atmosphere (TOA) energy budget shows a small imbalance of about $0.9 \pm 0.3 \mathrm{Wm}^{-2}$ (Hansen et al. 2011; Lyman et al. 2010; Stevens and Schwartz 2012; Trenberth and Fasullo 2012). This imbalance, which is due to recent changes in atmospheric composition and to the ocean thermal inertia, leads to the current global warming. A perfect climate model run with the current atmospheric composition and initialized with present-day conditions should produce a comparable imbalance and should drift naturally toward a warmer climate. Therefore there is no obvious choice on how to simulate an equilibrium global temperature close to current observations. Performing control runs with present-day conditions requires making some ad hoc adaptations. We have chosen to compensate the oceanic heat uptake by uniformly increasing the albedo of the oceanic surface by 0.01 during (and only during) this tuning phase. Most runs performed in this phase covered a few decades and only a few of them were extended to a few centuries. No historical runs were performed and no adjustment was made to specifically reproduce the temperature increase which has been observed for a few decades.

The following adjustments were made for the IPSLCM5A-LR model. For the atmospheric model, the final tuning of the global energy balance was achieved by considering a sub-set of three parameters of the cloud parameterizations (Hourdin et al. 2013a): two upper clouds parameters (maximum precipitation efficiency of the deep convection scheme and fall velocity of the ice cloud particles) and one parameter related to the conversion of cloud water to rainfall in the large-scale cloud scheme. In addition to the global energy balance, particular attention was given to the partitioning between SW and LW radiative fluxes and between clear sky and all sky radiative fluxes. The mean values, zonal distribution, and partition between convective and subsiding regimes in the tropics were considered.

In addition to the global energy balance, some other aspects were also considered during the final tuning. For the land-surface model, the soil depth was increased from 2- to 4-m to reduce the strong underestimation of the leaf area index (LAI) and of the carbon pools in the northeastern Amazon and in other tropical regions. The soil depth increase allows for greater seasonal soil water retention and reduces these biases. For the ocean, the new TKE parameterization has been tuned to reduce the error of the modeled mixed layer depth pattern and to obtain the best match with observations for the sea surface temperature (SST) pattern.

As shown later in Sect. 4.2, the IPSL-CM5A-LR historical runs show a cold bias of about $1 \mathrm{~K}$ compared to present-day observations. This bias is due to the fact that during the tuning phase the oceanic model was far from equilibrium and the aerosols, volcanoes, and ozone forcings did not reach their final values. When this problem was identified it was too late to rerun the whole set of simulations within the CMIP5 schedule. A better methodology than the one used here would probably have been to perform the final tunings in order to reach a net heat budget equilibrium with the global mean pre-industrial temperature even though this temperature is not precisely known.

With the same parameters as in the IPSL-CM5A-LR version, the medium-resolution IPSL-CM5A-MR version 
was producing a mean temperature warmer by only a few tenths of a degree. It was thus decided to reduce the mean temperature bias in this configuration with a uniform 0.01 increase of the solar absorption coefficient in the ocean.

For the IPSL-CM5B-LR model, all components and parameter values are the same as in the IPSL-CM5A-LR model except for the atmospheric component, which is now LMDZ5B (Hourdin et al. 2013b). The radiative flux at the TOA has been adjusted using the same methodology and tuning parameters as for IPSL-CM5A. However the net radiative flux at the TOA is not zero even at equilibrium because the energy is not fully conserved in the atmospheric model LMDZ5B: the difference between the net flux at the TOA and at the surface is about $-0.71 \mathrm{Wm}^{-2}$ in IPSLCM5B-LR and about $0.01 \mathrm{Wm}^{-2}$ in IPSL-CM5A-LR.

\section{Experiments, model configurations and forcings for CMIP5}

\subsection{The CMIP5 experimental protocol}

The CMIP5 project (Taylor et al. 2012) has been designed to address a much wider range of scientific questions than CMIP3 (Meehl et al. 2005), requiring a wider spectrum of models, configurations, and experiments. Here we only report on the long-term experiments. They include a fewcenturies long pre-industrial control simulation, the historical simulations (1850-2005), and the future projections simulations (2006-2100, 2006-2300). The future projections are performed under the new scenarios proposed by CMIP5, the RCP (Representative Concentration Pathway) scenarios (Moss et al. 2010; van Vuuren et al. 2011), each labeled according to the approximate value of the radiative forcing (in $\mathrm{Wm}^{-2}$ ) at the end of the twenty-first century: RCP 2.6, RCP 4.5, RCP 6.0 and RCP 8.5. The RCPs are supplemented with extensions (Extended Concentration Pathways, ECPs) until year 2300 without reference to specific underlying societal, technological or population scenarios (Meinshausen et al. 2011). As in Taylor et al. (2012) we refer to both RCPs and ECPs as RCPs in the remainder of this paper. CMIP5 also included simulations with idealized forcings $\left(1 \%\right.$ year $\mathrm{CO}_{2}$ increase, 4 times $\mathrm{CO}_{2}$ abrupt increase), forcings corresponding to prescribed or idealized sea-surface conditions (e.g. observed SST, aqua-planet), forcings representative of specific paleo-climate periods, and others. The total length of all these simulations is a few thousands of years. This of course calls for optimizations and compromises between the available computing time and the simulations' degrees of complexity. Our general strategy has been to run the atmospheric component of the ESM at a rather low resolution and to treat some of the atmospheric chemistry and transport processes controlling the greenhouse gases and the aerosols outside the ESM in a semi-offline way.

\subsection{Model horizontal resolution}

In the standard version of the IPSL-CM4 model used for CMIP3, the atmospheric model has 72 points in longitude and 96 points in latitude, corresponding to a resolution of $3.75^{\circ} \times 2.5^{\circ}$. For CMIP5 a rather coarse resolution was used, which allows for the coverage of most of the long term simulations in a reasonable amount of time. A computationally affordable model is also helpful to obtain an initial state of the climate system close to equilibrium, which requires multi-century runs particularly when the carbon cycle is included.

A systematic exploration of the impact of the atmospheric grid configuration on the simulated climate was conducted with IPSL-CM4 by (Hourdin et al. 2013a). They found that the grid refinement has a strong impact on the jet locations and on the pronounced mid latitude cold bias, which was one of the major deficiencies of the IPSL-CM4 model. The impact of grid refinement on the jets location was also studied by Guemas and Codron (2011) in an idealized dynamical-core setting. They found that an increase of the resolution in latitude produced a poleward shift of the jet because an enhanced baroclinic wave activity brought more momentum from the Tropics. An increased resolution in longitude produced no such shift because a tendency towards more cyclonic wave breaking canceled the increase of wave activity in that case. The errors associated with the equatorward jet position could thus be reduced at moderate computational cost by increasing the resolution in latitude more than in longitude. Based on these results two grids were used for CMIP5. They have almost the same number of points in longitude and latitude so that the meshes are isotropic $(\delta x=\delta y)$ at latitude $60^{\circ}$ and $\delta x=2 \delta y$ at the equator. At Low Resolution (LR), the model has $96 \times 95$ points corresponding to a resolution of $3.75^{\circ} \times 1.875^{\circ}$ in longitude and latitude respectively and at Medium Resolution (MR) the model has $144 \times 143$ points, corresponding to a resolution of $2.5^{\circ} \times 1.25^{\circ}$.

\subsection{Ozone concentrations}

Interannual ozone variations are considered in the IPSLCM5 simulations for CMIP5. This was not the case in the IPSL-CM4 simulations for CMIP3 for which the model was only forced with a constant seasonally-varying ozone field. Nevertheless this interannually varying ozone cannot be routinely computed online using the very comprehensive aerosols and chemistry coupled models (Sects. 2.2.2 and 2.2.3) in the IPSL ESM because they require a lot of 
computing time: LMDZ-INCA and LMDZ-REPROBUS both need 50-100 tracers, and running these models increases the CPU time by more than a factor of $10 \mathrm{com}-$ pared to the atmospheric model LMDZ alone.

To circumvent this difficulty, variations in ozone concentration shorter than a month even initially caused by short-term climate variability were assumed to play a relatively small, possibly negligible, role in the long-term evolution of climate. This assumption has been shown to be valid for stratospheric ozone (e.g. Son et al. 2010). On long time scales stratospheric ozone is mostly influenced by climate change via stratospheric cooling due to $\mathrm{CO}_{2}$ increase and tropospheric ozone is influenced by changes in global mean temperature via the water vapor concentration. These climate effects on ozone are accounted for in chemistry climate models run with prescribed SST (Fig. 1b). In turn the climate evolution depends on the long-term changes in ozone concentration. The treatment of the two-way interactions between ozone and climate can thus be simplified by decoupling them using a semi-offline approach instead of the fully coupled online approach.

This approach is fully described in Szopa et al. (2013) and consists in specifying the ozone fields predicted by dedicated atmospheric chemistry coupled model simulations in the ESM. In order to do so, both the INCA and the REPROBUS atmospheric chemistry models were used. Since the RCP climate model simulations were not yet available, the SST and sea ice concentrations prescribed in the chemistry simulations were taken from existing historical and scenario runs performed with the IPSL-CM4 model. We use the SST of the SRES-A2 scenario for the RCP 8.5 simulation, the SST of the SRES-A1B scenario for the RCP 6.0 simulation, the SST of the SRES-B1 scenario for the RCP 4.5 simulation and the SST of the scenario E1 (Johns et al. 2011) for the RCP 2.6 simulation. The differences between the prescribed SST and those obtained with the RCP scenarios are not expected to strongly impact the atmospheric chemistry. First, the LMDZ-INCA model (Sect. 2.2.3) with 19 vertical levels has been used to generate time-varying 3D fields of ozone in the troposphere. The simulations include decadal emissions of methane, carbon monoxide, nitrogen oxides and non methane hydrocarbons for anthropogenic and biomass burning emissions. They are taken from Lamarque et al. (2010) for the historical period and from Lamarque et al. (2011) for the RCP scenarios. Also, the monthly biogenic emissions are from Lathière et al. (2005) and are kept constant over the period. Second, the LMDZ-REPROBUS model (Sect. 2.2.2) with 50 vertical levels is used to generate timevarying 3D fields of ozone in the stratosphere. Instead of running all the scenarios, time-varying ozone fields for some of the RCP scenarios are reconstructed by interpolating or extrapolating linearly from the CCMVal REF-B2 and SCN-B2c scenarios (Morgenstern et al. 2010) using a time-varying weighing coefficient proportional to the $\mathrm{CO}_{2}$ level. This approach is based on the somewhat linear dependence of stratospheric ozone changes on $\mathrm{CO}_{2}$ changes, which has been found in coupled chemistry models run under the RCP scenarios (Eyring et al. 2010a, b). The INCA (tropospheric) and REPROBUS (stratospheric) ozone fields are then merged with a transition region centered on the tropopause region and averaged over longitudes to produce time-varying zonally-averaged monthlymean ozone fields.

Figure 2 shows the total column ozone as a function of latitude and time, from 1960 to 2100, for RCP 2.6 and RCP 6.0 scenarios, as well as for the ACC/SPARC ozone dataset, which is the commonly used ozone climatology in CMIP5 (Cionni et al. 2011; Eyring et al. 2012). The time evolutions of the globally-averaged total column ozone in the RCP 2.6, 4.5, 6.0 and 8.5 scenarios and in the ACC/ SPARC climatology are shown on Fig. 3. The evolutions of column ozone as a function of latitude and time are similar in our CMIP5 climatologies and in ACC/SPARC climatology. From 1960 onwards, column ozone decreases at all latitudes with smaller trends over the tropics and largest trends over Antarctica. This evolution is mostly due to the increase in ODSs (Ozone Depleting Substances) until the end of the twentieth century. The pre-2000 ozone decrease is followed by an increase with a rate that depends on the RCP scenario and on the region.

There are three main differences between our CMIP5 ozone forcings and the ACC/SPARC dataset. First, the Antarctic ozone hole is more pronounced in our dataset than in the ACC/SPARC dataset. Second, although the decrease in column ozone is stronger over Antarctica in our dataset, the decline in global ozone during the end of the last century is weaker (Fig. 3) indicating that the past tropical column ozone declines less quickly in our climatology. Third, the values of column ozone are generally higher in our dataset.

Globally-averaged total column ozone is about $10-18$ DU higher in our RCP 6.0 climatology than in the ACC/ SPARC climatology (Fig. 3). The faster the growth in GHG emissions (increasing from RCP 2.6 to RCP 8.5), the stronger the rate of ozone increase is during the twenty-first century in our forcings. By 2030 or 2040, depending on the RCP scenario, the 1960 levels in global column ozone are reached in all forcings (Fig. 3). However from 2040 onward, the global ozone levels off in RCP 2.6, continues to increase slightly in RCP 4.5 and RCP 6.0 and increase quite sharply in RCP 8.5. The ozone super-recovery (i.e. ozone levels exceeding the 1960s levels in the late twentyfirst century) is most visible at mid-latitudes and at northern high latitudes. The time evolution of the ACC/SPARC global ozone resembles the evolution of our RCP 2.6 global ozone. It is worth pointing out that much larger differences 

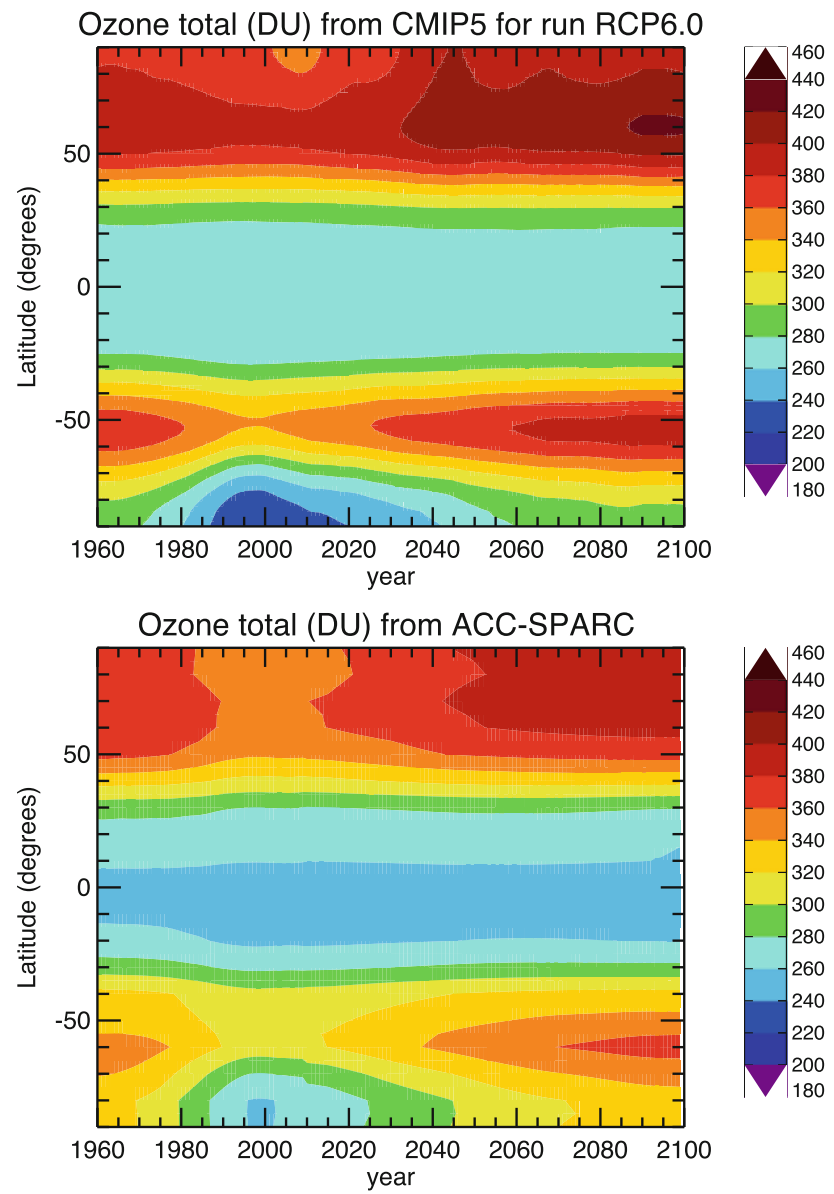

Fig. 2 Zonal mean of the total column ozone (in Dobson unit) as a function of latitude and time, from 1960 to 2100 for the IPSL-CM5 (top) and ACC-SPARC (bottom) climatologies. The RCP 6.0 scenario is used for the future period (2006-2100). All the data have been annually averaged and smoothed with an 11-year running mean filter

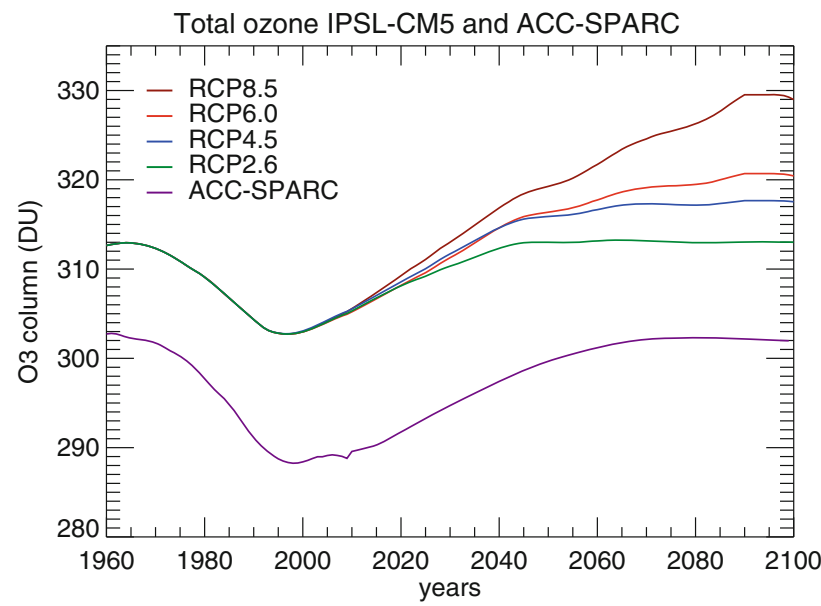

Fig. 3 Time series of globally-averaged total column ozone (in Dobson unit) from 1960 to 2100 for the IPSL-CM5 and ACC-SPARC climatologies. IPSL RCP 2.6, RCP 4.5, RCP 6.0 and RCP 8.5 ozone climatologies are shown with green, blue, red and brown solid lines respectively. Only the RCP 6.0 ACC-SPARC climatology is shown (purple solid line). All the data have been annually averaged and smoothed with an 11-year running mean filter in column ozone have been found when comparing all the climatologies used to force the CMIP5 simulations (Eyring et al. 2012).

\subsection{Aerosol concentrations}

For CMIP5 the radiative impact of dust, sea salt, BC and organic carbon aerosols are modeled in LMDZ following Déandreis (2008) and Balkanski (2011). Again this is a substantial improvement compared to the IPSL-CM4 model used for CMIP3 in which only the sulfate aerosols were considered (Dufresne et al. 2005).

As for ozone, aerosol microphysics strongly depends on weather and climate. However, there is no strong evidence that short-term variations in aerosol concentration play a significant role in the long-term evolution of climate. The treatment of the coupling between aerosols and climate can again be simplified by using a semi-offline approach. For the aerosols this approach is supported by Déandreis et al. (2012) who made a careful comparison between online and offline runs in the case of sulfate aerosols. They found little differences in the model results between the two approaches. Nevertheless, the short term variations of dust aerosols probably impact individual meteorological events. This effect should be tested in a fully coupled environment.

The past and future evolutions of aerosol distribution are computed using the LMDZ-INCA model (Sect. 2.2.3). Anthropogenic and biomass burning emissions are provided by Lamarque et al. (2010) for the historical period, and by Lamarque et al. (2011) for the RCP scenarios. Since the IPSL-CM5 model has biases in surface winds, the natural emissions of dust and sea salt are computed using the $10 \mathrm{~m}$ wind components provided by ECMWF for 2006 and, consequently, have seasonal cycles but no inter-annual variations. The computed monthly mean aerosol fields are then smoothed with an 11-year running mean. The methodology to build the aerosol field as well as its evolution and realism is described in more detail in Szopa et al. (2013). In the first release of these climatologies (used for the IPSL-CM5A-LR simulations) the particulate organic matter computation was underestimated by almost $20 \%$. This induces a slight underestimation of the aerosol cooling effect but additional simulations show that it has very little impact on climate. There is no coupling between dust and sea-salt emissions and climate via the surface winds. Nonetheless, the couplings via the transport, the wet and dry deposition and the forcing via land-use changes are described in the model.

\section{5 $\mathrm{CO}_{2}$ concentrations and emissions}

In CMIP5, the models are driven by $\mathrm{CO}_{2}$ concentrations in most of the runs and by $\mathrm{CO}_{2}$ emissions in some of them 
(Taylor et al. 2012). These two classes of simulations can both be performed with the full carbon-cycle configuration of the IPSL-CM5A-LR model (Fig. 1c, d). Unlike the chemistry and aerosols models, the interactive carbon cycle configuration of the model is affordable to run. The main difficulty lies in the estimation of the initial state of carbon stocks, which requires very long runs to reach a steadystate. Despite using some dedicated approaches to speed up the spin-up, a few hundred years of model integration are required in order for the various carbon pools to be close to equilibrium and hence suitable for use as initial states.

For the non-interactive (i.e. offline) concentration-driven simulations from 1850 to $2300, \mathrm{CO}_{2}$ being well mixed in the atmosphere, the prescribed global $\mathrm{CO}_{2}$ concentration is directly used by LMDZ to compute the radiative budget and by the PISCES and ORCHIDEE models to compute air-sea $\mathrm{CO}_{2}$ exchange and land photosynthesis respectively. The prescribed evolution of $\mathrm{CO}_{2}$ concentrations is taken from the CMIP5 recommended dataset and is described in Meinshausen et al. (2011). For the historical period 1850-2005, the $\mathrm{CO}_{2}$ concentration has been derived from the Law Dome ice core record, the SIO Mauna Loa record and the NOAA global-mean record. From 2006 and onwards, $\mathrm{CO}_{2}$ emissions have been projected by four different Integrated Assessment Models (IAMs) (van Vuuren et al. 2011), and corresponding $\mathrm{CO}_{2}$ concentrations have been generated with the same reduced-complexity carbon cycle-climate model MAGICC6 (Meinshausen et al. 2011). In the $\mathrm{RCP} 2.6$ scenario, $\mathrm{CO}_{2}$ concentration peaks at 440 ppmv in 2050 and then declines. In the RCP 6.0 and RCP 4.5 scenarios, $\mathrm{CO}_{2}$ concentration stabilizes at 752 and 543 ppmv in 2150 respectively. In the RCP 8.5 scenario, $\mathrm{CO}_{2}$ concentration reaches $935 \mathrm{ppmv}$ in 2100 and continues to increase up to $1961 \mathrm{ppmv}$ in 2250.

\subsection{Other greenhouse gas concentrations}

Other greenhouse gases (apart from ozone) are assumed to be well mixed in the atmosphere and are prescribed as time series of annual global mean mixing ratio. The concentrations of $\mathrm{CH}_{4}, \mathrm{~N}_{2} \mathrm{O}, \mathrm{CFC}-11$ and CFC-12 are directly prescribed in the radiative code of LMDZ. The concentrations are taken from the recommended CMIP5 dataset $^{1}$ and are described in Meinshausen et al. (2011). As the radiative schemes of GCMs do not generally represent separately all the fluorinated gases emitted by human activities, the radiative effects of all fluorinated gases controlled under the Montreal and Kyoto protocols are represented in terms of concentrations of "equivalent CFC-12" and "equivalent HFC-134a"respectively. The "equivalent CFC-12" concentration is directly used in LMDZ whereas the

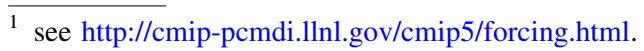

"equivalent HFC-134a" is converted in "equivalent CFC11 " prior to being used. For this conversion, the radiative efficiency of the two gases are used: $0.15 \mathrm{~W} . \mathrm{m}^{-2} \cdot \mathrm{ppb}^{-1}$ for HFC-134a and 0.25 W.m ${ }^{-2} \cdot \mathrm{ppb}^{-1}$ for CFC-11 (Ramaswamy et al. 2001, Table 6.7).

\subsection{Land use changes}

We use the transient historical and future crop and pasture datasets developed by Hurtt et al. (2011) (hereafter referred to as the UNH dataset) for both the historical period and the 4 RCPs scenarios for the future period. All the information is provided on $0.5^{\circ} \times 0.5^{\circ}$ horizontal grid.

Those datasets provide information on human activities (crop land and grazed pastureland) in each grid-cell but do not provide specific information on the characteristics of the natural vegetation. Moreover, the information provided cannot be directly used by land surface models embedded within GCMs like ORCHIDEE. The land-cover map used for both the historical and future period has been obtained starting from an observed present-day land-cover map (Loveland et al. 2000), which already includes both natural and anthropogenic vegetation types with the following methodology.

Firstly, the area covered by crops per year and per gridcell is set to the value provided by the UNH dataset. The expansion of this crop area occurs at the expense of all natural vegetation types proportionally. This means that the percent by which natural grasses and tree areas are reduced is the same for all biomes/PFTs. Conversely, a reduction of anthropogenic area implies a proportional increase in all natural vegetation types which exist in any given grid-cell. If no information is available on the natural distribution of vegetation at a specific location (i.e. $100 \%$ anthropogenic on the original land-cover map used), the nearest point which has natural vegetation is searched and this vegetation is introduced. Finally, the extent covered by desert in each grid-cell is unchanged from pre-industrial times until the end of the twenty-first century. We only encroach on desert if the anthropogenic area is larger than the natural vegetation part of the grid-cell.

After this first step where the change in crop area has been handled, the remaining area is a combination of natural vegetation and grazing activities. Grazing activities were included as follows: if the grazed area is smaller than the area covered with grasses and shrubs, no further change to the land-cover map has been made. If the grazed area is larger than the area covered with grasses and shrubs, part of the forested area is removed.

\subsection{Solar irradiance and volcanic aerosols}

The IPSL model is directly forced by the annual mean of solar irradiance using the data recommended by CMIP5 
(Lean 2009; Lean et al. 2005). For the past, the estimate of the total solar irradiance (TSI) variations is the sum of two terms, the first is related to an estimate of the past solar cycles (Fröhlich and Lean 2004) and the second to an estimate of long term variations (Wang et al. 2005). For the future, it is assumed that there is no long term variation but repeated solar cycles identical to the last cycle (cycle 23), i.e. with solar irradiance values from 1996 to 2008 (Fig. 4, continuous line). For other than historical and scenario simulations, the TSI is held constant and equal to the mean TSI estimate between the years 1845 and 1855 , i.e. 1365.7 $\mathrm{Wm}^{-2}$ (Fig. 4, dashed line).

The volcanic radiative forcing is accounted for by an additional change to the solar constant. For the historical period, the aerosol optical depth of volcanic aerosol is an updated version of Sato et al. (1993, 516 http://data.giss. nasa.gov/modelforce/strataer/). The aerosol optical depth $\tau$ is converted to radiative forcing $F_{v}\left(\mathrm{Wm}^{-2}\right)$ according to the relationship $F_{v}=-23 \tau$ suggested by Hansen et al. (2005). The average value $\bar{F}_{v}$ of this forcing over the period $1860-2000$ is $-0.25 \mathrm{Wm}^{-2}$, and the solar forcing $F$ prescribed to the model is:

$F=T S I+\frac{4\left(F_{v}-\bar{F}_{v}\right)}{1-\alpha}$

where $\alpha=0.31$ is the planetary albedo. For the future scenarios, the volcanic forcing is assumed to be constant, i.e. a constant volcanic eruption produces a constant radiative forcing $F_{v}=\bar{F}_{v}$. This explains the jump of $F$ between 2005 and 2006 (Fig. 4, continuous line); in 2005 there is almost no volcanic aerosols, as observed, whereas in 2006 a constant volcanic eruption takes place that produces a constant radiative forcing.

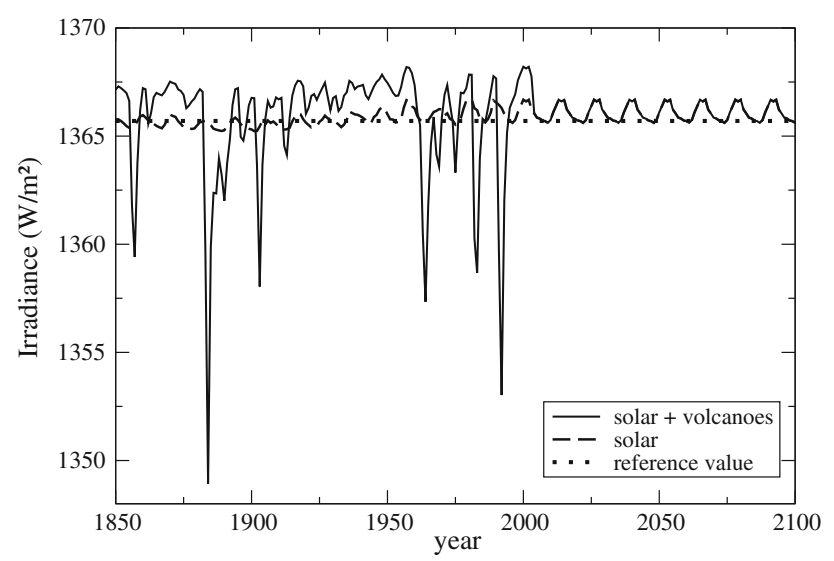

Fig. 4 Time evolution of the total solar irradiance with (solid line) and without (dashed line) volcanic eruptions. Also reported is the reference value used for all the runs except the historical and the scenario runs (dotted line)

\section{Recent warming and current climate}

The initial state and the simulation of some key climatic variables in the control and in the historical runs are described in this Section. Three versions of the IPSL-CM5 model are currently used for CMIP5: IPSL-CM5A-LR, which has been extensively used to perform large ensembles of runs, IPSL-CM5A-MR, which has a higher horizontal resolution of the atmosphere $\left(1.25^{\circ} \times 2.5^{\circ}\right.$, see Sect. 3.2) and IPSL-CM5B-LR for which the atmospheric parameterizations have been modified (see Sect. 2.2.1). A comparison with results from the IPSL-CM4 model, which has been used for CMIP3 (Dufresne et al. 2005) and whose key climatic characteristics have been presented in Braconnot et al. (2007) and Marti et al. (2010) is also presented in this Section.

For the IPSL-CM5A-LR model, many other aspects of the simulated climate are presented in companion papers such as the global climatology (Hourdin et al. 2013a), cloud properties (Konsta et al. 2013), land-atmosphere interactions (Cheruy et al. 2013), tropical variability (Maury et al. 2013; Duvel et al. 2013), mid-latitude variability (Gastineau et al. 2013; Vial et al. 2013; Cattiaux et al. 2013), climate over Europe (Menut et al. 2013), the AMOC bi-decadal variability in (Escudier et al. 2013), predictability in perfect model framework (Persechino et al. 2013) and over the last 60 years (Swingedouw et al. 2013).

\subsection{Initial state and control run}

The initial state of the IPSL-CM5A-LR model was obtained in four steps. First, a 2,500-year long simulation of the oceanic model without carbon cycle where the atmospheric conditions are imposed and correspond to the version 2 of the Coordinated Ocean-ice Reference Experiments data sets (Large and Yeager 2009) was achieved. Second, the full carbon-cycle configuration of the IPSLCM5A-LR model was integrated for a period of 600 years with the solar constant and the concentrations of GHGs and aerosols corresponding to their pre-industrial values. Third, because this last simulation is too short for the ocean and biosphere carbon pools to reach equilibrium, offline simulations a few thousand year-long with the ocean and land carbon cycle models (ORCHIDEE and PISCES) were conducted separately. These offline simulations were forced by the atmospheric and oceanic variables from the preceding 600-year simulation and by a constant preindustrial value for the atmospheric $\mathrm{CO}_{2}$. Fourth, and once the carbon pools are equilibrated, their values are included back into the complete IPSL-CM5A-LR model, which is again integrated for another 400 years. At this time, carbon pools are close to equilibrium in the coupled model as well. 
This long integration is used as initial state for the control pre-industrial simulations.

To illustrate the stability of the IPSL-CM5A-LR control run, Fig. 5 shows the global average values of a few variables during the first 1,000 years of this run. The surface temperature has almost no drift and the heat budget is close to zero. There is no discernible difference between the flux at the TOA and at the surface, which means that the internal heat budget of the atmosphere is conserved. The small imbalance in the heat budget at the TOA (about $0.25 \mathrm{Wm}^{-2}$ ) is due to a small non conservation of energy in the sea-ice model, the ocean model and at their interface. The surface salinity has almost no drift, nor has the sea surface height (about $2 \mathrm{~cm} /$ century, not shown), confirming that the water cycle is closed. Also, there is no drift of the carbon flux over land and there is a small drift of the carbon flux over oceans, which begins at $0.4 \mathrm{PgC} /$ year and decreases to less than $0.1 \mathrm{PgC} / \mathrm{year}$ at the end of the 1,000year period.

The initial state of IPSL-CM5A-MR was obtained starting from the initial state of the IPSL-CM5A-LR control run. After a 300-year long run with the full carboncycle configuration of IPSL-CM5A-MR, only the carbon cycle over land was not in equilibrium. A few thousand year long offline simulation with the land carbon cycle model was performed to bring the biosphere carbon pools to equilibrium. Finally the complete IPSL-CM5A-MR model was integrated again for another 200 years to obtain the initial state of the control simulation.

The initial state of IPSL-CM5B-LR was obtained starting from the initial state of IPSL-CM5A-LR control run and by performing a 280 -year long simulation. Although
Fig. 5 Time evolution of a the global mean heat budget at surface and at the TOA, $\mathbf{b}$ the global mean surface air temperature, $\mathbf{c}$ the sea-ice volume in the northern (black) and southern (red) hemispheres, d the global mean surface salinity and $\mathbf{e}$ the carbon flux (PgC/year) over ocean (black) and over land (red), for the first 1,000 years of the control run in the IPSL-CM5A-LR model. The data are smoothed using a

11-year Hanning filter

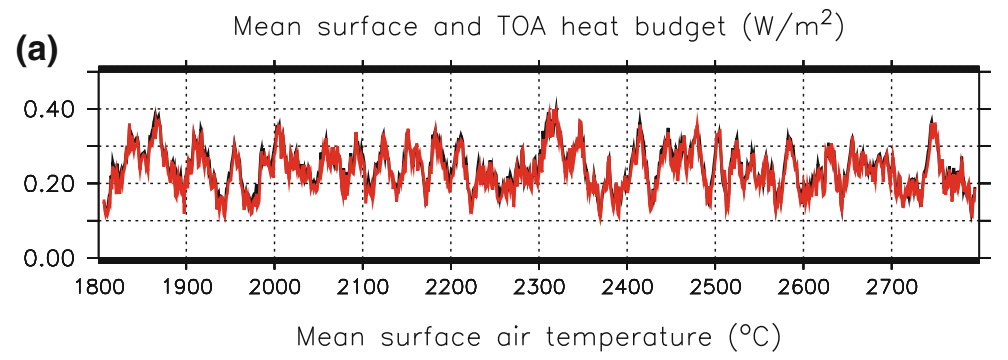

(b)

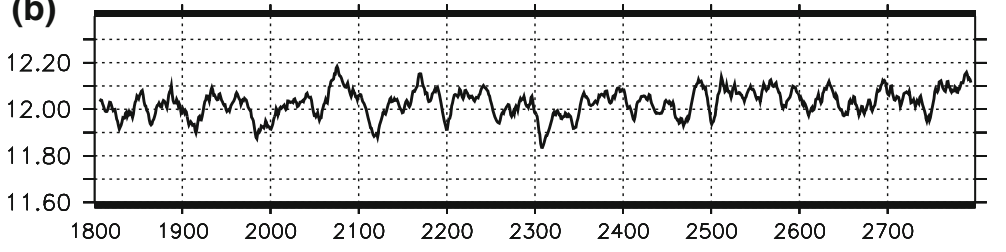

(c) Northern and southern hemisphere sea ice volume $\left(10^{13} \mathrm{~m}^{3}\right)$

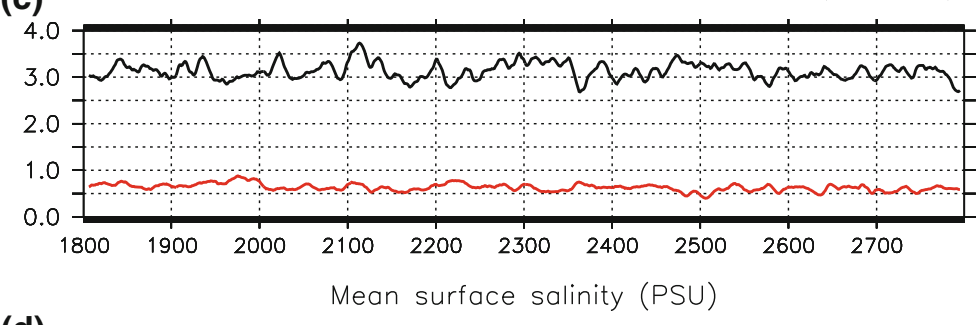

(d)

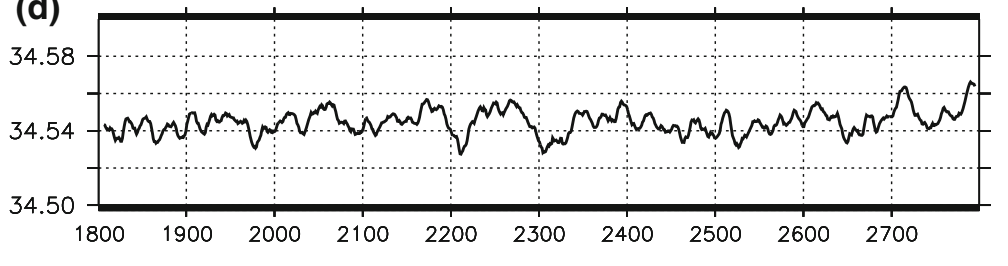

(e)

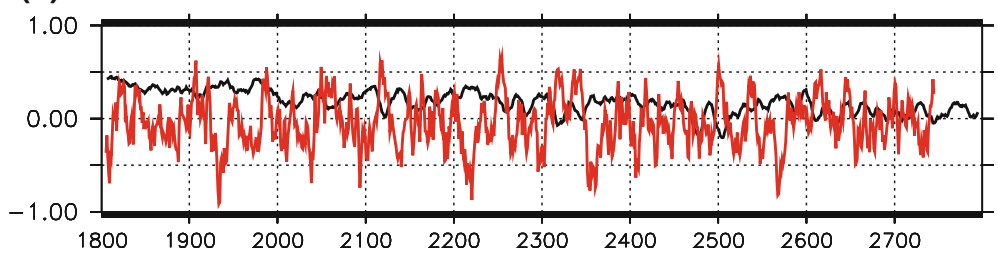


the full carbon-cycle configuration is used in IPSL-CM5BLR, this spin-up period is not long enough for the carbon pools to reach an equilibrium. The carbon variables are therefore not relevant for this model version. They have not been made available on the CMIP5 data base and will not be discussed in this paper.

\subsection{Twentieth century temperature}

Figure 6a displays the time evolution of the global mean air surface temperature from observations (Hadcrut3v dataset, Jones et al. 1999; Hadcrut3v dataset, Brohan et al. 2006) and simulated by the IPSL-CM4 which participated in CMIP3, the IPSL-CM5A-LR, the IPSL-CM5A-MR, and the IPSL-CM5B-LR models. On this figure, the IPSLCM5A and IPSL-CM5B simulations include all the anthropogenic and natural forcings as described in Sect. 3 whereas the IPSL-CM4 simulation only includes the GHGs and sulfate aerosol forcings with no natural forcing (Dufresne et al. 2005). As expected all the historical simulations indicate a substantial global warming induced by increased greenhouse gas concentrations in the atmosphere. For all models the global trend and multi-annual variability agree rather well with observations but the warming trend simulated during recent decades (e.g. from 1960 onwards) by most of the model configurations seems exaggerated.

To extract the temperature trends more accurately, the monthly temperature time series from the simulations and from the observations were subjected to the STL (Seasonal-Trend decomposition procedure based on Loess) additive scheme, which is a powerful statistical technique for describing a time series (Cleveland et al. 1990). The STL is a filtering procedure where the analyzed $X(t)$ monthly time series is decomposed into three terms:

$X(t)=T(t)+A(t)+R(t)$

The $T(t)$ term quantifies the trend and low-frequency variations in the time series. The $A(t)$ term describes the annual cycle and its modulation through time. Finally the $R(t)$ term contains the interannual signal and the noise present in the data. As demonstrated by Morissey (1990) or Terray (2011), this procedure is particularly useful to extract the interannual and trend signals from nonstationary and noisy climate datasets. Here the grid-box temperature time series are first expressed as monthly anomalies with respect to the 1961-1990 climatology before computing the global area-averaged time series and running the STL statistical procedure.

The trends estimated using the STL decomposition appear very clearly on Fig. 6-b. The simulations performed with IPSL-CM5 (A-LR, A-MR and B-LR) are closer to observations than the simulations performed with IPSLCM4. This was expected because the IPSL-CM5 models
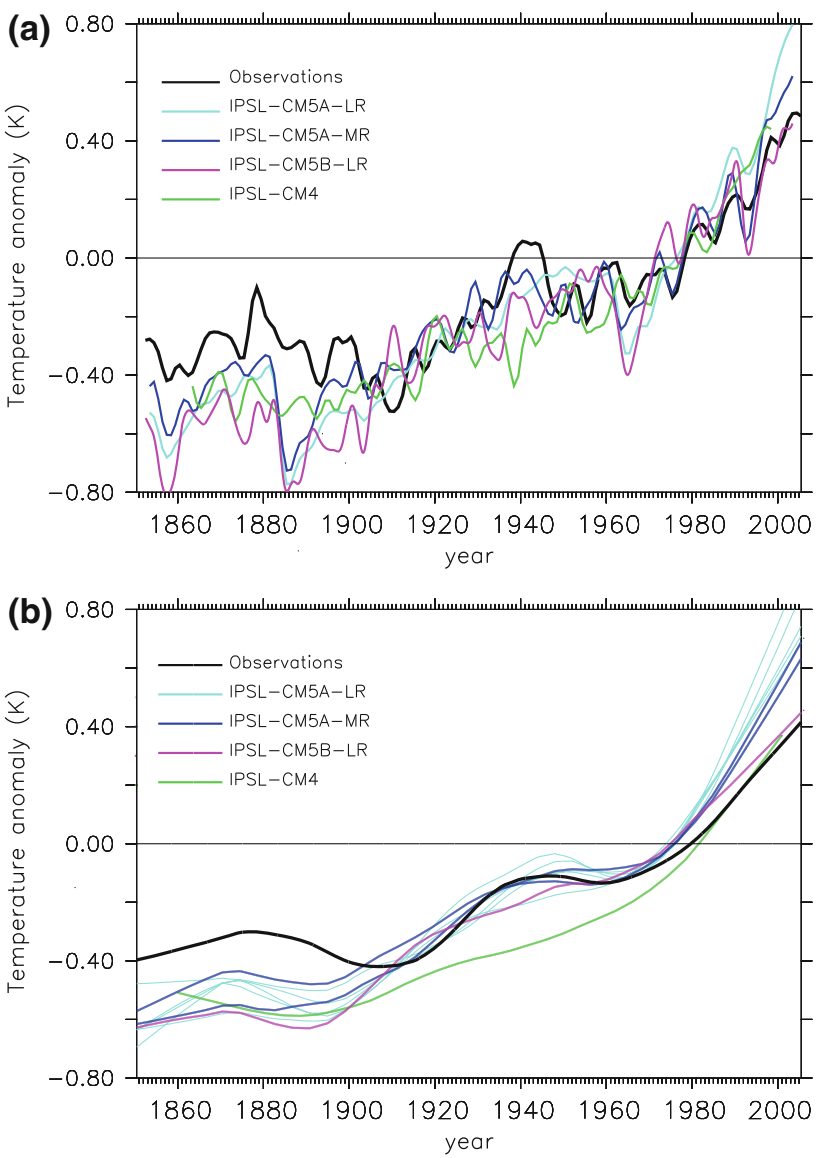

Fig. 6 a Time evolution of the global mean air surface temperature anomaly as observed (Hadcrut $3 \mathrm{v}$ dataset, black) and simulated by the IPSL-CM5A-LR (light blue), the IPSL-CM5A-MR (blue), the IPSLCM5B-LR (magenta) and the IPSL-CM4 (green) models. The temperatures are smoothed using a 5-year Hanning filter b Trends of the same variable estimated from the global area-averaged temperature anomalies monthly time series as defined by the STL procedure (see text). The unit is $K$ and the temperature anomalies are computed with respect to the 1961-1990 period. Note that 5 members are available for IPSL-CM5A-LR, 2 members are available for IPSLCM5A-MR, and only 1 member is available for IPSL-CM5B-LR and IPSL-CM4. On panel a the averaged value of these members is shown for clarity whereas on panel, $\mathbf{b}$ the trends have been estimated separately in each simulation member and each of these trends is shown

include more realistic forcings than the IPSL-CM4 model. For example, the IPSL-CM4 simulation does not reproduce the two cold periods observed around 1910 and 1960. The IPSL-CM5 models simulate the cooling around 1960 but the 1910s cooling is simulated too early. These improvements in the new model version essentially come from the inclusion of the volcanic forcing. However IPSL-CM5A simulates a larger temperature increase than IPSL-CM4 after 1970 compared to observations although both models have a similar climate sensitivity (Sect. 6.1). During this period the difference is probably due to the changes in 
ozone and absorbing aerosol concentrations, both of them increasing significantly after 1950 .

For the IPSL-CM5A model, there is almost no difference between the low- and mid-resolution configurations (LR and MR). The differences between those simulations are within the range of internal variability. IPSL-CM5BLR exhibits a much smaller temperature increase after 1970 than IPSL-CM5A and this difference further increases in the future period (Sect. 5.1). The IPSL-CM5B-LR model has a much smaller climate sensitivity than the other model versions as will be shown in Sect. 6.1 and this is probably the main reason for this smaller temperature increase.

Compared to the observed temperature (Hadcrut $3 \mathrm{v}$ dataset, Jones et al. 1999; Hadcrut3v dataset, Brohan et al. 2006) over the period 1961-1990, the models have the following biases on average: $-0.7 \mathrm{~K}$ for IPSL-CM4, $-1.4 \mathrm{~K}$ for IPSL-CM5A-LR, $-0.4 \mathrm{~K}$ for IPSL-CM5A-MR and $-0.6 \mathrm{~K}$ for IPSL-CM5B-LR. The geographical structure of the temperature bias shows common patterns for IPSL-CM4, IPSL-CM5A-LR and IPSL-CM5A-MR. The amplitude of these biases is weakest in IPSL-CM5A-MR (Fig. 7), it is slightly stronger in IPSL-CM5A-LR and it is significantly stronger in IPSL-CM4. In the Pacific and Atlantic tropical oceans there is a systematic bias with the eastern part of the ocean basins being too warm compared to the western part, which is a common weakness of coupled models. Over the Pacific, another common bias is a cold tongue along the equator. In the mid latitudes there is a systematic cold bias whose amplitude is weaker in IPSLCM5A-LR and MR than in IPSL-CM4. At high latitudes, there is a warm bias over eastern Siberia, Alaska and western Canada in the northern hemisphere and poleward of $60^{\circ} \mathrm{S}$ in the southern hemisphere. The geographical pattern of the temperature bias does not change significantly on a seasonal scale.

The IPSL-CM5B-LR model displays a significantly different bias pattern compared to other models. There is a strong asymmetry between the two hemispheres with a large cold bias over most of the northern hemisphere and a large warm bias in the southern hemisphere, particularly poleward of $60^{\circ} \mathrm{S}$. In the tropics, this model exhibits an east-west bias in the ocean basins but there is no cold tongue over the equator. The temperatures in the tropics are reasonable, which is not the case in the mid and high latitude regions, probably due to an equatorward shift of the mid-latitude jets. This shift, which is larger in IPSLCM5B-LR than in IPSL-CM5A-LR despite the same resolution (Hourdin et al. 2013b) is not yet understood. In the Arctic region, IPSL-CM5B-LR is about $4{ }^{\circ} \mathrm{C}$ colder than IPSL-CM5A-LR in the AMIP simulations where the sea surface temperature and the sea-ice fraction are prescribed.
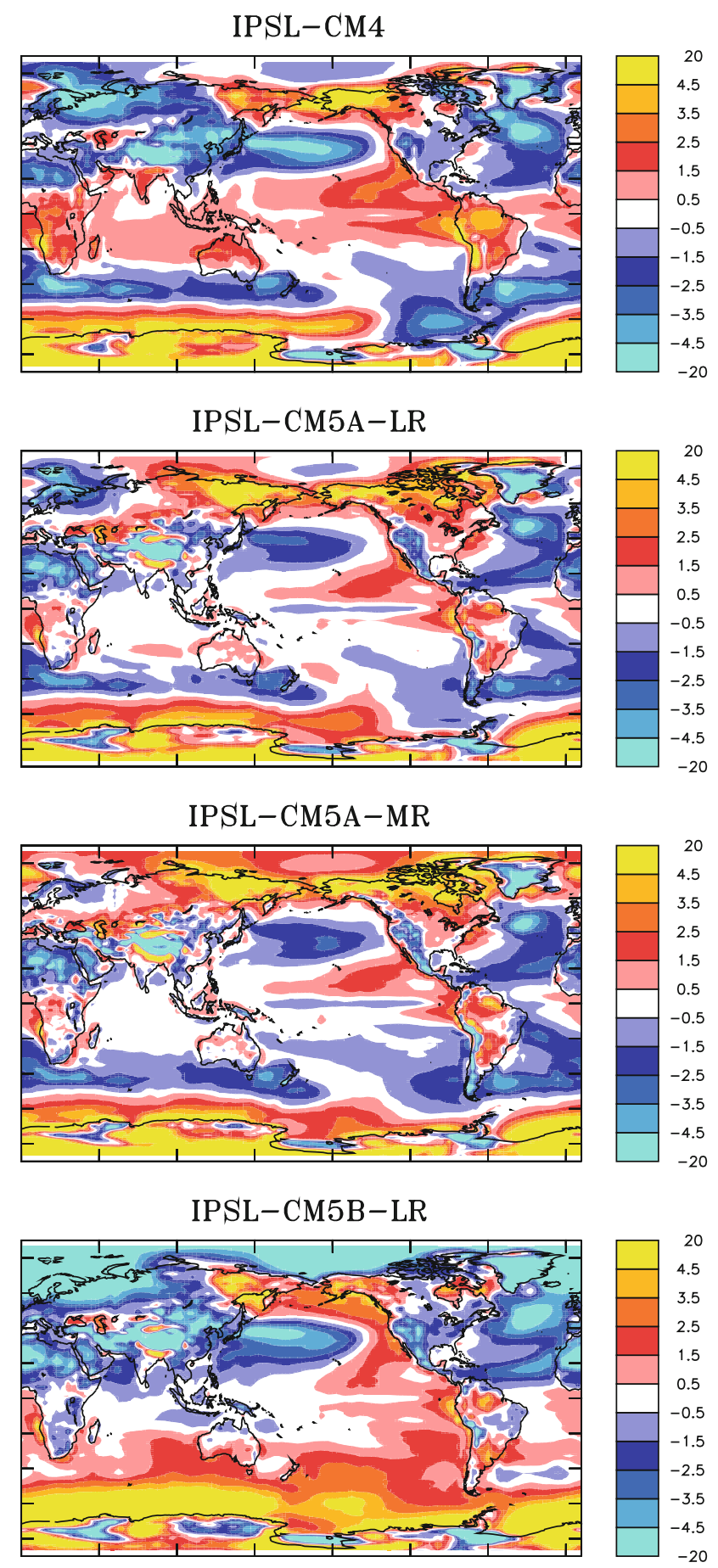

Fig. 7 Geographical distribution of the bias in the annual mean air surface temperature climatology (with respect to the period 1961-1990) simulated by, from top to bottom, IPSL-CM4, IPSLCM5A-LR, IPSL-CM5A-MR and IPSL-CM5B-LR models, compared to estimate from observations (Jones et al. 1999). The global mean difference with observations is removed in order to focus on the bias structure. This global mean difference is $-0.7 \mathrm{~K}$ for IPSL-CM4, $-1.4 \mathrm{~K}$ for IPSL-CM5A-LR, $-0.4 \mathrm{~K}$ for IPSL-CM5A-MR and $-0.6 \mathrm{~K}$ for IPSL-CM5B-LR. For all models, the climatology is computed using the first member of the historical run. The unit is $\mathrm{K}$ 
This difference is amplified by about $50 \%$ in the coupled simulations. Over the Antarctic, there is also a cold bias of about $4^{\circ} \mathrm{C}$ in the AMIP simulations and this cold bias almost vanishes in the coupled simulations due to the strong warming of the southern ocean (Fig. 7).

\subsection{Tropical precipitation and tropical variability}

The tropics are of primary importance for climate variability and climate sensitivity, and the improvement of the simulation of the tropical climate has been a main goal of IPSL for many years. A new convective scheme (Emanuel 1991) and cloud scheme (Bony and Emanuel 2001) were introduced in the LMDZ4 atmospheric model (Hourdin et al. 2006), leading to an improved simulated tropical climate in the IPSL-CM4 model (Braconnot et al. 2007). No major changes of the atmospheric parameterizations were made in IPSL-CM5A compared to IPSL-CM4 whereas parameterizations were strongly modified in the atmospheric component of IPSL-CM5B in order to improve the representation of some processes that are known to be important for the tropical climate such as: boundary layer, convection and clouds processes (see Sect. 2.2.1). The impact of these developments on the mean climate are documented in Hourdin et al. (2013b), in particular on the atmosphere-only configuration. The mean precipitation in the tropics and two major modes of tropical variability, the El Niño Southern Oscillation (ENSO) and the Madden Julian Oscillation (MJO), simulated in the different versions of the IPSL coupled model are described here. These modes have a large impact on the tropical and global circulation (e.g. Cassou 2008; e.g. Alexander et al. 2002; e.g. Maury et al. 2013) and their representation in current climate models varies greatly (e.g. Guilyardi et al. 2009; e.g. Xavier et al. 2010).

\subsubsection{Tropical mean precipitation}

Figure 8 presents the 10-year (1990-1999) annual mean rainfall from GPCP (Global Precipitation Climatology Dataset) observations (Huffman et al. 2001) and for historical simulations with the four versions of the IPSL model (IPSL-CM4, IPSL-CM5A-LR, IPSL-CM5A-MR and IPSLCM5B-LR). The precipitation pattern is similar for all model versions, which are able to qualitatively reproduce the main observed structures. The same major biases are present in all model configurations. In the tropics the models show the so-called double Intertropical Convergence Zone (ITCZ) structure with a first realistic precipitation maximum around $5^{\circ} \mathrm{N}$ and a secondary maximum around $5^{\circ} \mathrm{S}$, which is not observed. The monsoon rainfall over West Africa and the Indian sub-continent does not extend sufficiently to the north. In the southern subtropics the models fail to simulate the large regions without rain observed over the ocean. Over Africa and the Arabian Peninsula on the contrary, the area with no rainfall is wider than observed. Precipitation is systematically overestimated in the Andes mountains and underestimated over the Amazon region. The simulated rainfall is too strong on the East tropical Indian Ocean compared to observations.

When focusing on the differences between model configurations, the impact of horizontal grid refinement from CM5A-LR to CM5A-MR is particularly weak. It slightly improves the representation of the Indian and West African monsoons, which extend farther to the north, but it tends to reinforce the double ITCZ structure.

Changing the cloud and convective physics from IPSLCM5A-LR to IPSL-CM5B-LR has a somewhat larger and often opposite impact. The monsoons are more confined in CM5B-LR and the rainfall excess over the East tropical ocean is even larger. The double ITCZ is less marked both over the Pacific and Atlantic Oceans. Also the South Pacific and Atlantic Convergence Zones (SPCZ and SACZ), which are not well captured in the CM5A-LR and MR configurations, are much better simulated with the new physical parameterizations.

\subsubsection{Madden-Julian oscillation}

When forced by prescribed SST, the LMDZ5B atmospheric model simulates a much larger tropical rainfall variability than LMDZ5A, which is in better agreement with observations in particular in the location and spectral range associated with the MJO (Hourdin et al. 2013b). A more detailed analysis of the MJO in the IPSL-CM5A and CM5B coupled models, which use these two atmospheric models, is presented here. The differences between the IPSL-CM5A-LR and CM5A-MR results are small and only the former will be presented. We restrict our analysis to the January-March period (JFM) because differences on the simulated MJO between IPSL-CM5A and CM5B are stronger during this season.

The large-scale convective perturbations associated with the MJO are extracted using the Local Mode Analysis (LMA, Goulet and Duvel 2000). The LMA is based on a series of complex EOF (CEOF) computed on relatively small time sections (every 5 days on a 120-day time window) of the outgoing longwave radiation (OLR) time series. The first complex eigenvector best characterizes (in phase and amplitude) the intraseasonal fluctuation for the 120-day time section. The corresponding percentage of variance represents the degree of spatial organization of this event. The LMA retains only maxima in the time series of the percentage of variance. For JFM, the LMA extracts 41 events for 30 years of observations (NOAA OLR, Liebmann and Smith 1996), 52 events for 30 years of the 
Fig. 8 10-year (1990-1999) annual mean rainfall ( $\mathrm{mm} /$ day) over the tropics in the GPCP observations and simulated by the IPSL-CM4, IPSL-CM5ALR, IPSL-CM5A-MR and IPSL-CM5B-LR models (from top to bottom)

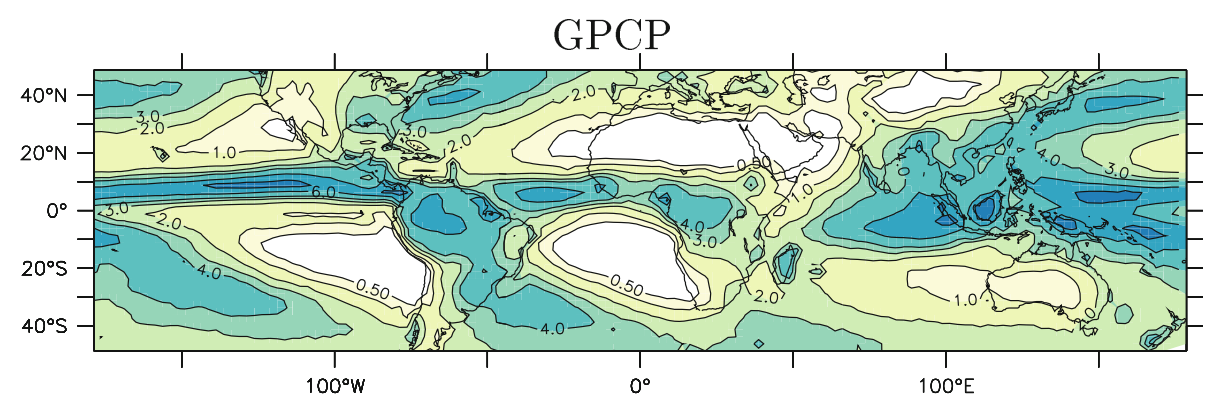

IPSL-CM4

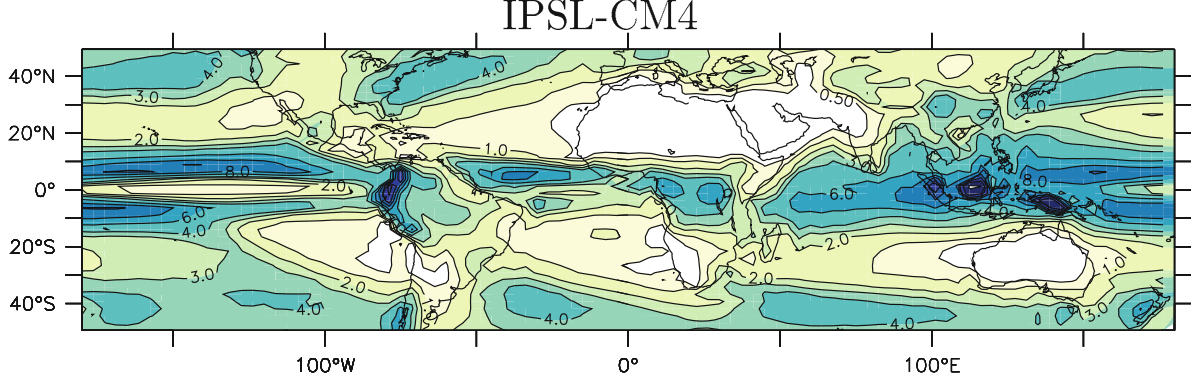

IPSL-CM5A-LR

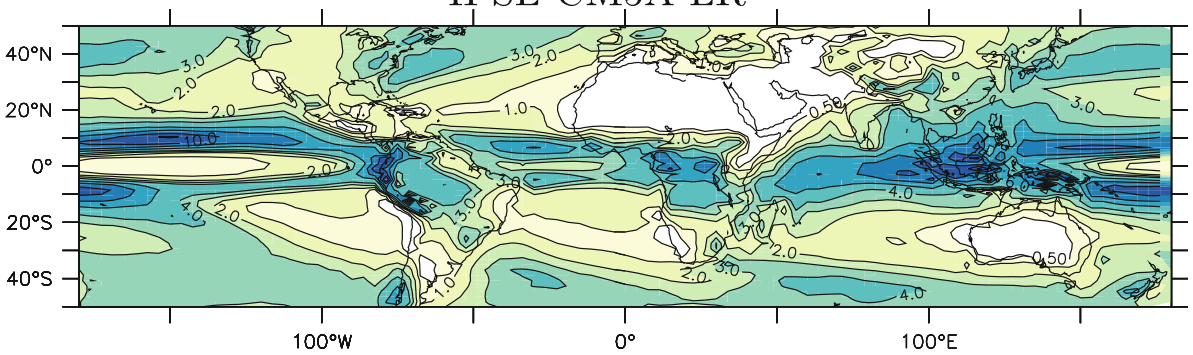

IPSL-CM5A-MR

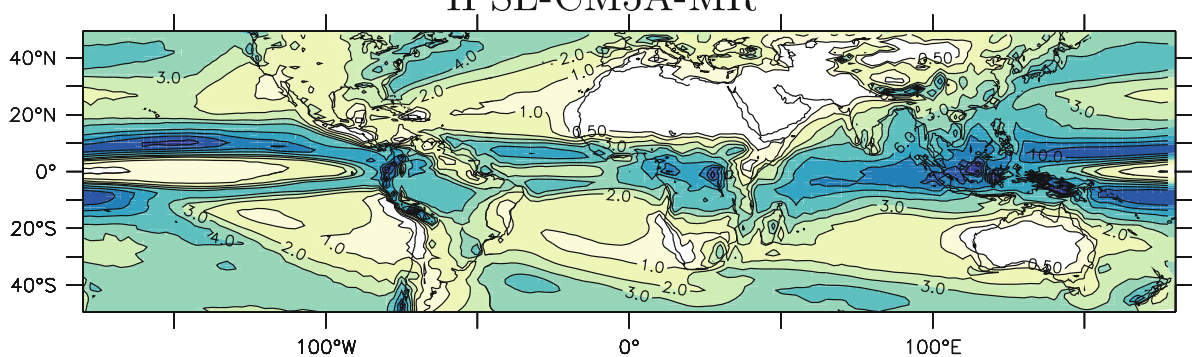

IPSL-CM5B-LR
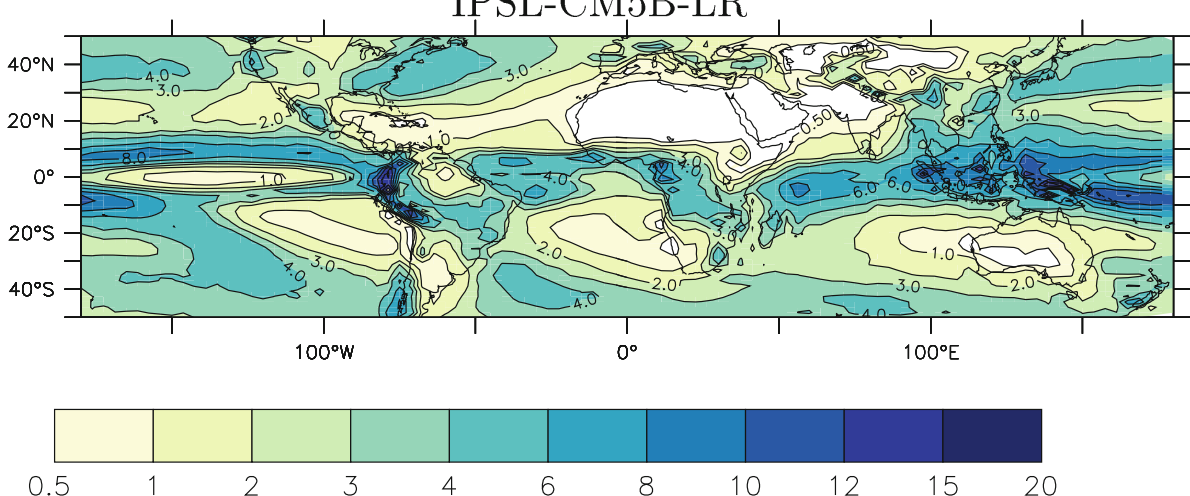

An average pattern is computed from the JFM events having a percentage of variance above the annual average. This average pattern gives the amplitude and phase 
distributions that best represent the considered events. This average pattern is shown on Fig. 9 for observations, IPSLCM5A-LR and IPSL-CM5B-LR. In the observations, the intraseasonal variability is confined between the equator and $20^{\circ} \mathrm{S}$. From the phases of the average pattern (Fig. 9a) we may deduce that on average, intraseasonal perturbations propagate eastward with a nearly constant speed of about 5-6 $\mathrm{ms}^{-1}$ (considering the phase opposition between roughly $90^{\circ} \mathrm{E}$ and $180^{\circ} \mathrm{E}$ and an average period of 40 days). The IPSL-CM5A-LR model produces MJO events that are confined in the Indian Ocean and propagate eastward at around $2 \mathrm{~ms}^{-1}$ only (Fig. 9b) over the eastern Indian Ocean. The IPSL-CM5B-LR model produces perturbations that are more centered on the Maritime Continent and propagating at a speed of about $2.5 \mathrm{~ms}^{-1}$ (Fig. 9c) over the eastern Indian Ocean and faster (around $4 \mathrm{~ms}^{-1}$ ) across northern Australia. The longitudinal position of the main MJO signal and the latitudinal position in the Indian ocean are thus improved in IPSL-CM5B-LR. However the slow propagation over the eastern Indian Ocean and the too strong variability north of the equator in the Pacific remain.

The ability of a model to represent organized convective perturbations on a large scale is critical for a correct simulation of the intraseasonal variability (Bellenger et al. 2009; Xavier et al. 2010). The percentage of variance measures the degree of large-scale organization of the intraseasonal variability. A large percentage of variance means that the intraseasonal variability of the region is

(a)
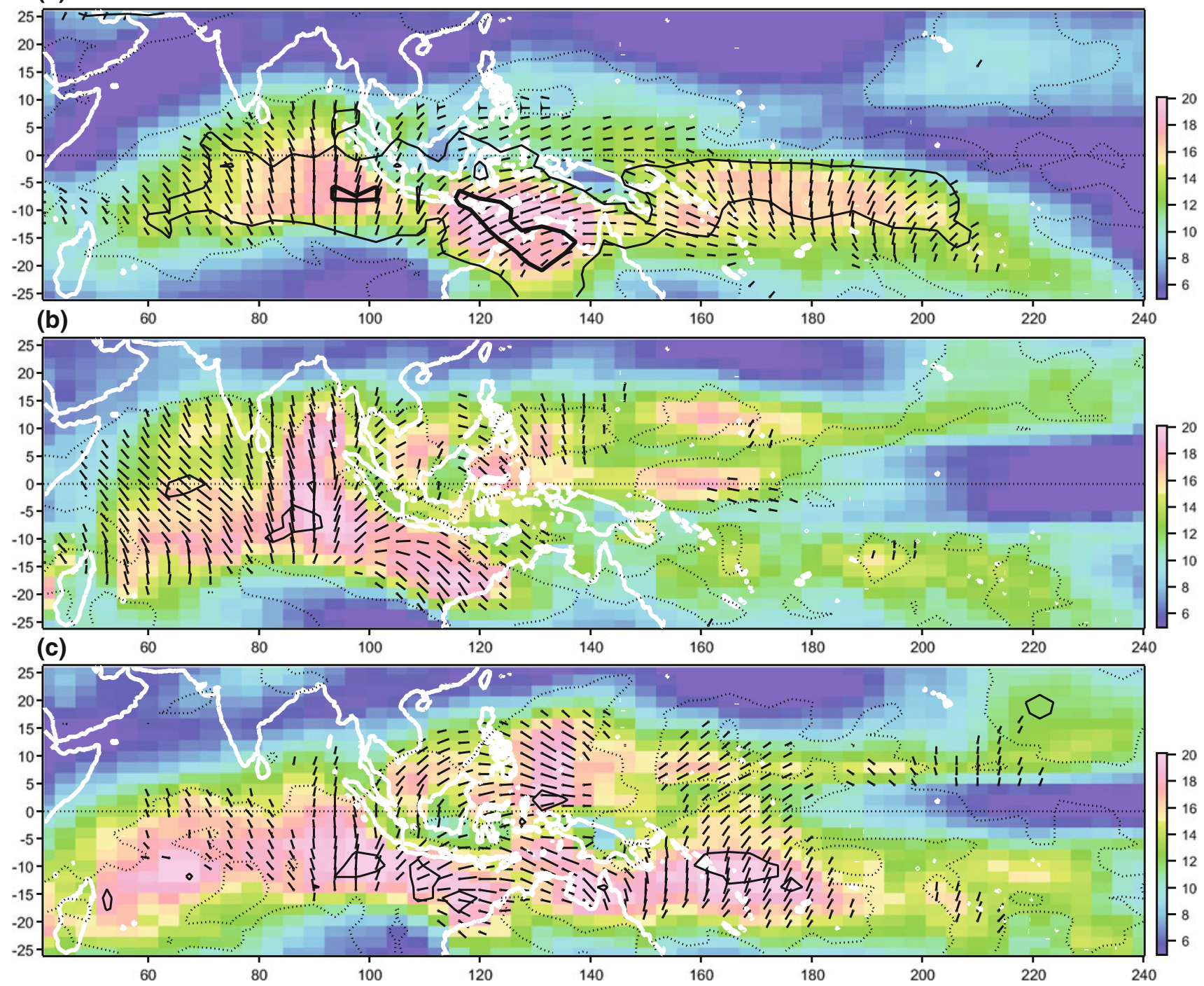

Fig. 9 Average intraseasonal OLR perturbation pattern for JFM, a NOAA OLR, b IPSL-CM5A-LR and c IPSL-CM5B-LR: (colors and stick length) Amplitude; (sticks angle) Relative phase with a clockwise rotation with time and a full rotation for one period of about 40 days; (contours) percentage of intraseasonal variance due to large-scale organized perturbations (40, 50 and $60 \%$ in bold) 
mostly due to large-scale organized perturbations and not to local red noise (see Duvel et al. 2013). This percentage of variance is larger in IPSL-CM5B than in IPSL-CM5A but it is still smaller than in observations (contours on Fig. 9).

\subsubsection{El Nino Southern Oscillation}

The ENSO spatial structure for the 3 models as measured by the SST standard deviation is compared to observations in Fig. 10. For the simulations we used 200 years of monthly outputs. The IPSL-CM5A and CM5B versions produce a weaker ENSO SST variability (by about $0.3 \mathrm{~K}$ ) than the IPSL-CM4 model with a pattern which is in good qualitative agreement with observations. The spurious westward extension of the SST pattern is reduced in CM5B-LR when compared to CM4 and CM5A-LR. The three model versions underestimate the SST variability along the South American coast, which is related to a common warm bias in this region.

ENSO spectral characteristics are difficult to estimate from 200 years or shorter time series (Wittenberg 2009). However spectra of the SST monthly anomalies over the Niño3 region $\left(90^{\circ} \mathrm{W}-150^{\circ} \mathrm{W}\right.$ and $\left.5^{\circ} \mathrm{S}-5^{\circ} \mathrm{N}\right)$ are indicative of an ENSO with longer periods in the later versions of
IPSL-CM. Spectral peaks around 3-3.5 years are visible for IPSL-CM5A-LR and CM5B-LR whereas CM4 shows a peak around 2.7 years (Fig. 11a). IPSL-CM5A-LR is in good qualitative agreement with observations showing a second spectral peak beyond 4 years. In addition ENSO is characterized by a strong seasonal phase locking with a peak in November-January and a minimum in April. This seasonality is well reproduced by IPSL-CM4 but the new versions fail at reproducing this feature. IPSL-CM5A-LR shows a marked seasonality with a peak in May-June and a minimum in October-November, whereas IPSL-CM5B-LR hardly shows any seasonal variation (not shown).

A number of studies point to a dominant role of the atmospheric GCMs in the simulation of ENSO (Guilyardi et al. 2009; Kim and Jin 2011; Clement et al. 2011). The main atmospheric feedbacks are evaluated following Lloyd et al. $(2011,2012)$. The feedback between the east-west SST gradient and wind speed (Bjerknes feedback) is evaluated by the linear regression coefficient between the zonal wind stress anomaly in the Niño4 region $\left(160^{\circ} \mathrm{E}-\right.$ $150^{\circ} \mathrm{W}$ and $5^{\circ} \mathrm{S}-5^{\circ} \mathrm{N}$ ) and the Niño3 SST anomaly. The heat flux feedback is evaluated by the regression coefficient between Niño3 heat flux and SST anomalies. This feedback is dominated by the shortwave and the latent heat fluxes and the former has a key role in explaining the spread of
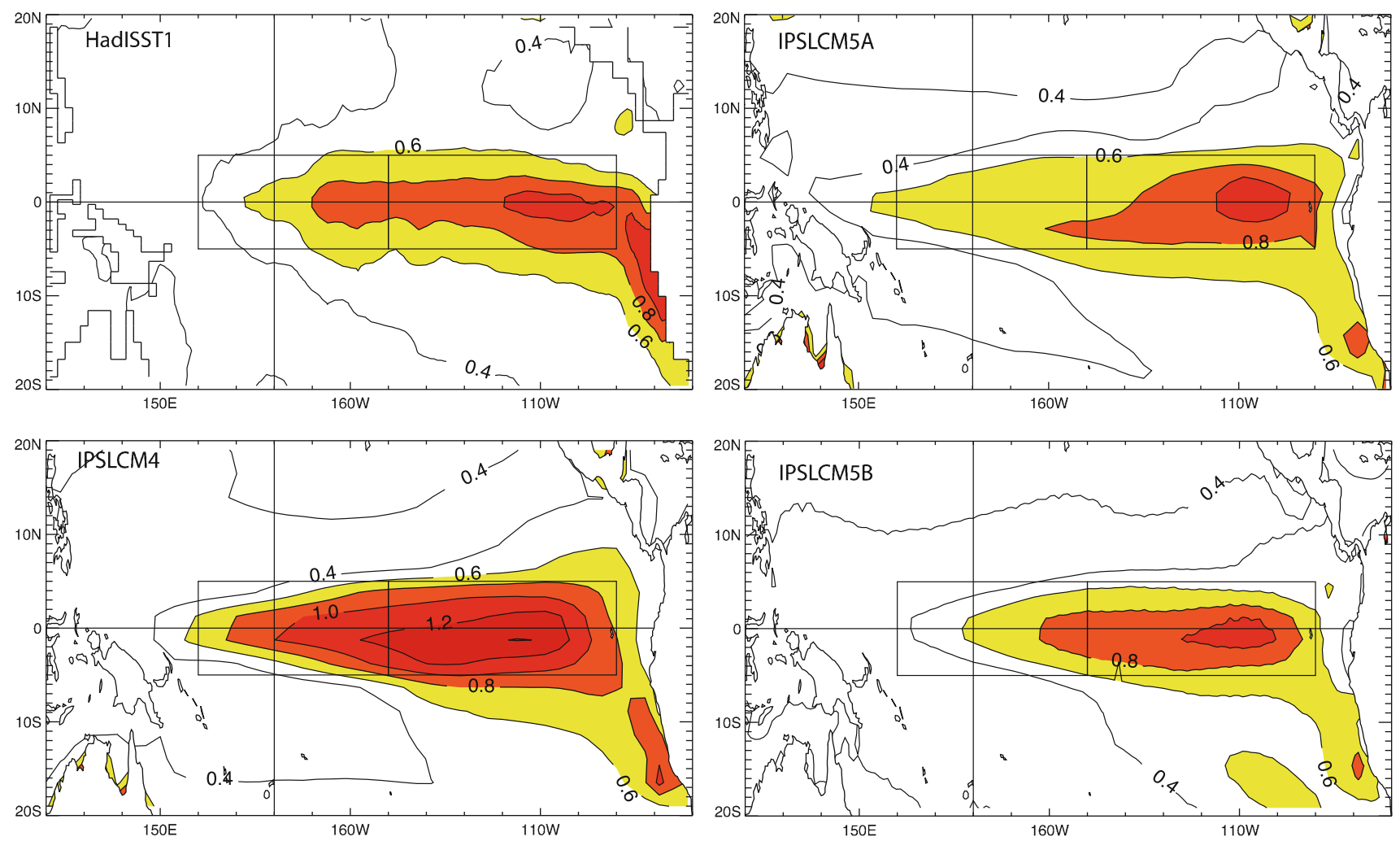

Fig. 10 Standard deviations (K) of monthly SST anomalies with respect to the mean seasonal cycle for HadISST1 (1870-2008) (Rayner et al. 2003) and for 200 years of IPSL-CM4, IPSL-CM5A-LR and IPSL-CM5B-LR 
Fig. 11 a Normalized power spectra of SST over the Niño3 region for HadISST1 (black), IPSL-CM4 (green), IPSLCM5A-LR (red) and IPSLCM5B-LR (blue). b Evaluation of the Bjerknes and heat flux feedbacks. The two main components of the latter, the shortwave and latent heat flux feedbacks, are also shown. For the feedback coefficients, the reference is ERA40 (1958-2001) and OAFlux (1984-2004)
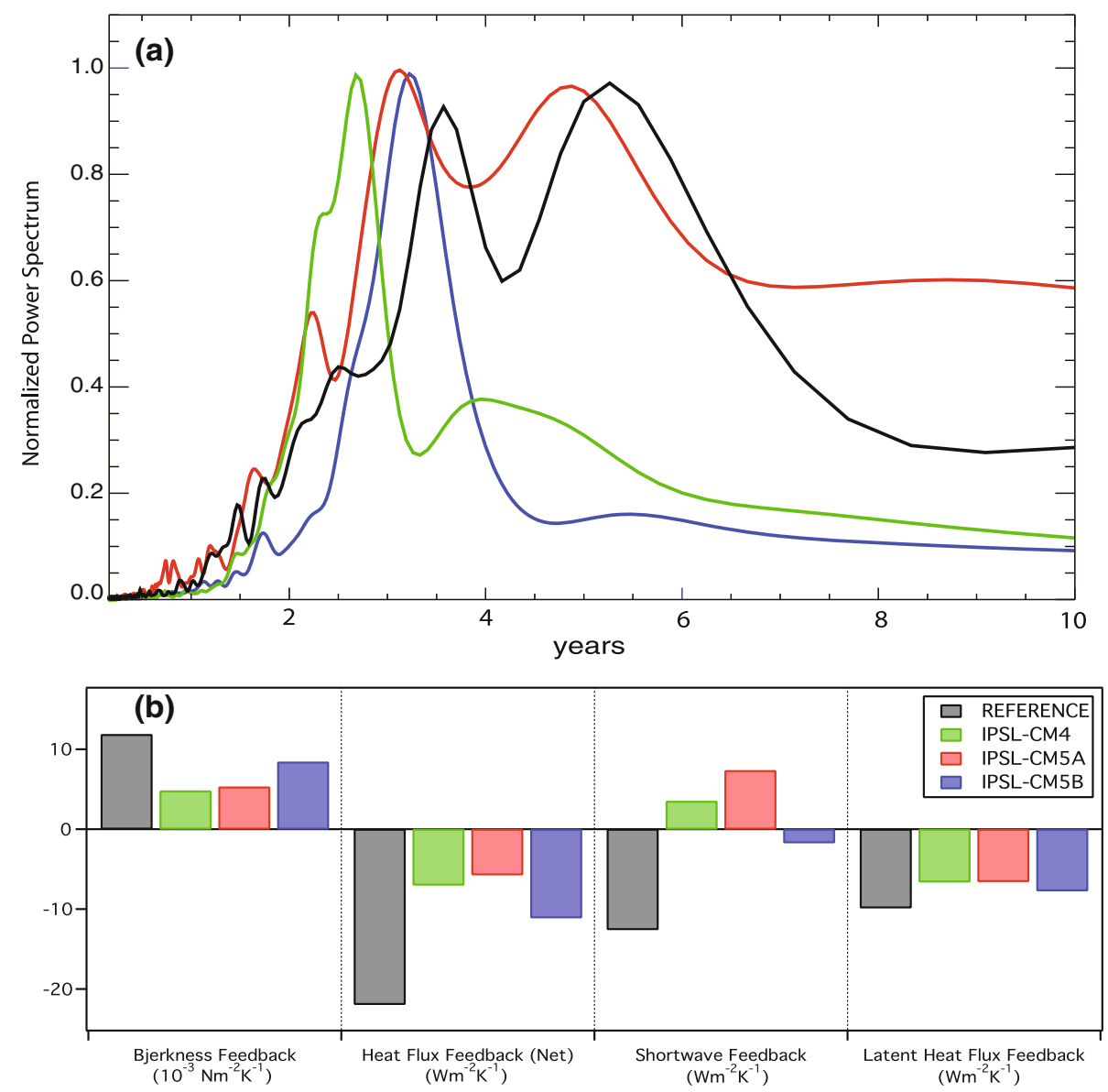

ENSO characteristics among models (Lloyd et al. 2012). Figure $11 \mathrm{~b}$ shows the process-based metrics associated to these atmospheric feedbacks. For all the four process-based metrics IPSL-CM5B-LR shows a better agreement with the reanalysis than IPSL-CM4 and IPSL-CM5A-LR. Both the Bjerknes and heat flux feedbacks are stronger in IPSLCM5B-LR and closer to observations. In particular, the stronger heat flux feedback is due to a better simulated latent feedback and to an improvement in the shortwave feedback, which has the right sign compared to IPSL-CM4 and CM5A-LR but is much too weak compared to observations. This change in the shortwave feedback sign in the Niño3 region is due to an increased occurrence of convective clouds that are responsible for a negative shortwave feedback. This improvement in CM5B-LR is mostly associated to the improved mean state in which the cold tongue spurious westward extension bias is reduced (Sect. 4.2). In contrast IPSL-CM4 has permanent upwelling conditions, which favor the subsidence regime and positive values for the shortwave feedback (Guilyardi et al. 2009; Lloyd et al. 2012). In summary, IPSL-CM5 (A and B) simulate a weaker ENSO than IPSL-CM4 closer to the observed amplitude and associated with a better representation of atmosphere feedbacks in IPSL-CM5B-LR.

\section{Future climate changes}

Projections of future climate changes are based on scenarios. The RCP scenarios used in CMIP5 are too different from the SRES scenarios used in CMIP3 (Sect. 3.1) to allow a direct comparison of CMIP3 and CMIP5 results for the scenario experiments. In this section the results obtained with the IPSL-CM5 models following the RCP scenarios are discussed. The comparison between results from one model, IPSL-CM5A-LR, following the SRES scenarios and the very same model following the RCP scenarios is also discussed.

\subsection{Future warming projections using RCP scenarios}

The global mean surface air temperature increase during the first three decades (2005-2035) is similar in the three IPSL-CM5 models (Fig. 12a) and for all the RCP scenarios. The temperature increase in the medium- and lowresolution versions of the IPSL-CM5A model remains very similar throughout the twenty-first century. Starting around 2040 the IPSL-CM5B model simulates a smaller temperature increase than the other model versions. The global mean air surface temperature increase levels off in the 
middle of the century for the RCP 2.6 scenario and at the end of the twenty-first century for the RCP 4.5 scenario, but it continues to increase for the RCP 6.0 and RCP 8.5 scenarios.

The prescribed aerosol concentration and the parameterizations of the aerosol direct and first indirect effects are the same in IPSL-CM5A and CM5B but their radiative effects differ (Fig. 12b). The aerosol first indirect effect is larger in absolute value in IPSL-CM5B-LR compared to IPSLCM5A-LR probably because of the larger fraction of low-level clouds in IPSL-CM5B-LR compared to IPSL-CM5ALR. The aerosol direct effect is smaller in IPSL-CM5B-LR compared to IPSL-CM5A-LR probably because a higher cloud fraction reduces the direct effect of aerosols. Overall, the total radiative effects of aerosols is slightly larger $\left(\approx 0.1 \mathrm{Wm}^{-2}\right)$ in IPSL-CM5B-LR than in IPSL-CM5A-LR. This partly contributes to the smaller global mean surface air temperature increase in the IPSL-CM5B-LR model. However IPSL-CM5B-LR has a much smaller climate sensitivity than the other model versions as discussed in Sect. 6.1 and this is probably the main reason for the smaller temperature increase in the late twentieth century.

As one may expect, the difference among scenarios appears earlier for the net heat flux at the TOA than for the surface temperature. This is illustrated on Fig. 13 for the IPSL-CM5A-LR model. The net heat flux at the TOA differs among scenarios starting in the early twenty-first century. These differences gradually become more pronounced and start to affect the temperature evolution. At the end of the twenty-third century, the difference in global mean annual temperature is $11^{\circ} \mathrm{C}$ between the scenario with the highest radiative forcing (RCP 8.5) and the scenario with the lowest radiative forcing (RCP 2.6). For the low RCP 2.6 scenario, the radiative forcing decreases and the temperature is almost constant from 2050 onward. It slightly decreases despite a positive net flux at the TOA due to the heat uptake by the ocean (not shown).

Many factors affect the local air surface temperature changes. One factor is the geographical distribution of the forcings such as aerosols concentration and land use. A second factor is the geographical distribution of the climate response to these forcings and in particular the relative strength of local and global feedbacks. In order to distinguish the geographical distribution pattern from the global mean value, the local temperature amplification factor is defined as the ratio between the local temperature change and the global mean temperature change. The zonal mean average of this temperature amplification has been shown to be only weakly dependent on the scenario for the CMIP3 simulations (Meehl et al. 2007b). The pattern of this local temperature amplification factor has been used as "pattern scaling" technique to estimate temperature changes under different scenarios (Mitchell et al. 1999; Moss et al. 2010).
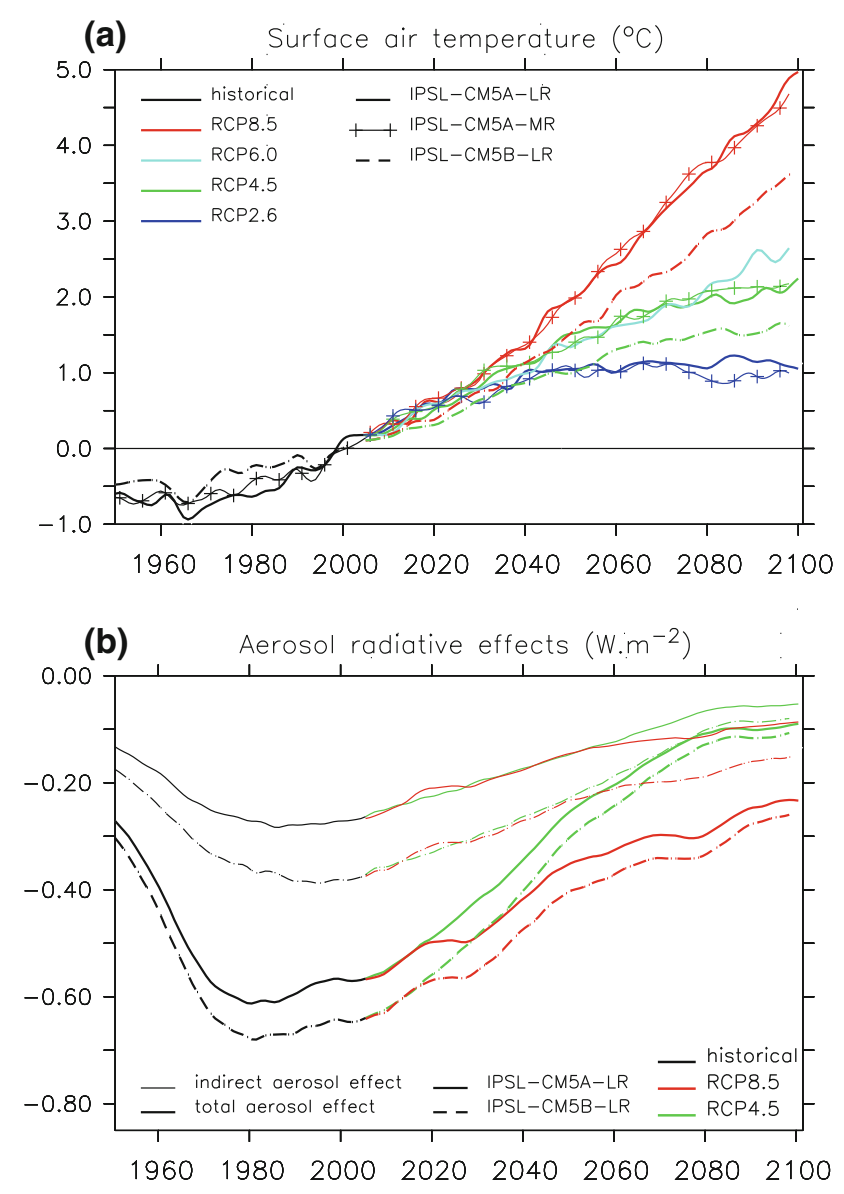

Fig. 12 a Time evolution of the global mean surface air temperature anomaly (in K) computed by the IPSL-CM5A-LR (thick line), the IPSL-CM5A-MR (thin line with crosses) and the IPSL-CM5B-LR (thick dash line) models, with historical conditions for the period 1950-2005 (black) and with RCPs conditions for the period 2006-2100: RCP 2.6 (blue), RCP 4.5 (green), RCP 6.0 (light blue), and RCP $8.5(r e d)$. The temperature anomaly is computed with respect to the 1985-2015 period. b Time evolution of the total (thick line) and the first indirect (thin line) aerosol radiative effects for the same runs as on panel (a). For clarity, results are only shown for the RCP 4.5 (green) and the RCP 8.5 (red) scenarios and for the IPSLCM5A-LR (line) and the IPSL-CM5B-LR (dash line) models. The unit is $W \cdot m^{-2}$. For $\mathbf{a}$ and $\mathbf{b}$, only one ensemble member is considered and the results are smoothed using a 7-year Hanning filter

Figure 14 shows the pattern of the local temperature amplification factor for the two extreme RCP scenarios (RCP 2.6 on the left, RCP 8.5 on the right) simulated by the IPSL-CM5A-LR, the CM5A-MR and the CM5B-LR models at the end of the twenty-first century (three upper rows). This geographical pattern is very similar in RCP 2.6 and RCP 8.5 scenarios (as well as in RCP 4.5 and RCP 6.0, not shown) even though the forcings are quite different, in particular the land use and $\mathrm{BC}$ forcings, which have strong local signatures. However the normalized warming is generally larger over the continent and smaller in the Arctic region for the RCP 8.5 scenario. The general pattern 

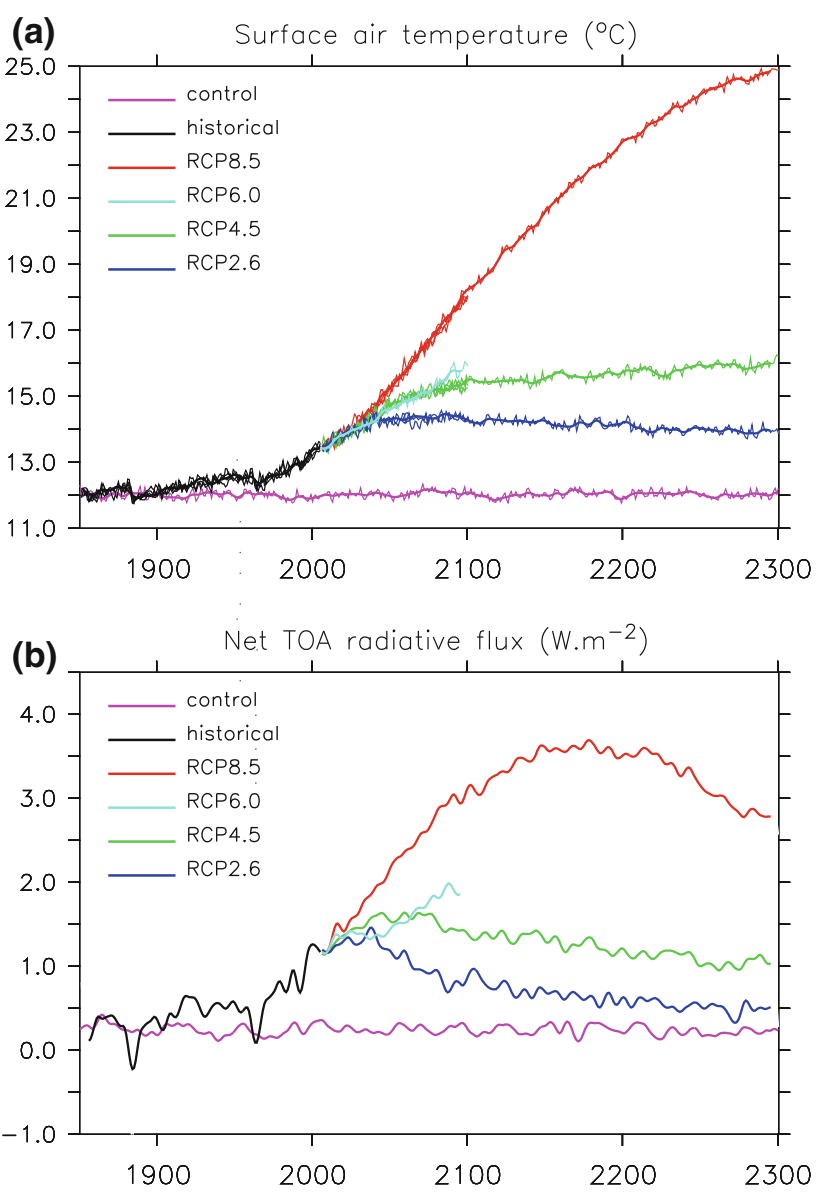

Fig. 13 For the IPSL-CM5A-LR model, time evolution of the global mean surface air temperature (a) and the net TOA radiative flux (b) for the control run (magenta), the historical runs (black), and for the RCP 2.6 (blue), the RCP 4.5 (green), the RCP 6.0 (light blue), and the RCP 8.5 (red) scenarios. In a the thin lines correspond to the annual value of individual run members, the thick lines correspond to the 11-year running mean of one particular member. In $\mathbf{b}$ the lines correspond to the 11-year running mean of one particular member. For all scenarios members extend to year 2300 except for the RCP 6.0 scenario for which the only member stops in 2100

of temperature change is consistent with the one previously obtained (Meehl et al. 2007b). More specifically, there is a larger temperature increase over the continents than over the oceans, a strong amplification in the Arctic regions, and the smallest warming is found over the Southern Ocean. The IPSL-CM5B-LR model shows a very large and probably unrealistic temperature increase poleward of $60^{\circ} \mathrm{N}$, which may be related to the very cold bias in these regions (Fig. 7), to the equatorward shift of the atmospheric zonal wind stress and to the very weak Atlantic meridional overturning circulation of this model (Sect. 5.5).

The RCP simulations have been extended until the end of the twenty-third century for the IPSL-CM5A-LR model. The differences among geographical patterns of temperature amplification in the two extreme scenarios are larger at the end of the twenty-third century than at the end of the twenty-first century even though they remain surprisingly small compared to the very large differences between the two global mean temperature changes: $1.9 \mathrm{~K}$ for RCP 2.6 and $12.7 \mathrm{~K}$ for RCP 8.5. Continental warming is larger in the RCP 8.5 scenario. The relatively small polar warming in RCP 8.5 reflects a very different polar amplification, which will be analyzed below (Sect. 5.6). For the RCP 2.6 scenario, there are minor differences between the end of the twenty-first and twenty-third centuries. The warming over the southern ocean at the end of the twenty-thired century remains small compared to the global warming. For the RCP 4.5 scenario, the pattern of the local temperature amplification in 2300 is very similar to the one for scenario RCP 2.6 (not shown).

\subsection{Future warming projections using SRES scenarios}

In this section the global mean surface air temperature increase and the radiative forcings obtained for the SRES scenarios used in CMIP3 are compared with those obtained for the RCP scenarios used in CMIP5. With the same IPSLCM5A-LR model, simulations with both SRES and RCP forcings were performed. The concentration of long-lived greenhouse gases are fully specified in both SRES and $\mathrm{RCP}$, which is not the case for ozone. Here we assumed that the ozone concentration of the SRES-A2, SRES-A1B and SRES-B1 scenarios were the same as the ozone concentration of the RCP 8.5, RCP 6.0 and RCP 4.5 scenarios, respectively. Little information regarding aerosols was given for the SRES scenarios whereas the information is available for the RCP scenarios. Therefore, six types of aerosols were considered in RCP simulations (see Sect. 2.2.3) but only the sulfate aerosol was considered in the SRES runs. For the SRES scenarios the sulfate aerosol concentrations computed by Pham et al. (2005) were used. To avoid a discontinuity of forcings at the beginning of these scenarios, a historical simulation was performed using the consistent distribution of sulfate aerosols (Boucher and Pham 2002). Land use changes were also considered in the RCP runs but not in the SRES runs for which the land use of year 2000 was used for the whole twentyfirst century. These choices are consistent with the fact that in CMIP3 most models considered ozone and sulfate aerosol forcings but no forcing due to other aerosols species nor forcing due to land use changes, whereas for CMIP5 most models are expected to consider a larger variety of aerosols as well as land use changes.

The range of future global mean warming for the RCP scenarios is much larger (Fig. 15) than for the SRES scenarios. The RCP 8.5 scenario leads to a higher warming than the SRES-A2 scenario, and the RCP 2.6 scenario leads to a stabilization of the global mean surface temperature, a feature that no SRES scenario simulates. Also, the global 
(a) IPSL-CM5A-LR, RCP26, 2100

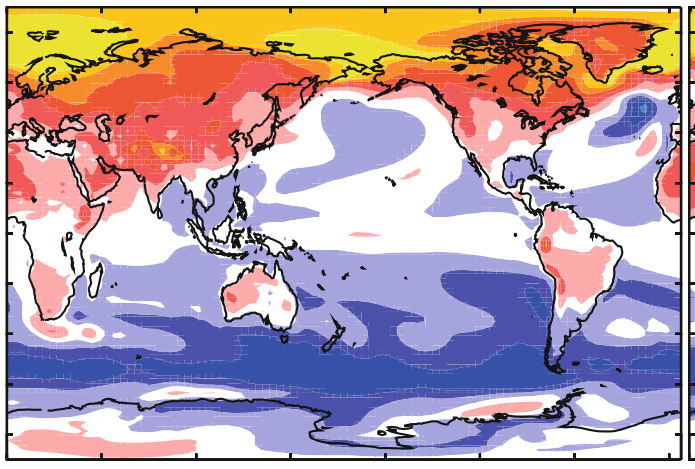

(c) IPSL-CM5A-MR, RCP26, 2100

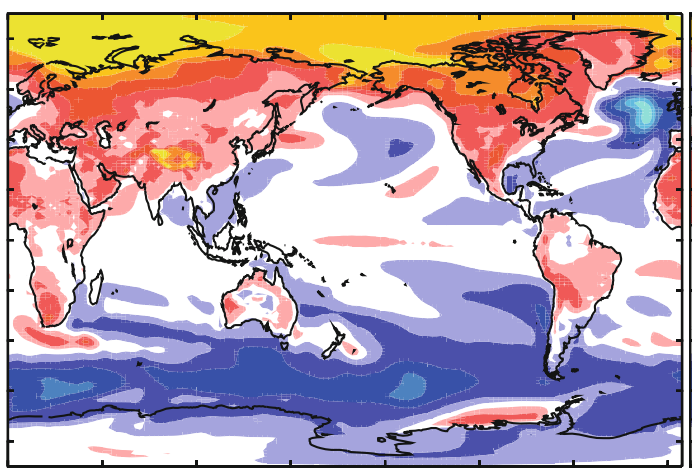

(e) IPSL-CM5B-LR, RCP26, 2100

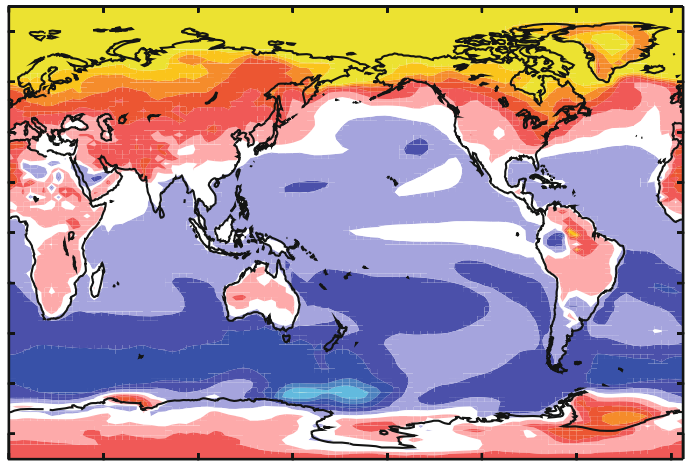

(g) IPSL-CM5A-LR, RCP26, 2300

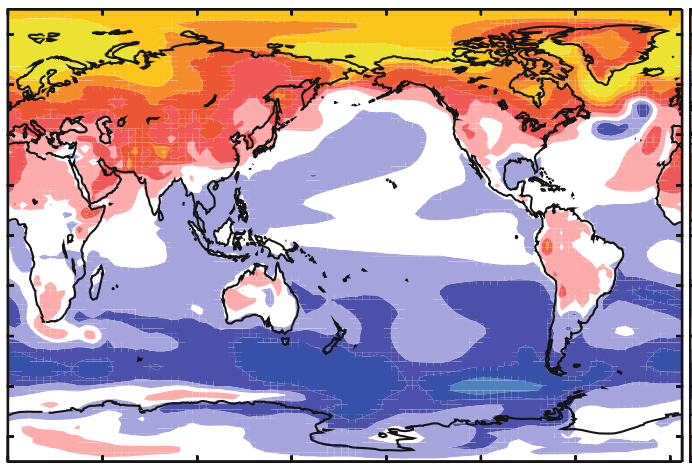

(b) IPSL-CM5A-LR, RCP85, 2100
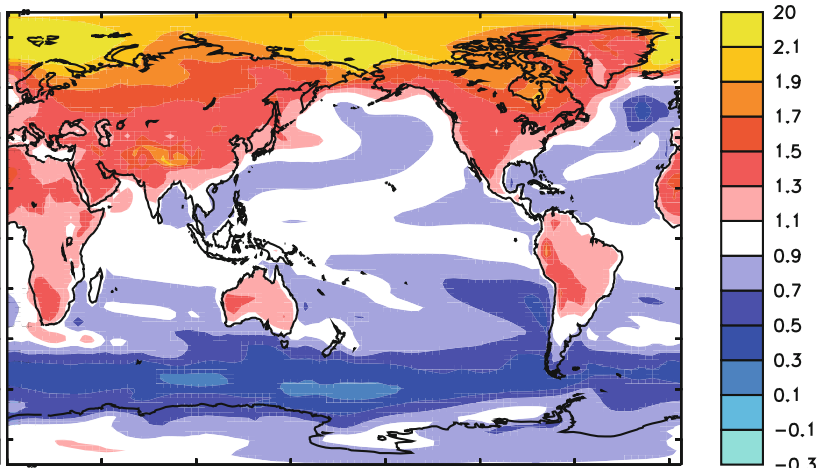

(d) IPSL-CM5A-MR, RCP85, 2100
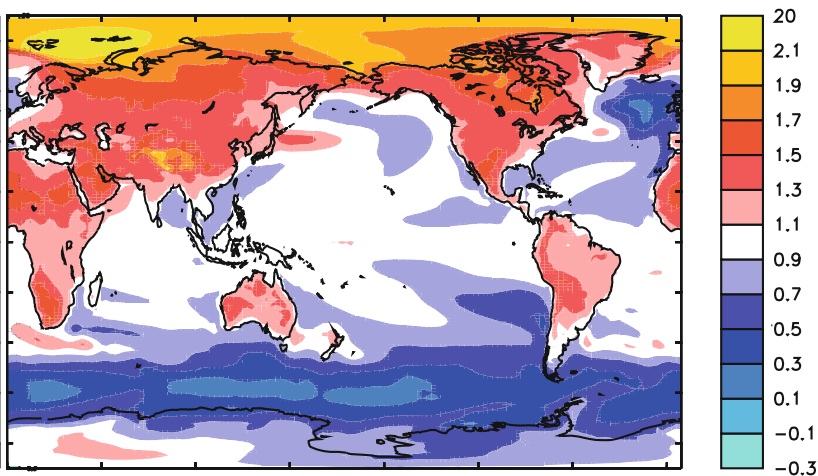

(f) IPSL-CM5B-LR, RCP85, 2100

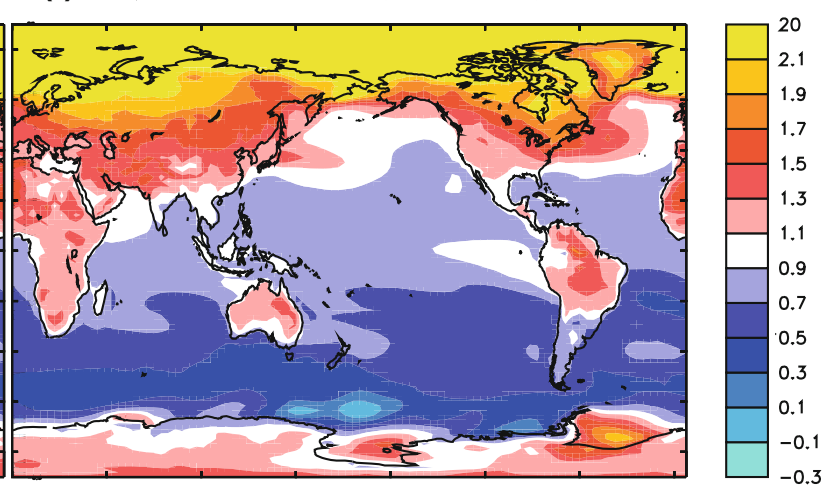

(h) IPSL-CM5A-LR, RCP85, 2300

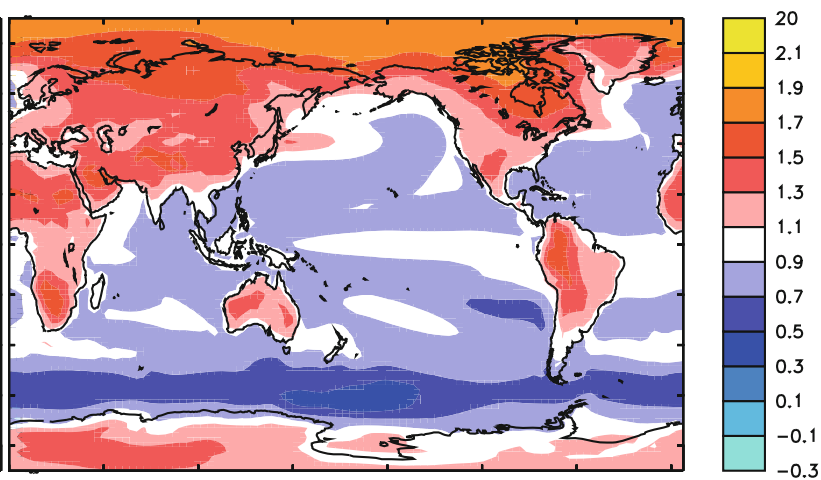


4 Fig. 14 Geographical distribution of the normalized temperature change for the RCP 2.6 (left column) and the RCP 8.5 (right column) scenarios at the end of the twenty-first century (2070-2100 period, three upper rows) for IPSL-CM5A-LR (a, b, first row), IPSL-CM5AMR (c, d, second row) and IPSL-CM5B-LR (e, f, third row). Normalized temperature change at the end of the twenty-third century (2270-2300 period) are shown on the bottom row $(\mathbf{g}, \mathbf{h})$ for the IPSLCM5A-LR model. The temperature changes are computed relative to the pre-industrial run (100-year average) and the normalized temperature change is defined as the local temperature change divided by the global average temperature change

mean surface temperature for RCP and SRES projections differs significantly except for RCP 4.5 and SRES-B1. For these two scenarios the long-lived greenhouse gases forcing and the temperature increase are very similar although the simulated temperature increase is somewhat smaller around 2040 for SRES-B1 compared to RCP 4.5 due to the radiative effect of aerosol, which is larger for SRES-B1.

The aerosol radiative forcings are very different between the two families of scenarios. These differences do not originate from the diagnostics because the aerosol forcings are calculated online with the same method in the different simulations. One difference is that in the RCP family aerosol concentrations reach a maximum around 2020 and then decrease whereas in the SRES family the aerosol concentrations increase until 2030-2050. The second difference is that only the sulfate aerosol was considered in the SRES experiments whereas absorbing aerosols were also considered in the RCP experiments, which strongly reduce the total aerosol radiative forcing. However for all scenarios the relative contribution of anthropogenic aerosols forcing compared to the total anthropogenic forcing is smaller in 2100 than in 2000.

A common feature observed in the model results using both scenario families is the delay between the time when the radiative forcing in two scenarios differ and the time when the temperature increase in response to these forcing differ. The different trend in radiative forcing between SRES-A2 and A1B scenarios on one hand, and between RCP 6.0 and RCP 4.5 on the other hand, starts around 2060. The divergence in temperature increase occurs 20 years later but is still small at the end of the century.

\subsection{Computing the $\mathrm{CO}_{2}$ flux and the "compatible emissions" of $\mathrm{CO}_{2}$}

For the historical period and for each of the RCP scenarios, the land (ORCHIDEE) and ocean (PISCES) carbon cycle models generate spatially-explicit carbon fluxes in response to the atmospheric $\mathrm{CO}_{2}$ concentrations and simulated climate. The simulated net land carbon flux includes a land-use component but the decomposition of this net flux into its land-use and natural parts has not yet been
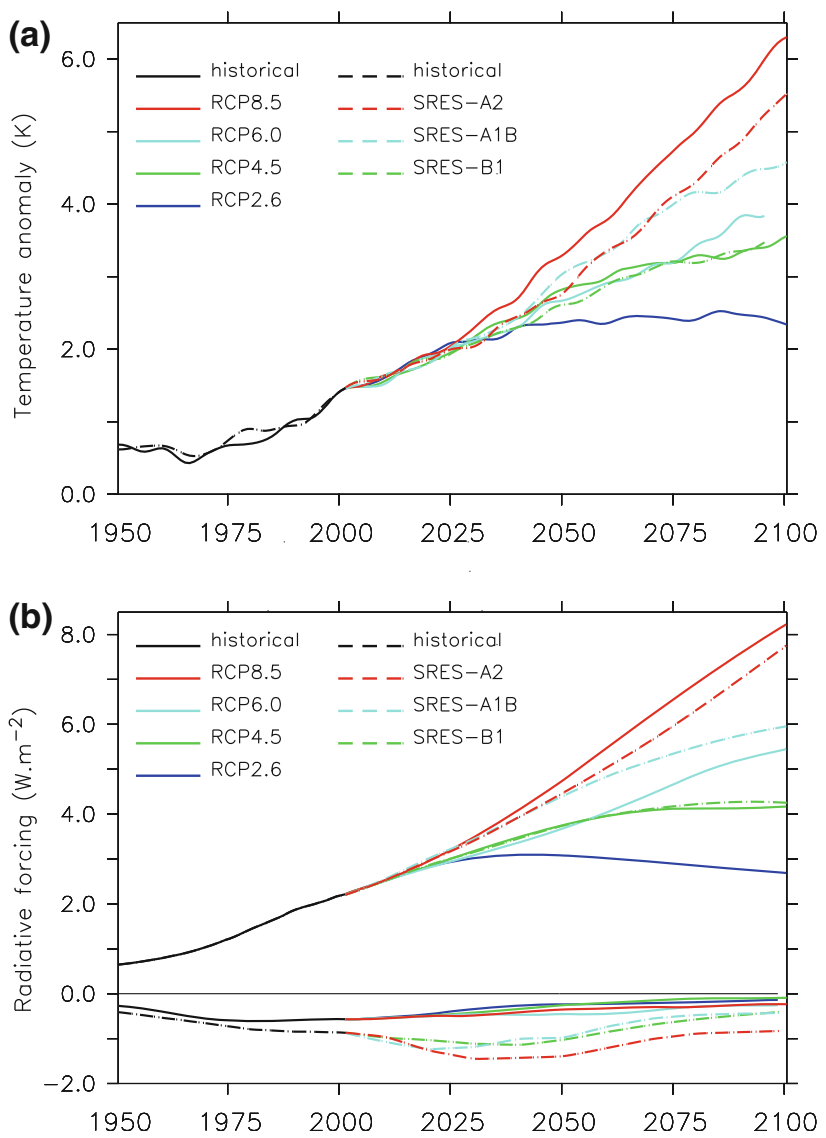

Fig. 15 Time evolution of a the global mean air surface temperature anomalies $(\mathrm{K})$ and of $\mathbf{b}$ the long-lived greenhouse gases $\left(\mathrm{CO}_{2}, \mathrm{CH}_{4}, \mathrm{~N}_{2} \mathrm{O}, \mathrm{CFC} \ldots\right.$ but no ozone) (positive values) and aerosol (negative values) radiative forcing $\left(\mathrm{Wm}^{-2}\right)$ (direct + first indirect) simulated with IPSL-CM5A-LR for the historical and for the future periods using the forcing of the RCP (line) and SRES (dash) scenarios. The historical runs are in black. The four RCP scenarios used in CMIP5 are RCP 2.6 (blue), RCP 4.5 (green), RCP 6 (light blue), and RCP 8.5 (red). The three SRES scenarios used in CMIP3 are SRES-B1 (green), SRES-A1B (light blue), and SRES-A2 (red)

analyzed. Piao et al. (2009) however did show that a similar version of ORCHIDEE was able to reproduce the estimated land use change related to carbon emissions when forced over the historical period by the Climate Research Unit temperatures and precipitations datasets (Jones et al. 1999; Brohan et al. 2006; Doherty et al. 1999). Only the results of IPSL-CM5A-LR and CM5A-MR runs are presented here because the carbon pools have not reached an equilibrium state for IPSL-CM5B-LR (Sect. 4.1).

In the historical simulations with IPSL-CM5A-LR the net ocean and land fluxes increase in the 1990-1999 decade to reach $2.2( \pm 0.05)$ and $1.28( \pm 0.1)$ Pg/year, respectively (Fig. 16). These values are in the range of recent estimations (Le Quéré et al. 2009) for the 1990-1999 
decade: $2.2 \pm 0.4 \mathrm{PgC} /$ year for the ocean and $1.1 \pm 0.9$ $\mathrm{PgC} /$ year for the land.

Over the 2005-2300 period, the ocean uptake increases up to $6 \mathrm{PgC} /$ year in 2100 for the RCP 8.5 scenario. The ocean uptake peaks at $5 \mathrm{PgC} /$ year in 2080 for the RCP 6.0 scenario, and at $3.7 \mathrm{PgC} / \mathrm{year}$ in 2030 for the RCP 4.5 scenario before decreasing throughout the remainder of the simulations. For the RCP 2.6 scenario, the ocean uptake does not exceed 3.2 PgC/year over the 2005-2300 period and is close to zero in 2300 . The differences in net land flux between the different scenarios over the 2005-2300 period is less pronounced. The net land flux (including land-use emissions) peaks at $5 \mathrm{PgC}$ /year in the RCP 8.5, RCP 6.0 and RCP 4.5 scenarios during the twenty-first century. For the RCP 2.6 scenario, the net land flux does not exceed $3 \mathrm{PgC} /$ year. After 2150 the net land flux is close to zero or negative for all RCP scenarios (i.e. the land becomes a source of carbon for the atmosphere).

We diagnosed the anthropogenic emissions compatible with the simulated land $\left(F_{l}\right)$ and ocean $\left(F_{o}\right)$ carbon fluxes and prescribed $\mathrm{CO}_{2}$ concentrations using the following equation for the emission rates

$F_{e}=\frac{d M_{C}}{d t}+\left(F_{o}+F_{l}\right)$

where $M_{C}$ is the mass of carbon in the atmosphere. The ORCHIDEE model explicitly simulates the natural and land-use components of land-atmosphere carbon fluxes so "compatible emissions" refer here to fossil fuel + cement production only emissions. The computed compatible emissions for the historical and RCPs simulations are shown in Fig. 17.

For the 1990-1999 decade, the compatible emissions amount to $6.6( \pm 0.2) \mathrm{PgC} /$ year, which compares well with data-based estimates of $6.4( \pm 0.4) \mathrm{PgC} /$ year (Forster et al. 2007). In 2100 the cumulative compatible emissions differ markedly between the scenarios and amount to 2,288 ( \pm 3 , 4 simulations), 1,644 (1 simulation), 1,349 ( $\pm 10,4$ simulations), 793 ( $\pm 1,4$ simulations) $\mathrm{PgC}$, for the RCP 8.5, the RCP 6.0, the RCP 4.5 and the RCP 2.6 scenarios, respectively. The uncertainties given here are the standard deviation of the estimates when multi-member simulations are available.

When using the mid-resolution model (IPSL-CM5AMR) forced by the same RCP scenarios, the cumulative compatible emissions amount to 2,244, 1,303 and $772 \mathrm{PgC}$ in 2100 for RCP 8.5 , RCP 4.5 and RCP 2.6, respectively (Fig. 17c). These values are similar to the ones obtained with IPSL-CM5A-LR but they are lower by $2-3 \%$ for each of the scenarios. These differences are explained by a weaker uptake of carbon by both the ocean and the land biosphere. The reasons for this difference may be related to the reduction of the southern westerlies biases in IPSL-
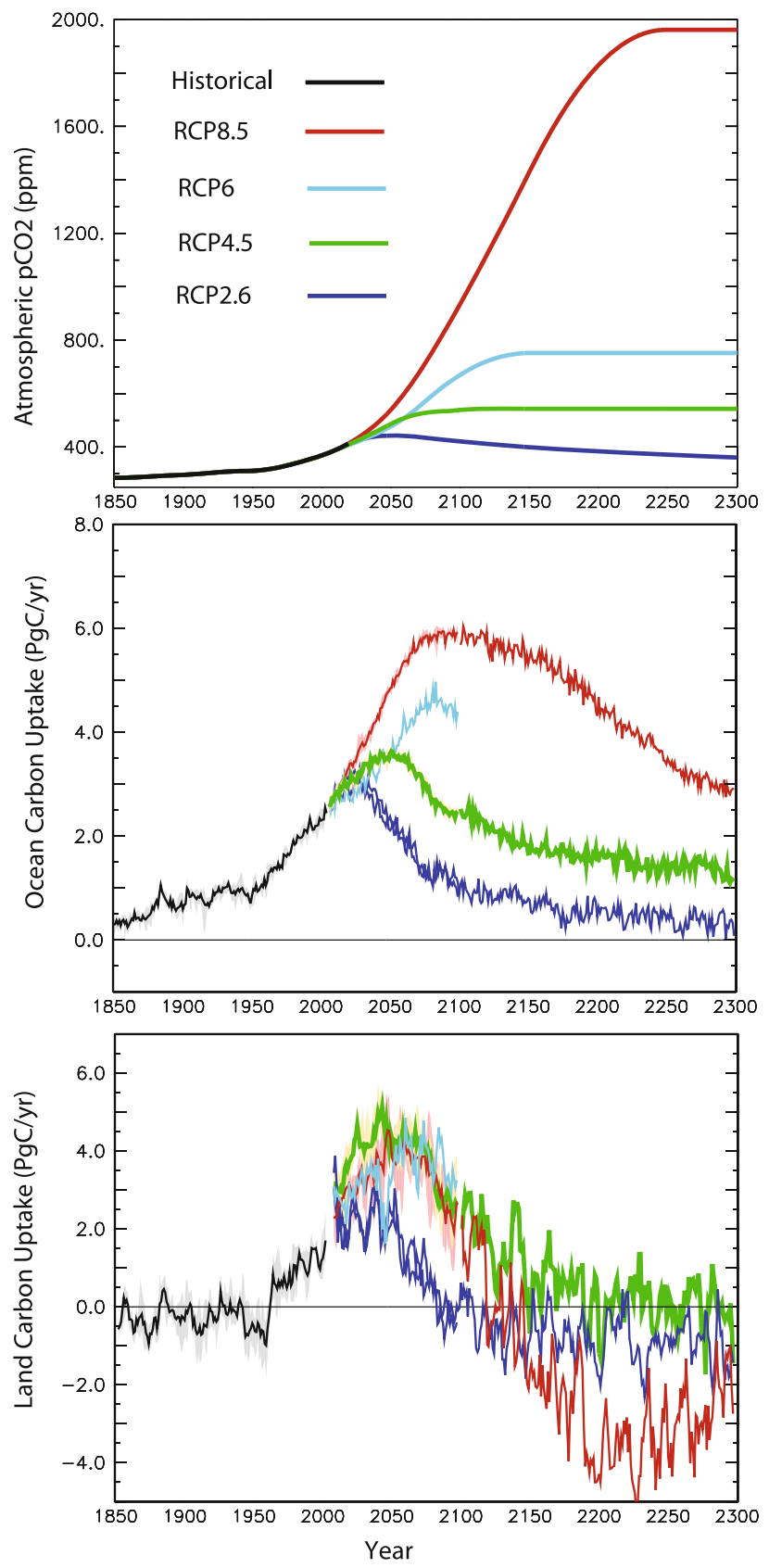

Fig. 16 Time evolution of the prescribed $\mathrm{CO}_{2}$ concentration (top), computed ocean carbon uptake (middle) and land carbon uptake (bottom) for the historical period (black) and for the RCP 2.6 (blue), the RCP 4.5 (green), the RCP 6.0 (light blue), and the RCP 8.5 (red) scenarios. The model used is IPSL-CM5A-LR, the concentration is in ppmv and the carbon flux is in $\mathrm{PgC} /$ year. Note that the simulated net land carbon flux includes a land-use component (see text)

CM5A-MR compared to IPSL-CM5A-LR (see Hourdin et al. 2013a) and its impact on oceanic carbon uptake as demonstrated in Swart and Fyfe (2012). For the land, the reduction of the global cool bias discussed above induces a reduction of the positive effect of global warming on the functioning of high- and mid-latitude vegetation, which 

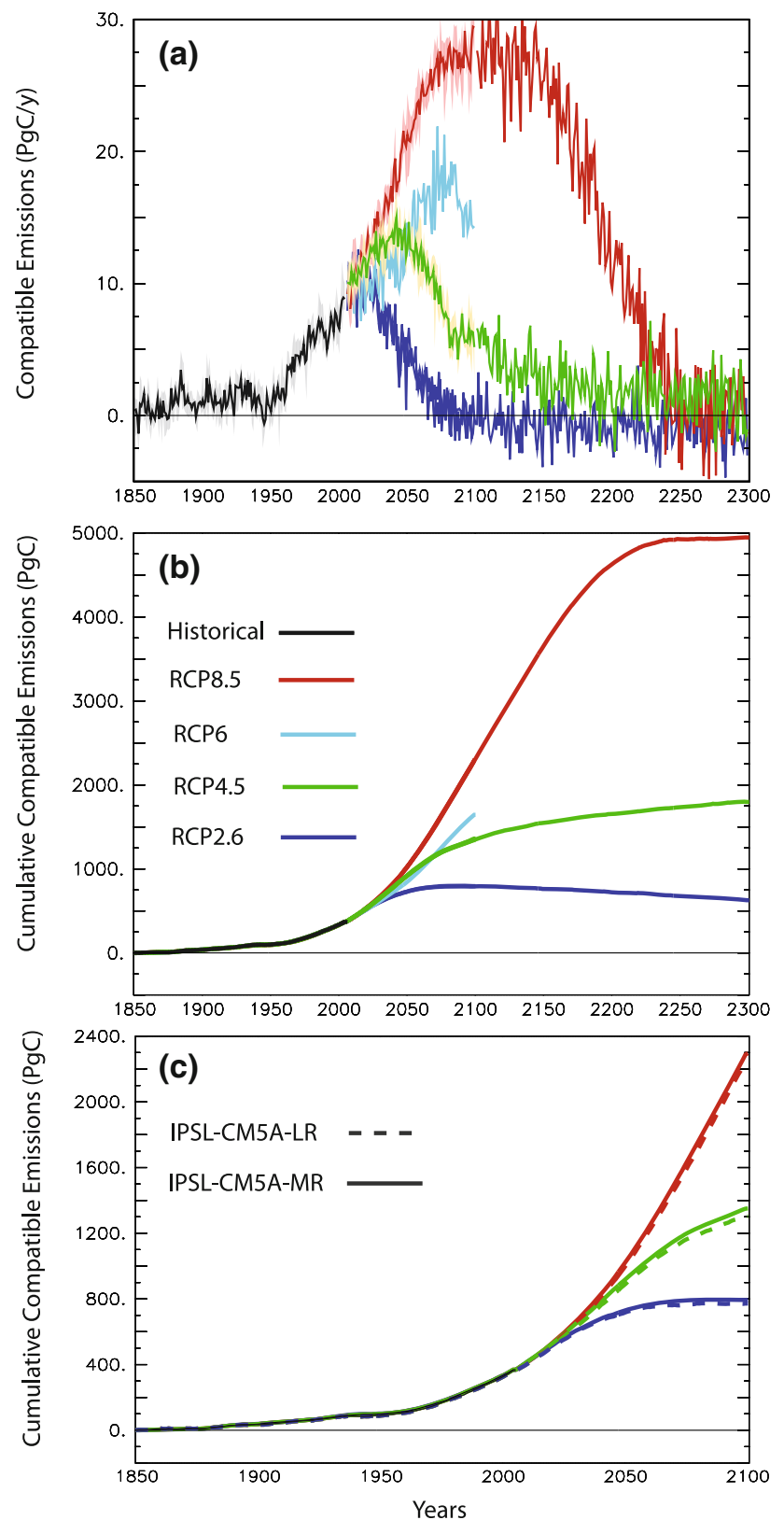

Fig. 17 Time evolution of the compatible $\mathrm{CO}_{2}$ emissions (a, in $\mathrm{PgC} /$ year) and of the cumulative emissions $(\mathbf{b}$, in $\mathrm{PgC}$ ) for the historical period (black) and for the RCP 2.6 (blue), the RCP 4.5 (green), the RCP 6.0 (light blue), and the RCP 8.5 (red) scenarios, simulated by the IPSL-CM5A-LR model. The time period is restricted to 1850-2100 in (c) where the results are shown for both the IPSLCM5A-LR and IPSL-CM5A-MR models. The compatible emissions refer here to fossil-fuel + cement production only and do not include land-use emissions

leads to a slight reduction in the ability of the vegetation to absorb $\mathrm{CO}_{2}$.

The cumulative emissions also differ from the initial IAMs (Integrated Assessment Models) emissions. For the RCP 8.5 scenario, the IAM emissions amount to $2,521 \mathrm{PgC}$ in 2100 . This is $230 \mathrm{PgC}$ (280 PgC for IPSL-CM5A-MR) less than with the initial IAMs. These differences are caused by weaker sinks than the ones used in IAMs, which could be due to a weaker response to atmospheric $\mathrm{CO}_{2}$ or to a stronger climate-carbon feedback in our simulations. More analysis is needed to confirm this hypothesis. For the RCP 2.6 scenario however, the IAM emissions and our estimates agree ( 790 vs $772 \mathrm{PgC}$, respectively).

In 2300, cumulative compatible emissions for IPSLCM5A-LR are 4,946, 1,797 and $627 \mathrm{PgC}$ for the RCP 8.5, the RCP 4.5 and the RCP 2.6 scenarios, respectively. Interestingly, the RCP 2.6 compatible emissions reach negative values from 2100 onwards.

\subsection{Future precipitation changes}

In contrast to surface-air temperature changes, which are positive over most of the globe, precipitation changes exhibit a complex regional pattern. To facilitate the comparison of precipitation projections associated with different scenarios, we use the "normalized relative precipitation change", i.e. the relative change in precipitation $(\mathrm{dP} / \mathrm{P}$ computed at each grid point) normalized by the globalmean surface-air temperature change. Units are thus \% $\mathrm{K}^{-1}$. The geographical distribution of the normalized relative precipitation changes for the different model versions and for the different scenarios features well-known patterns such as precipitation decrease in most of the subtropics and an increase in the equatorial regions and in the mid and high latitudes (Fig. 18).

Despite the differences among the forcings in each scenario, the pattern of the change in precipitation in 2100 for a given model version is strikingly similar for the different RCPs scenarios (Fig. 18a-f). The regions where precipitation decreases are almost the same for all scenarios, both over ocean and land, and the amplitudes of the normalized precipitation changes are very similar. Over north Asia and north America, the regions where precipitation increases are very similar but the normalized amplitude is a somewhat larger for the scenario with the lowest radiative forcing (RCP 2.6) than for the scenario with the highest radiative forcing (RCP 8.5). This is consistent with the results published by Johns et al. (2011).

The relative precipitation change has very similar patterns for the IPSL-CM5A-LR and the CM5A-MR models, which only differ in the horizontal resolution of the atmospheric model (Fig. 18a-d). Increased resolution provides more details in the geographical distribution, for instance in the Himalayan region, but does not lead to significant large scale pattern differences.

In contrast, the relative precipitation change displays dramatic differences for the IPSL-CM5A-LR and the CM5B-LR models, which only differ in the physical package of the atmospheric model (Fig. 18a, b, e, f). In the 
(a) IPSL-CM5A-LR, RCP26, 2100

(b) IPSL-CM5A-LR, RCP85, 2100
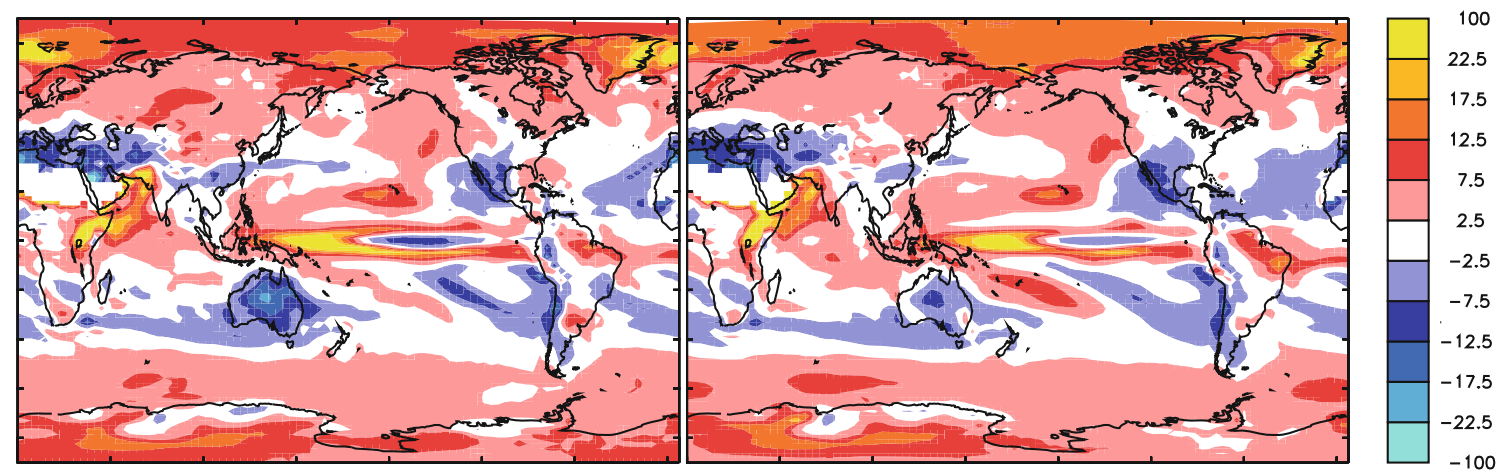

(c) IPSL-CM5A-MR, RCP26, 2100

(d) IPSL-CM5A-MR, RCP85, 2100
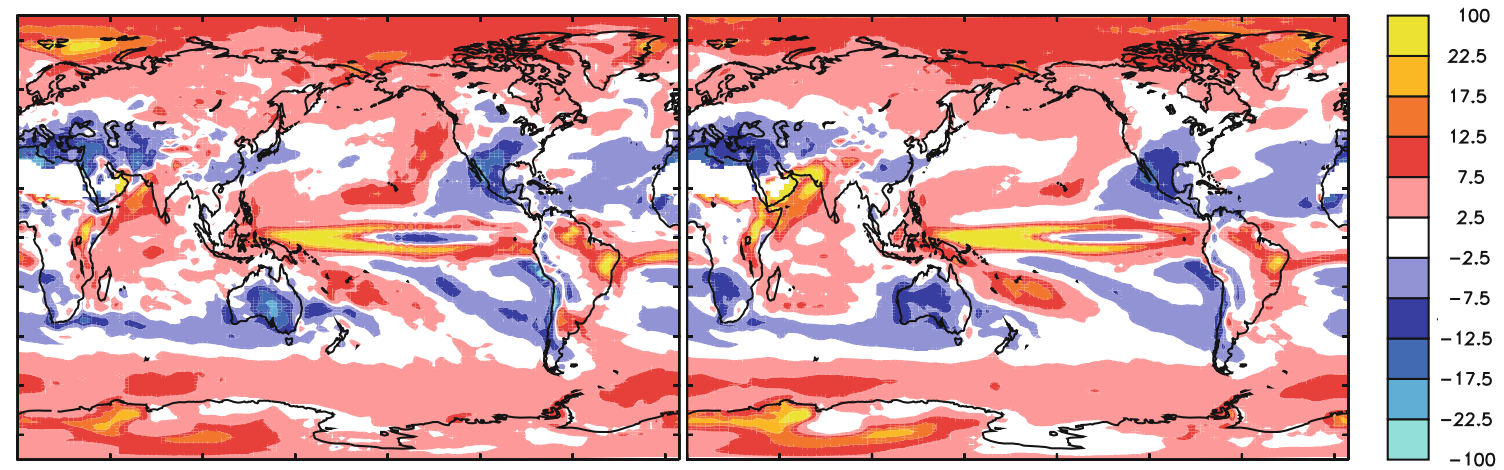

(e) IPSL-CM5B-LR, RCP26, 2100

(f) IPSL-CM5B-LR, RCP85, 2100
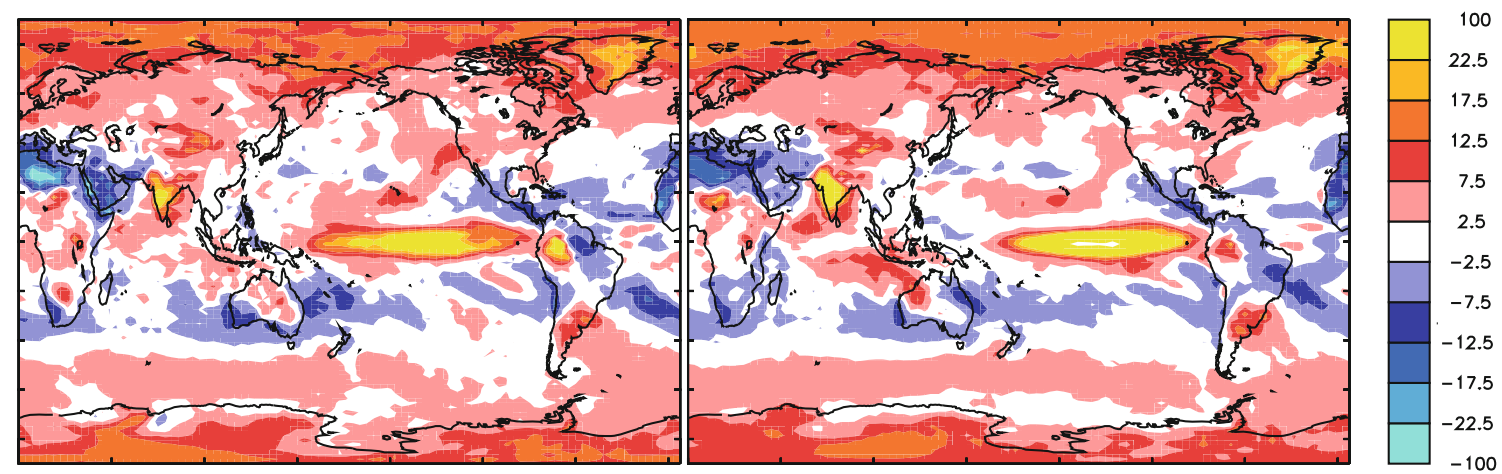

(g) IPSL-CM5A-LR, RCP26, 2300

(h) IPSL-CM5A-LR, RCP85, 2300
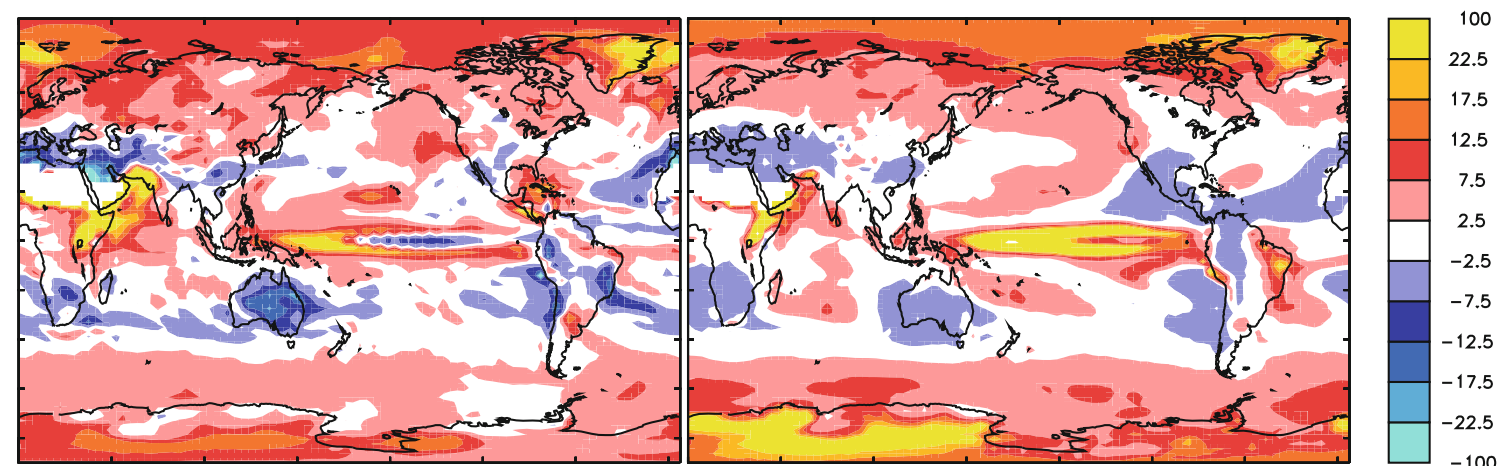
4 Fig. 18 Geographical distribution of the normalized relative precipitation changes for the RCP 2.6 (left column) and the RCP 8.5 (right column) scenarios at the end of the twenty-first century (2070-2100 period, three upper rows) for IPSL-CM5A-LR (a, b, first row), IPSLCM5A-MR (c, d, second row) and IPSL-CM5B-LR (e, f, third row). Normalized relative precipitation change at the end of the twentythird century (2270-2300 period) are shown on the bottom row $(\mathbf{g}, \mathbf{h})$ for the IPSL-CM5A-LR model. The local precipitation changes are computed relative to their local preindustrial values on a yearly mean basis and are then normalized with the global average temperature change. Regions where the annual mean precipitation is less than $0.01 \mathrm{~mm} /$ day (i.e. the Sahara region except for IPSLCM5B-LR which has higher precipitation there) are in white

Pacific ocean the precipitation changes along the equator are located in the center and in the east of the basin in CM5B, whereas it is located more westward in CM5A with a double ITCZ signature. There is no signature of the SPCZ in the precipitation response simulated by CM5B. Over the tropical continents the differences in precipitation changes are also large between CM5A and CM5B, especially over India, East Africa, South America and Australia. The amplitude and the sign of the precipitation changes differ. These large differences among models in the precipitation changes contrast with the relatively small differences in the climatology of precipitation among models (Fig. 8).

At the end of the twenty-third century the differences among geographical patterns of the relative precipitation change simulated by IPSL-CM5A-LR for the two extremes scenarios are very large (Fig. 18g, h). They are much larger than the differences in the relative temperature changes (Fig. 14g, h). For instance, the relative precipitation changes along the equator in the Pacific ocean are much larger and located more westward in RCP 8.5 than in RCP 2.6. Also, the extent of the drier regions in the subtropics is increased and the relative precipitation increase at high latitudes is larger in RCP 8.5 than in RCP 2.6.

A useful framework to interpret the projected precipitation changes consists in decomposing those changes into precipitation changes related to atmospheric circulation changes and precipitation changes related to water vapor changes, referred to as dynamical and thermodynamical components, respectively. At mid and high latitudes, the precipitation increase is mainly explained by the thermodynamical component (Emori and Brown 2005).

Over the tropical oceans and in the absence of atmospheric circulation change, an increase of water vapor in the boundary layer leads to an increase of moisture convergence, and therefore to an increase of precipitation in the convective regions and an increase of moisture divergence in the subsidence regions (Chou and Neelin 2004; Held and Soden 2006). This latter effect may be partly compensated by an increase of evaporation but the net effect is an increase of the precipitation contrast between wet and dry regions (Chou et al. 2009). However the atmospheric circulation significantly changes in response to the temperature increase and this circulation change is closely coupled to precipitation changes. We use the monthly-mean vertical velocity at $500 \mathrm{hPa}\left(\omega_{500}\right)$ as a proxy for large-scale atmospheric vertical motions. Figure 19 shows the change in $\omega_{500}$ (compared to preindustrial climate) predicted by the IPSL-CM5A-LR and IPSL-CM5B-LR models at the end of the twenty-first century in the RCP 8.5 scenario.

In the middle of the Pacific, along the equator, the large precipitation increase simulated by IPSL-CM5B-LR (Fig. 18f) is associated with a large increase in the largescale rising motion (or weakening of the large-scale subsidence) in the same region (negative values of $\omega_{500}$, Fig. 19b). In contrast, the change in precipitation simulated by IPSL-CM5A-LR is very small in this region (Fig. 18b) and so is the change in vertical velocity (Fig. 19a). Along the ITCZ, the strength of large-scale rising motions decreases in both model versions (Fig. 19) but more strongly in IPSL-CM5B-LR over the warm-pool (about $20 \mathrm{hPa} \mathrm{day}^{-1}$ ). This circulation change partly counteracts the precipitation increase induced by the larger water vapor amount in the atmosphere and explains why the two model versions predict very different changes in precipitation in this region (Fig. 18b). Further analysis and understanding of the reasons why the precipitation changes projected by these two models are so different will be the subject of a forthcoming paper.

\subsection{Atlantic meridional overturning circulation}

The Atlantic Meridional Overturning Circulation (AMOC) maximum is represented in Fig. 20 for different simulations from the IPSL-CM5A-LR and the IPSL-CM5A-MR models. This index represents the strength of the meridional circulation over the North Atlantic $\left(30^{\circ} \mathrm{S}-80^{\circ} \mathrm{N}\right.$, $500 \mathrm{~m}-5,000 \mathrm{~m}$ ) and the amount of ocean water sinking at depth in the North Atlantic. This overturning circulation is very weak in the IPSL-CM5B-LR pre-industrial run (AMOC index about $4 \mathrm{~Sv}$ ) probably due to a strong bias in the zonal wind and it will not be discussed in this section.

In the control simulations the mean AMOC maximum is $10.3 \mathrm{~Sv}$ in the IPSL-CM5A-LR model and 13.5 Sv in the IPSL-CM5A-MR model. Both values are too weak compared to observational estimates (Kanzow et al. 2010) because of a lack of convection in the Labrador Sea. This bias was also featured in previous versions of the IPSL model (Swingedouw et al. 2007a). The improvement in the IPSL-CM5A-MR is mainly related to a smaller equatorward shift in the atmospheric zonal wind stress, which is very strong in IPSL-CM5A-LR (Marti et al. 2010). As a consequence, the North Atlantic Ocean is saltier in IPSLCM5A-MR and convection occurs east of the Labrador 
(a) IPSL-CM5A-LR

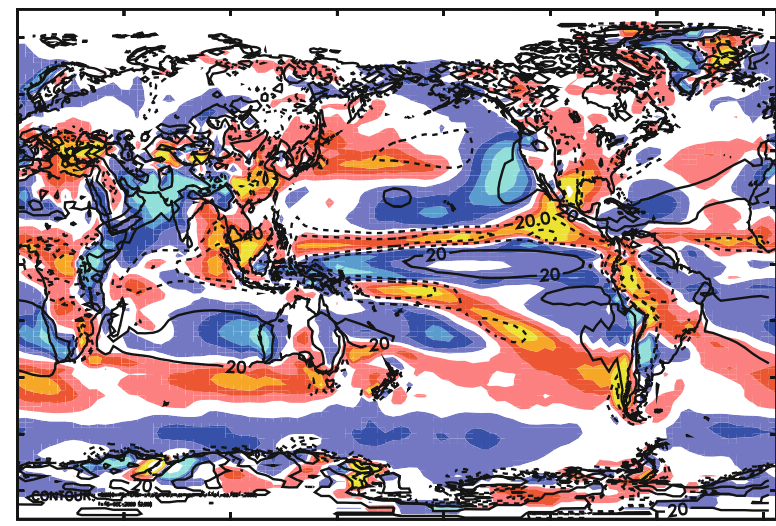

(b) IPSL-CM5B-LR

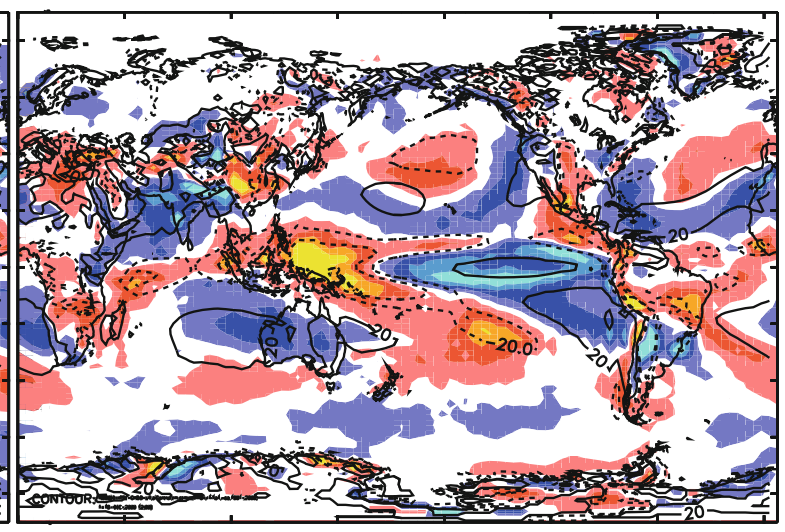

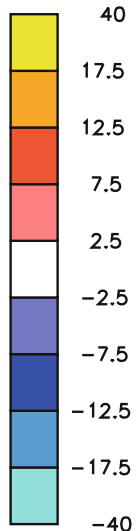

$-40$
Fig. 19 In color, geographical distribution of the mean vertical velocity change at $500 \mathrm{hPa} \omega_{500}\left(\mathrm{hPa}\right.$ day $\left.^{-1}\right)$ simulated by IPSLCM5A-LR (a, left) and IPSL-CM5B-LR (b, right) at the end of the twenty-first century (2070-2100 period) for the RCP 8.5 scenario relative to its value in the pre-industrial control run. The mean vertical velocity at $500 \mathrm{hPa}$ for the control run is contoured (contour values: $-40,-20$ and $20 \mathrm{hPa}$ day $^{-1}$ with dash lines for negative values). Negative values of $\omega_{500}$ correspond to large-scale rising motion, positive value to subsidence

component is decreasing in all the simulations as early as the 1960s. The haline component has a more complex behavior. It increases in the 1960s and remains higher than in the control simulations in all the projections until 2060. Later on, it decreases significantly in the RCP 8.5 long projections while it remains at the level of the control simulation in RCP 4.5 and even above it in RCP 2.6.

The increase in local SST is part of the increase of the global surface temperature in response to the GHG increase. The increase in sea surface salinity from the 1960s is the result of the balance between two opposite effects which are the transport of saltier waters from the tropics where the evaporation increases and precipitation decreases compared to pre-industrial values (not shown), and the increase in precipitation and runoff at high latitudes. In this model the balance seems to favor a salinification of the North Atlantic, which stabilizes the AMOC as was also the case in the former version of this model (Swingedouw et al. 2007b). The total evaporation integrated over the whole Atlantic (from $30^{\circ} \mathrm{S}$ to $80^{\circ} \mathrm{N}$ and including the Arctic basin) increases from $0.49 \mathrm{~Sv}$ in the control simulations (the Atlantic is an evaporative basin as in the real system) up to $0.62,0.65$ and $1.23 \mathrm{~Sv}$ for the last 30 years of RCP 2.6, RCP 4.5 and RCP 8.5 , respectively. This is associated with a large increase in fresh water export by the atmosphere from the Atlantic to the Pacific as in IPSL-CM4 (Fig. 11 from Swingedouw et al. (2007b)). Nevertheless, because of the thermal component that tends to weaken deep convection in the northern North Atlantic, the AMOC gradually weakens. For a sufficient weakening (as in RCP 8.5) of this large-scale northward transport of heat and salt, an oceanic feedback becomes dominant: the northward oceanic salinity transport associated with the 


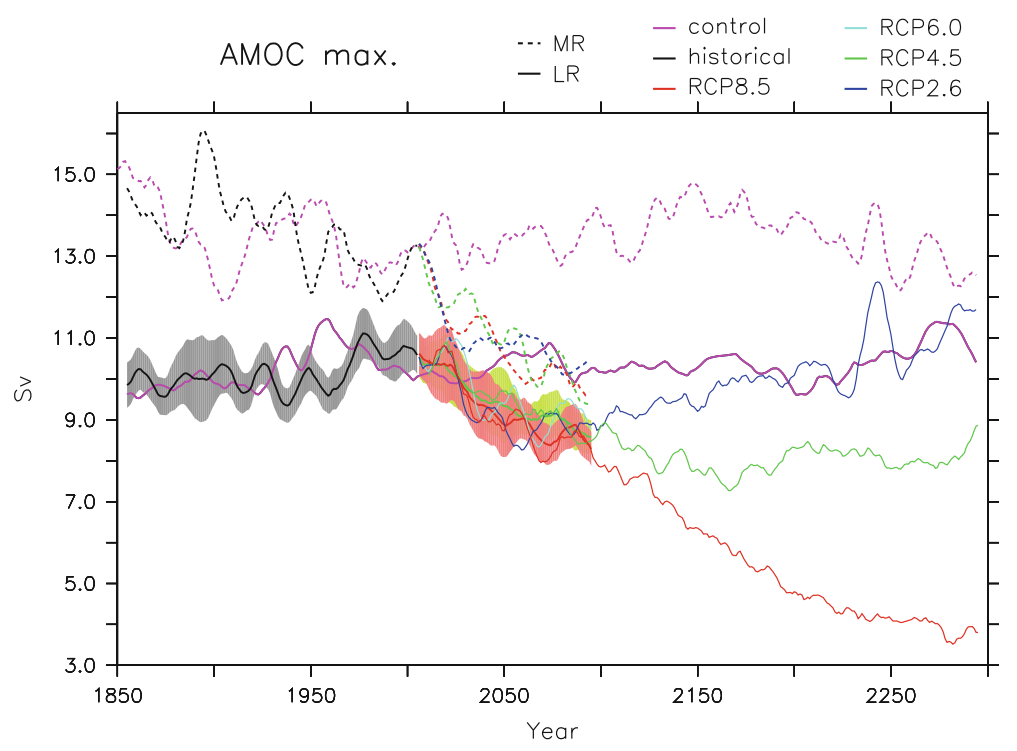

Fig. 20 Time evolution of the Atlantic Meridional Overturning Circulation (AMOC) maximum taken between $500 \mathrm{~m}$ and the ocean floor and from $30^{\circ} \mathrm{S}$ to $80^{\circ} \mathrm{N}$ for the preindustrial control run (magenta), the historical period (black) and the RCP 2.6 (blue), RCP 4.5 (green), RCP 6.0 (light blue) and RCP 8.5 (red) scenarios. Simulations using IPSL-CM5A-LR are in continuous line and the

AMOC decreases, leading to a decrease in sea surface salinity in the convection sites and a collapse of the AMOC. This mechanism is the so-called Stommel positive feedback (Stommel 1961). It explains the negative contribution of the haline component of the density in RCP 8.5 around 2060 (Fig. 21c).

The Greenland ice sheet melting is not taken into account in the IPSL-CM5A models although it can have a large impact on the AMOC (Swingedouw et al. 2007b). The analysis of such an effect will be achieved through the coupling of IPSL-CM5A-LR with a Greenland ice sheet model and will be presented in a future study.

\subsection{Polar amplification and sea-ice extent}

Due to the large extent of snow and ice covered surfaces over polar areas and their significant decrease with global warming, specific feedback mechanisms take place at high latitudes (Manabe and Stouffer 1980). Snow and ice are strongly sensitive to air temperature but they also strongly affect the surface energy budget by increasing the surface albedo and thermally isolating the oceanic surface from the air. As a result, the temperature increase due to global warming in the Arctic as simulated by most models is amplified (Meehl et al. 2007b). It is also the case for the IPSL models (Fig. 14). We focus here on the IPSL-CM5ALR model results.

To quantify the polar amplification effect, we defined the ratio between the mean increase of surface air temperature poleward of the Arctic and Antarctic circles ones using IPSL-CM5A-MR are in dashed line. For IPSL-CM5A-LR simulations for which multi-member ensembles are available, the lines show the ensemble means and the shading in gray, light red and light green display the two standard deviation error bar for the historical, RCP 8.5 and RCP 4.5 experiments respectively

respectively, and the globally averaged temperature increase. To better understand the relationship between polar amplification and sea ice extent, the total sea ice area in September for each scenario is computed, September being the month during which this area is minimum and thus the month during which the Arctic Ocean is predicted to first become seasonally free of ice (Fig. 22). In the Southern Ocean, summer sea ice area is limited by the Antarctic continent located over the pole. Therefore, the absolute value of the Antarctic sea-ice area is more sensitive to climate change in winter than in summer.

Figure 23 shows the polar amplification for the Arctic (top) and Antarctic (bottom) until 2300. The amplitude of the internal variability is large for all scenarios, in particular during the initial 25 years (dashed lines). By the end of the twenty-first century (for which simulations for all scenarios are available) the warming in the Arctic as projected by IPSL-CM5A-LR reaches about twice the global value independent of the scenario. In the RCP 8.5 scenario the Arctic ocean becomes free of ice at the end of summer by 2070 (Fig. 22). About 30 years later and after weak oscillations, the Arctic amplification slowly and continuously decreases. In the RCP 4.5 scenario, the Arctic is never projected to become free of sea ice but the minimum sea ice area decreases to about a fifth of its present-day value. The Arctic amplification in RCP 2.6 displays the highest variability in agreement with pronounced minimum sea ice area variability and no significant trend. The strong variability in RCP 2.6 might arise from a seasonal effect. Summer Arctic amplification strongly depends on sea ice cover and snow 
Fig. 21 Same as Fig. 20 but for a the mixed layer depth (MLD) in meters for winter season (DJFM) averaged over the convection sites as defined in Escudier et al. (2013), b surface density averaged over the same region (in $\mathrm{kg} / \mathrm{m} 3$ ),

c decomposition in haline components (related to salinity) of the linearized surface density (in $\mathrm{kg} / \mathrm{m} 3$ ), $\mathbf{d}$ thermal components (related to temperature) of the same linearization. The convection sites are located in the Nordic Seas, south of Greenland just outside the Labrador Sea, and in an extended area south of Iceland including the Irminger Sea (Escudier et al. 2013)
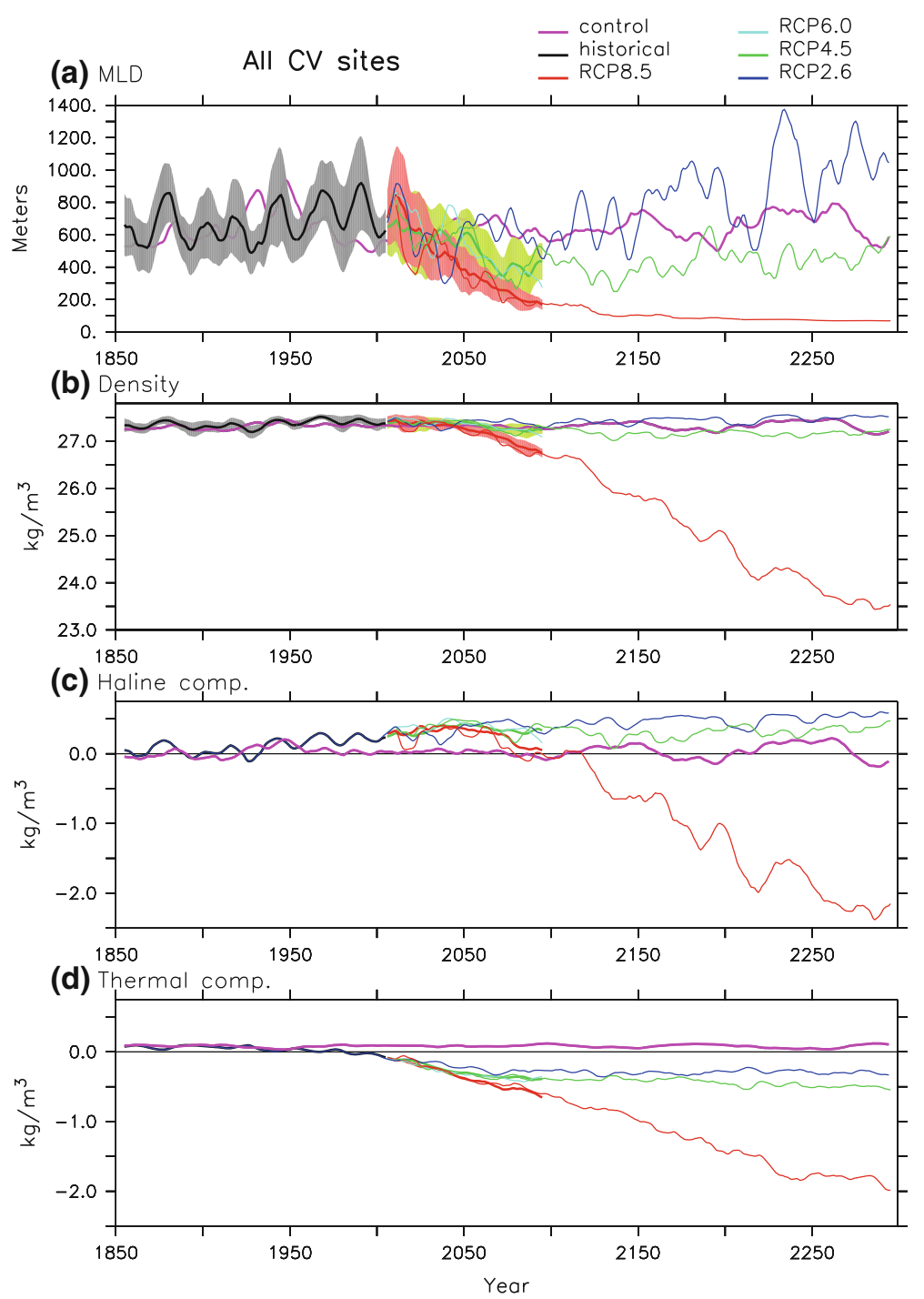

covered areas are the main source of winter Arctic amplification variability (Hall 2004). Given that snow extent is larger and potentially more variable, the impact of land covered with snow in the scenario with the lowest radiative forcing (RCP 2.6) might be one reason for the high Arctic amplification variability in RCP 2.6. Another reason is that the global and regional mean climate change signal in RCP 2.6 is of course weaker than in the other scenarios. Therefore the computed polar amplification is necessarily more strongly affected by internal variability on all relevant spatial and temporal scales for this scenario.

In the southern hemisphere, the computed polar amplification is very close to one. Austral amplification mostly takes place over sea ice and decreases poleward (Hall 2004). It is therefore not included in the area where the polar amplification was computed (Fig. 14). Variability is highest in the scenario with the lowest radiative forcing (RCP 2.6) and strongly correlated with sea ice area. Unlike in the northern hemisphere, seasonal snow cover in the southern hemisphere is small. Therefore sea ice is the most obvious polar surface amplifier of mean climate change and internal variability via the snow-albedo feedback mainly in summer and its effect on ocean-atmosphere heat fluxes mainly in winter. The two sets of curves (Figs. 22 bottom, 23 bottom) are indeed highly correlated. The warming over the Antarctic continent only reaches the global value in the RCP 8.5 scenario around 2300. Large effective heat capacity of the Southern Ocean delays the Antarctic warming.

\section{Temperature and precipitation changes using idealized scenarios}

6.1 Climate sensitivity and feedbacks

Two types of experiments are particularly useful in CMIP5 to estimate the temperature response to an increase in $\mathrm{CO}_{2}$ 

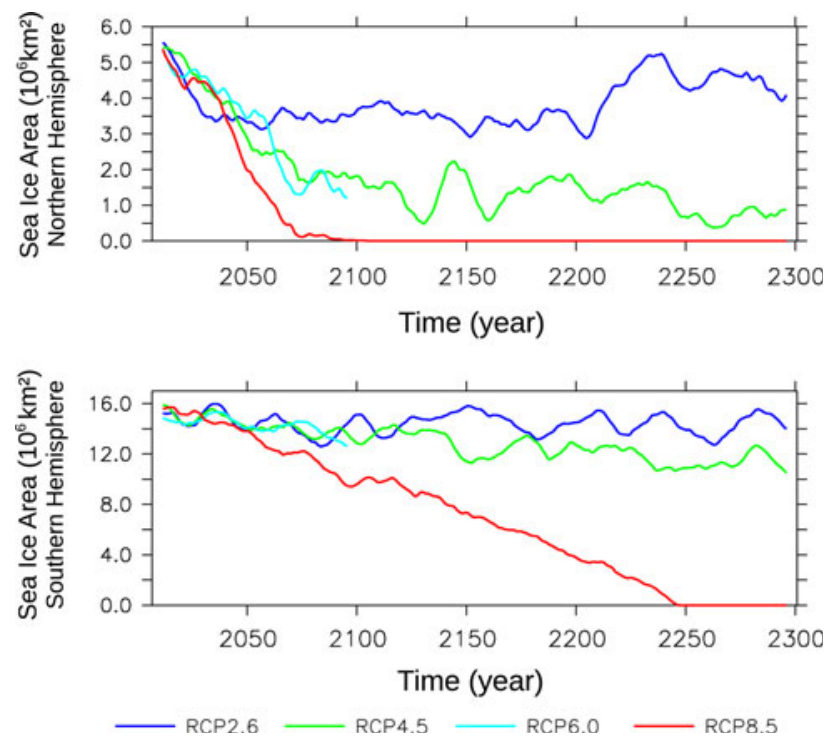

Fig. 22 Time evolution of the sea ice area $\left(\mathrm{km}^{2}\right)$ in September, for the four RCP scenarios and for the north (top) and the south (bottom) hemispheres. A 10-year running average is applied

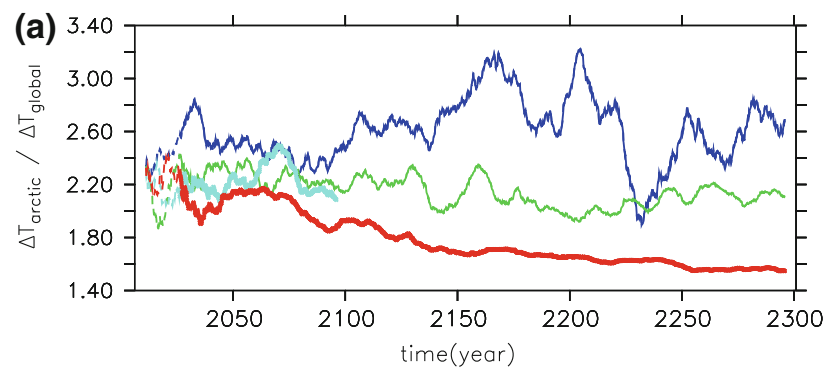

(b)

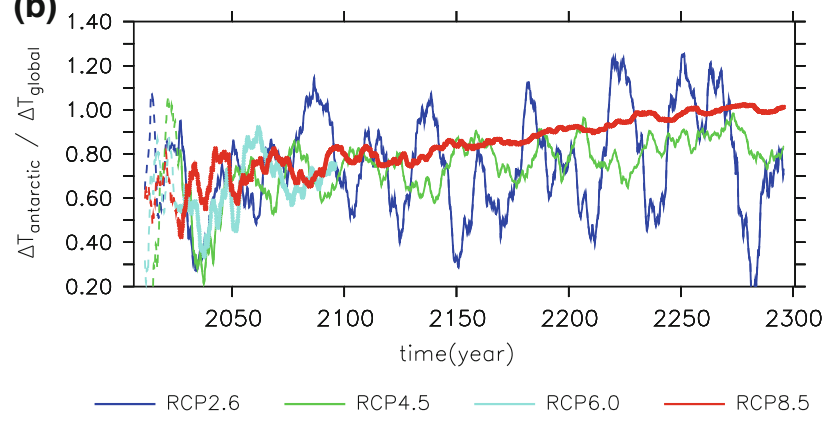

Fig. 23 Time evolution of polar amplification for both hemisphere, poleward of the Arctic (top) and Antarctic (bottom) circles, for the four RCP scenarios. The polar amplification is computed every month and plotted with a 10-year running average. The simulation ends in 2100 for the RCP 6.0 scenario. The temperature increase is computed relative to the preindustrial run

concentration: the $1 \%$ per year experiment in which, starting from the control run, the $\mathrm{CO}_{2}$ concentration increases by $1 \%$ per year until a quadrupling of its initial value (i.e. after 140 years), and the abrupt $4 \mathrm{CO}_{2}$ experiment in which the $\mathrm{CO}_{2}$ concentration is instantaneously increased to 4 times its initial value and is then held constant. This latter experiment was not run for the IPSLCM4 model because it does not belong to the CMIP3 experimental design.

The feedback analysis framework detailed by Dufresne and Bony (2008) was used to analyse the temperature response to the $\mathrm{CO} 2$ forcing. In response to a radiative forcing at the TOA $\Delta Q_{t}$, the changes in surface temperature $\Delta T_{s}$ and radiative flux at the TOA $\Delta F_{t}$ are related by the following equation:

$\Delta T_{s}=\frac{\Delta F_{t}-\Delta Q_{t}}{\lambda}$.

where $\lambda$ is the "climate feedback parameter" (fluxes are positive downward). Within this framework, when the model reaches a new equilibrium after a constant forcing has been applied, the net flux at the TOA $\Delta F_{t}$ approaches zero, yielding an equilibrium temperature change $\Delta T_{s}^{e}=-\Delta Q_{t} / \lambda$.

The definition of the forcing $\Delta Q_{t}$ is not unequivocal. A classical method to compute this forcing is to assume an adjustment of the stratospheric temperature (e.g. Forster et al. 2007). Using a radiative offline calculation with stratospheric adjustment, we obtained $\Delta Q_{t}\left(2 \mathrm{CO}_{2}\right) \approx$ $3.5 \mathrm{~W} . \mathrm{m}^{-2}\left(3.7 \mathrm{Wm}^{-2}\right.$ in clear sky conditions) for a doubling of the $\mathrm{CO}_{2}$ concentration, and twice these values $\left(\Delta Q_{t}\left(4 \mathrm{CO}_{2}\right) \approx 7.0 \mathrm{Wm}^{-2},\left(7.4 \mathrm{Wm}^{-2}\right.\right.$ clear sky) $)$ for a quadrupling of the $\mathrm{CO}_{2}$ concentration. The same values were obtained for the IPSL-CM4, IPSL-CM5A and IPSLCM5B models, which have the same radiative code. For intermediate values $x$ of the ratio between the $\mathrm{CO}_{2}$ concentration and its pre-industrial value, the radiative forcing is estimated using the usual relationship: $\Delta Q_{t}(x)=$ $\Delta Q_{t}\left(2 \mathrm{CO}_{2}\right) \cdot \log (x) / \log (2)$. Using this forcing and the results of the $1 \%$-per-year experiment, the time series of the climate feedback parameter $\lambda$ were computed for the different versions of the IPSL-CM model. The values reported in Table 1 are the 30-year average values of $\lambda$ around the time of $\mathrm{CO}_{2}$ doubling (i.e. between years 56 and $85)$. The feedback parameter $\lambda$ in IPSL-CM5A-LR is very similar to that in the previous version, IPSL-CM4, and it is also very similar to that in IPSL-CM5A-MR. On the other hand, the value of the feedback parameter in IPSL-CM5BLR differs by about $70 \%$ from that in the other model versions. The same results hold for the equilibrium temperature change $\Delta T_{s}^{e}\left(2 \mathrm{CO}_{2}\right)$ for a doubling of the $\mathrm{CO}_{2}$ concentration (often called "climate sensitivity").

Another classical metric to characterize the response to an increase in $\mathrm{CO}_{2}$ concentration is the "transient climate response" (TCR), i.e. the surface air temperature increase in a $1 \%$-per-year experiment when the $\mathrm{CO}_{2}$ concentration has doubled, i.e. 70 years after it started to increase (here we computed the 30 -year average, i.e. the average between years 56 and 85). This transient temperature change is found to be very similar for IPSL-CM5A-LR and IPSL- 
Table 1 Radiative forcing for a doubling of $\mathrm{CO}_{2} \Delta Q_{t}\left(2 \mathrm{CO}_{2}\right)$, feedback parameter $\lambda$, transient $\mathrm{TCR}\left(\mathrm{CO}_{2}\right)$ and equilibrium $\Delta T_{s}^{e}\left(2 \mathrm{CO}_{2}\right)$ surface air temperature increase in response to a $\mathrm{CO}_{2}$ doubling for the different IPSL-CM model versions

\begin{tabular}{|c|c|c|c|c|c|c|c|}
\hline \multirow[t]{2}{*}{ Model } & \multicolumn{4}{|l|}{$1 \% /$ Year $\mathrm{CO}_{2}$ increase } & \multicolumn{3}{|l|}{ Abrupt $4 \mathrm{xCO}_{2}$} \\
\hline & $\Delta Q_{t}\left(2 \mathrm{CO}_{2}\right)\left(\mathrm{Wm}^{-2}\right)$ & $\lambda\left(\mathrm{Wm}^{-2} \mathrm{~K}^{-1}\right)$ & $\operatorname{TCR}\left(2 \mathrm{CO}_{2}\right)(\mathrm{K})$ & $\Delta T_{s}^{e}\left(2 \mathrm{CO}_{2}\right)(\mathrm{K})$ & $\Delta Q_{t}\left(2 \mathrm{CO}_{2}\right)\left(\mathrm{Wm}^{-2}\right)$ & $\lambda\left(\mathrm{Wm}^{-2} \mathrm{~K}^{-1}\right)$ & $\overline{\Delta T_{s}^{e}\left(2 \mathrm{CO}_{2}\right)(\mathrm{K})}$ \\
\hline IPSL-CM4 & 3.5 & -0.92 & 2.13 & 3.79 & & & \\
\hline IPSL-CM5A-LR & 3.5 & -0.98 & 2.09 & 3.59 & 3.12 & -0.76 & 4.10 \\
\hline IPSL-CM5A-MR & 3.5 & -1.01 & 2.05 & 3.47 & 3.29 & -0.80 & 4.12 \\
\hline IPSL-CM5B-LR & 3.5 & -1.68 & 1.52 & 2.09 & 2.66 & -1.03 & 2.59 \\
\hline
\end{tabular}

These values (except the transient temperature response) are estimated using either the $1 \% / y e a r \mathrm{CO}_{2}$ increase experiment or the abrupt $4 \mathrm{CO}_{2}$ experiment

CM5A-MR (Table 1). This result is consistent with those obtained by Hourdin et al. (2013a) with a broader range of horizontal resolutions of the atmospheric model. This transient temperature change is also similar for IPSLCM4 and IPSL-CM5A-LR. Again, IPSL-CM5B-LR is different from the other models, with a much lower value $(\approx-25 \%)$ of the TCR.

As stated earlier, the definition of the forcing $\Delta Q_{t}$ is not unequivocal and recent work shows that the decomposition of the forcing into a fast and a slow part allows for a better analysis and understanding of the temperature and precipitation responses to a $\mathrm{CO}_{2}$ forcing (Andrews and Forster 2008; Gregory and Webb 2008). The forcing including the fast response can be obtained using the abrupt $4 \times \mathrm{xCO} 2$ experiment (Gregory et al. 2004). In response to a constant forcing, Eq. 4 implies that the slope of the regression of the net flux at the TOA as a function of the global mean surface temperature provides an estimate of climate feedback. The intercept of the regression line and the $\mathrm{Y}$ axis $\left(\Delta T_{s}=0\right)$ is an estimate of the radiative forcing including the fast response of the atmosphere (Fig. 24). The intercept of the regression line and the $\mathrm{X}$ axis $\left(\Delta F_{t}=0\right)$ is an estimate of temperature change at equilibrium $\Delta T_{s}^{e}$. Here we suppose that the radiative forcing and the temperature change at equilibrium for a doubling of $\mathrm{CO}_{2}$ are half of the values for a quadrupling of $\mathrm{CO}_{2}$.

For the IPSL-CM5A-LR and CM5A-MR models, the radiative forcing obtained with this method is only slightly smaller than the classical one: 3.1 and 3.3 instead of 3.5 $\mathrm{Wm}^{-2}$ (Table 1). However this small difference masks the large variation in shortwave and longwave forcings, which compensate each other. For IPSL-CM5B-LR, the difference is larger: 2.7 instead of $3.5 \mathrm{Wm}^{-2}$ (i.e. $\approx-20 \%$ ). With the regression method, the feedback parameter is significantly smaller (in absolute value) and the temperature change at equilibrium is significantly larger than the one obtained with the $1 \%$-per-year experiment. This difference between the two methods holds for all the model versions. The difference in temperature change at equilibrium should be zero if the two methods and the feedback framework were perfect, which is not the case. It is therefore important to compare values that have been estimated using the same method.

In addition to the net flux for all sky conditions, the net flux for clear sky conditions and the net flux change due to the presence of clouds can also be used when performing the linear regression with the global mean surface air temperature (Fig. 24b, c). Under clear sky conditions, the radiative forcing estimates using the regression method are similar for all the model versions. The values of the feedback parameter are also similar although the absolute value for IPSL-CM5B-LR is lower. When focusing on the effect of clouds, the differences between IPSL-CM5A-LR and CM5A-MR are small whereas the differences between IPSL-CM5A-LR and CM5B-LR are large (Fig. 24c). The differences between IPSL-CM5A-LR and CM5B-LR are mainly due to change of the cloud radiative effect in the short wave domain (not shown).

An important result for IPSL-CM5 is the very strong difference between the climate sensitivities obtained with IPSL-CM5A-LR and IPSL-CM5B-LR. While the climate sensitivity of IPSL-CM5A-LR $\left(\Delta T_{s}^{e}\left(2 \mathrm{CO}_{2}\right) \approx 4.1 \mathrm{~K}\right)$ lies in the upper part of the sensitivity range of the CMIP3 models, the sensitivity of IPSL-CM5B-LR $\left(\Delta T_{s}^{e}\left(2 \mathrm{CO}_{2}\right) \approx\right.$ $2.6 \mathrm{~K}$ ) falls in the lower part (Meehl et al. 2007b). The analysis of the reasons for these differences requires further work.

\subsection{Patterns of changes in surface air temperature and in precipitation}

As illustrated in previous sections, the normalized patterns of temperature and precipitation changes are weakly dependent on the scenario (Figs. 14 and 18). However, the IPSL-CM4 model used for CMIP3 was not included in these figures as no simulation with this model was performed with the forcings of the RCP scenarios. In this section, we use the results of the $1 \%$-per-year experiment to compare IPSL-CM4 with IPSL-CM5. The temperature and precipitation changes are computed over a 30 -year 
(a) all sky

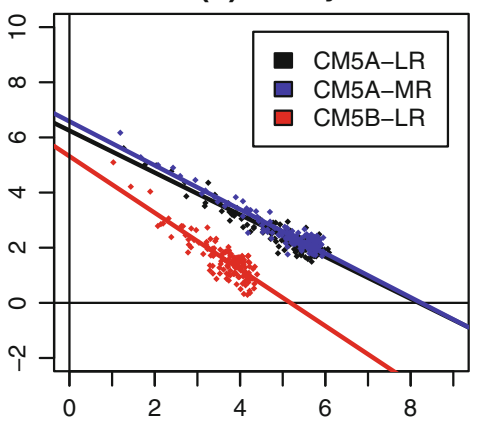

(b) clear sky

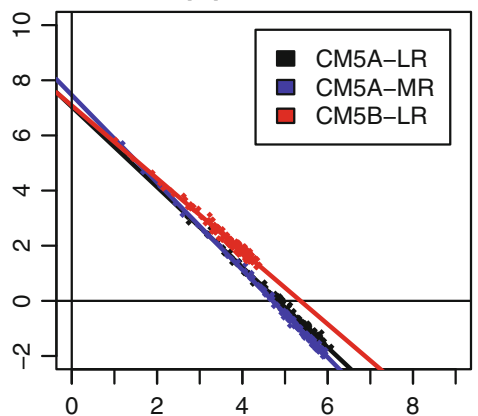

(c) cloud effect

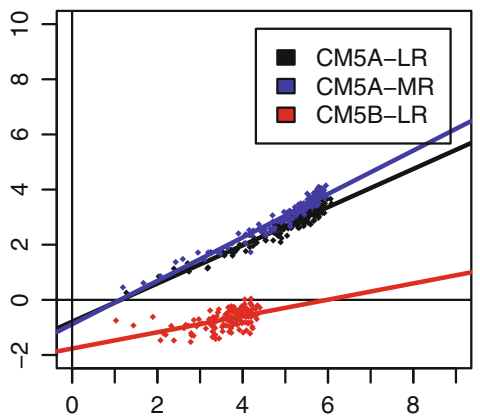

Fig. 24 Scatter plot of the net flux change $\left(\Delta F_{t}\right.$ in $\left.\mathrm{Wm}^{-2}\right)$ at the TOA as a function of the global mean surface air temperature change $\left(\Delta T_{s}\right.$ in $\left.\mathrm{K}\right)$ simulated in response to an abrupt quadrupling of $\mathrm{CO}_{2}$ concentration. The net flux at the TOA is computed for a all sky conditions and $\mathbf{b}$ clear sky conditions. The difference between these two terms is the change in the cloud radiative effect $\mathbf{c}$. Annual mean values are shown in black for IPSL-CM5A-LR, in blue for IPSL-
CM5A-MR, and in red for IPSL-CM5B-LR. The straight lines corresponds to linear regressions of the data. Intersection with the horizontal axis $\left(\Delta F_{t}=0 \mathrm{Wm}^{-2}\right)$ gives the expected temperature change at equilibrium, intersection with the vertical axis $\left(\Delta T_{s}=0\right)$ gives an estimate of the radiative forcing. The flux and temperature changes are computed relative to the values of the pre-industrial control experiment average period centered around the time of $\mathrm{CO}_{2}$ doubling, i.e. between years 56 and 85 after the beginning of the experiment.

The changes simulated by the IPSL-CM4 model and the IPSL-CM5A-LR model are quite different, especially over the continents (Fig. 25). The normalized temperature increase over north America is larger in IPSL-CM4 than in IPSL-CM5A-LR and precipitation changes are significantly different over south America, India and over the center of the Pacific ocean. Although dedicated simulations to attribute the origins of these differences have not been performed, they are consistent with some known modifications. For example, the LAI was prescribed in CM4 whereas it is computed by the phenology part of the vegetation model (Sect. 2.3) in CM5. Numerical instabilities of the surface temperature, which were present in IPSL-CM4, have been now suppressed. The soil depth has been increased allowing greater seasonal soil water retention, especially in the tropics. Similar differences of temperature and precipitation changes over the continents between the IPSL-CM4 model and the IPSL-CM5A-LR model are also highlighted in paleoclimate experiments (Kageyama et al. 2013a). Finally, the change of the horizontal and vertical resolutions of the atmospheric model and the tuning process that followed have reduced the biases in the location of the mid-latitude jets and have slightly modified the precipitation over the Pacific ocean (Hourdin et al. 2013a).

For the IPSL-CM5A-LR model, the patterns of temperature and precipitation changes obtained with the $1 \%$ per year experiment (Fig. 25) are similar to those obtained with the RCP scenarios (Fig. 18), confirming that these patterns are not very sensitive to the scenarios. The same similarity of patterns between $1 \%$ per year experiment and
RCP scenarios holds for IPSL-CM5A-MR and IPSLCM5B-LR (not shown).

\section{Summary and conclusion}

The IPSL-CM5 ESM presented in this paper represents a major evolution in the development of coupled dynamicalphysical-biogeochemical global general circulation models. This model aims at studying the Earth's system and anticipating its evolution under natural and anthropogenic influences. The interactive carbon cycle, the tropospheric and stratospheric chemistry, and a comprehensive description of aerosols represented in the model allow science questions that could not be addressed with the IPSL-CM4 coupled ocean-atmosphere climate model used in CMIP3. These questions include the study of carbonclimate feedbacks and the estimate of $\mathrm{CO}_{2}$ emissions compatible with specific atmospheric concentrations of $\mathrm{CO}_{2}$ and land-use, the assessment of chemistry-climate interactions, the estimate of the role played by different forcings such as stratospheric ozone, tropospheric ozone, and aerosols other than sulfate. An important feature of this model is that it may be used in a large variety of configurations associated with a range of boundary conditions and it includes the possibility of switching on and off specific feedbacks (e.g. carbon-climate feedbacks, chemistry-climate feedbacks, ocean-atmosphere interactions). During the development phase of the model, this possibility has always been considered as a key feature to facilitate the interpretation of the model results. In some configurations the model may also be used with two different versions of atmospheric parameterizations (referred to as CM5A and 
(a) Temp, IPSL-CM4

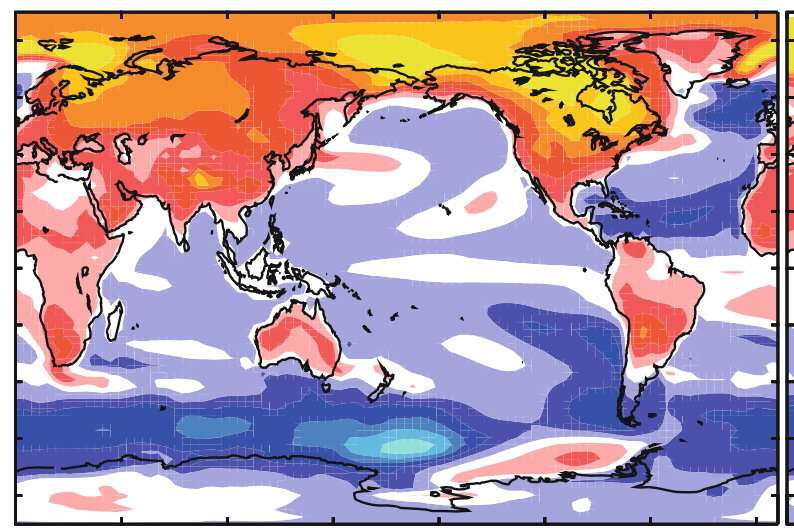

(c) Precip, IPSL-CM4

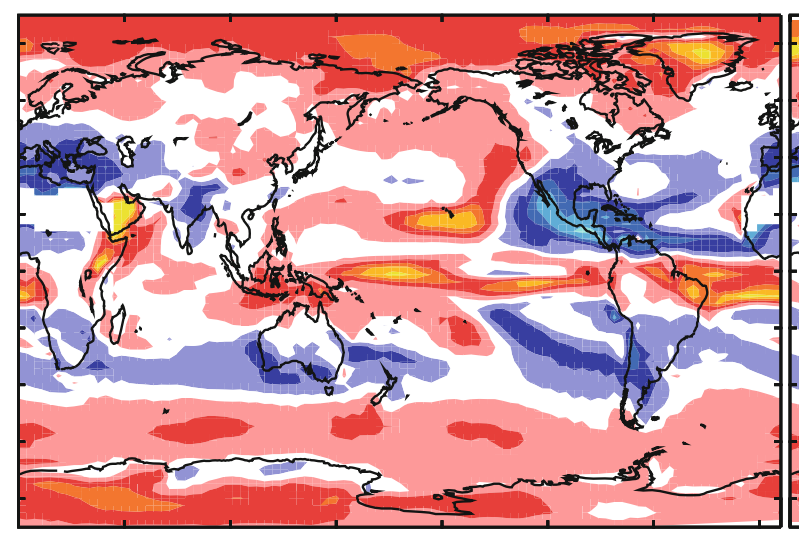

Fig. 25 Geographical distribution of the normalized surface air temperature change ( $\mathrm{K}$, upper row) and the normalized relative precipitation changes $\left(\% . \mathrm{K}^{-1}\right.$, lower row) simulated by the IPSLCM4 (left column) and IPSL-CM5A-LR (right column) models in response to a doubling of the concentration of $\mathrm{CO}_{2}$. The temperature and precipitation changes are computed relative to the pre-industrial control run. The local temperature change is normalized with the

CM5B) and at different horizontal resolutions (referred to as CM5A-LR and CM5A-MR).

The IPSL-CM5A-LR version of the model has been used to perform most of the numerical experiments defined in CMIP5 (Taylor et al. 2012) such as simulations of the present climate, paleoclimate (Kageyama et al. 2013a, b), climate projections associated with different RCPs scenarios, and multiple idealized experiments aiming at a better interpretation of ESM results and inter-model differences. In particular, the ozone and aerosols radiative forcings used to simulate the evolution of climate both for the historical and future periods have been derived from components of the IPSL-CM5 platform rather than from external models. As part of CMIP5 this model has also been used to perform decadal hindcasts and forecasts initialized by a realistic ocean state and to explore the (b) Temp, IPSL-CM5A-LR

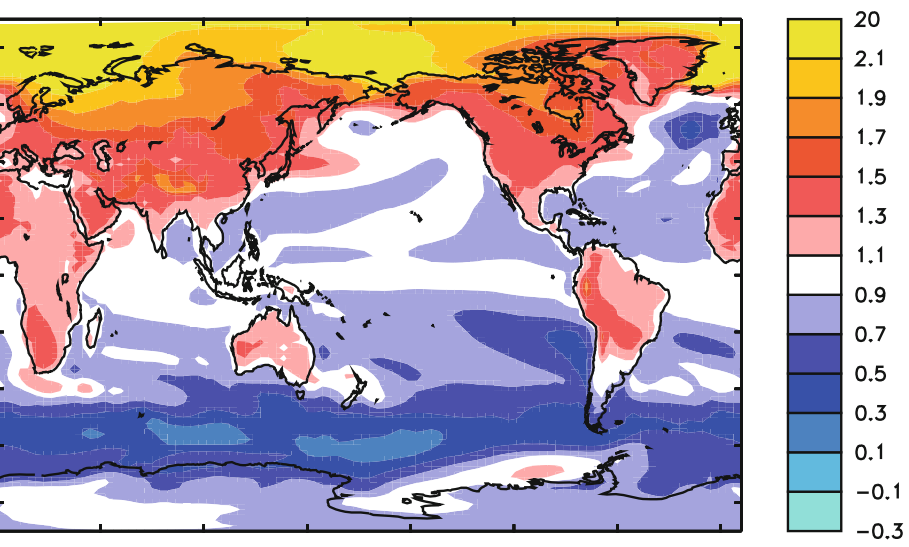

(d) Precip, IPSL-CM5A-LR
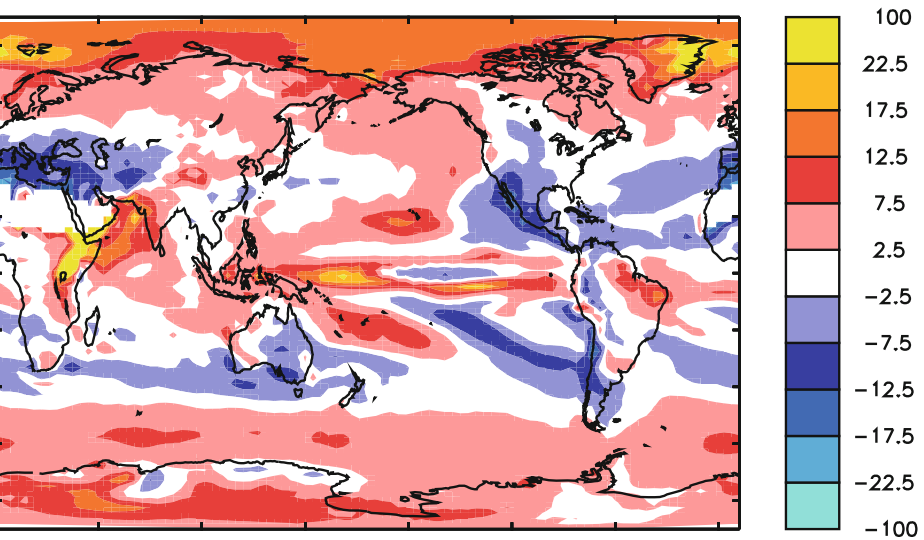

global average temperature change. The local precipitation changes are computed relative to their local pre-industrial values on a yearly mean basis and are then normalized with the global average temperature change. The regions where the annual mean precipitation in the pre-industrial run is less than $0.01 \mathrm{~mm} /$ day (i.e. the Sahara region) are left blank

predictability of the climate system at decadal timescales (Swingedouw et al. 2013).

The evaluation of IPSL-CM5A-LR simulations shows that the model exhibits many biases considered as longstanding systematic biases of many coupled ocean-atmosphere models such as a warm bias of the ocean surface over equatorial upwelling regions, the presence of a double ITCZ in the equatorial eastern Pacific, the overestimation of precipitation in regimes of atmospheric subsidence, the underestimation of tropical intra-seasonal variability, and an underestimation of the AMOC. In addition, the model exhibits a substantial and pervasive cold bias especially at mid-latitudes. The pre-industrial control simulation does not exhibit any climate drift and the model predicts realistic amplitude and spectral characteristics of the ENSO variability. Over the historical period, the net ocean and 
land $\mathrm{CO}_{2}$ fluxes are fully consistent with recent estimations. Compared to its IPSL-CM4 parent (the IPSL OAGCM used in CMIP3), many aspects of the simulations have been improved partly due to the increase of horizontal and vertical model resolutions, to the improvement of the land surface model and its coupling with the atmosphere, and to several improvements of the ocean model. A further increase in horizontal resolution of the atmospheric model does not result in significant further improvements except for the location of the extratropical jets. Coupled oceanatmosphere simulations performed with an improved atmospheric GCM (IPSL-CM5B) exhibit improvements in terms of tropical climatology (e.g. reduced double ITCZ, improved cloudiness) and tropical variability (e.g. MJO, ENSO) of the current climate, although the representation of the mid-latitude atmospheric circulation and the oceanic circulation needs to be improved.

The IPSL-CM5A-LR ESM has been used to perform climate projections associated with different sets of socioeconomic scenarios including CMIP5 RCPs and CMIP3 SRES. Consistently with other model results, the magnitude of global warming projections strongly depends on the socio-economic scenario considered. Simulations associated with different RCPs suggest that an aggressive mitigation policy (RCP 2.6) to limit global warming to about two degrees is possible. However it would require a substantial and fast reduction of $\mathrm{CO}_{2}$ emissions with no emission at the end of the twenty-first century and even negative emissions after that. The emissions refer here to fossil-fuel plus cement production emissions and they do not include land-use emissions. We also found that the behavior of some climate system components may change drastically by the end of the twenty-first century in the case of a no climate policy scenario (RCP 8.5): the Arctic ocean would become free of sea ice by about 2070, and the Atlantic Meridional Overturning Circulation would collapse mainly due to an oceanic feedback: the northward oceanic salinity transport associated with the AMOC decreases, leading to a decrease in sea surface salinity in the convection sites and a further decrease of the AMOC. The magnitude of regional temperature and precipitation changes is found to depend almost linearly on the magnitude of the projected global warming and thus on the scenario considered. However the geographical patterns of temperature and precipitation changes were strikingly similar for the different scenarios. This suggests that a key and critical step towards a better anticipation and assessment of the regional climate response to different climate policy scenarios will consist in physically understanding what controls these robust regional patterns using the wide range of CMIP5 idealized experiments for each model.

The climate sensitivity and regional climate changes associated with a given scenario are significantly different when using different representations of physical processes. The pattern of precipitation changes over continents and the transient climate response are significantly different between the IPSL-CM4 and IPSL-CM5A models. The equilibrium climate sensitivity of IPSL-CM5A and IPSLCM5B are drastically different: 3.9 and $2.4 \mathrm{~K}$, respectively. The reasons for these differences are currently under investigation and will be reported in a future paper.

The comparison between multi-model CMIP3 and CMIP5 climate projections needs to account for significant differences between the forcings of the RCP and SRES scenarios. Nevertheless we found similarities between climate projections associated with RCP 4.5 and SRES B1 scenarios. This is consistent with the similar value of the radiative forcing due to greenhouse gases for these two scenarios and it is also consistent with the results obtained with a statistical approach using a model of reduced complexity (Rogelj et al. 2012). The comparison of SRES B1 and RCP 4.5 projections might be a useful benchmark to assess how the spread of model projections has evolved between CMIP3 and CMIP5.

Acknowledgments The development of the IPSL coupled model and of its various components has largely benefited from the work of numerous colleagues, post-doctoral scientists, or Ph.D. students. We gratefully acknowledgement their contribution to this community effort, and among them Gillali Abdelaziz, Gaëlle Drouot, Alexandre Durand. The research leading to these results was supported by CNRS, CEA, the INSU-LEFE French Program under the project MissTerre, the European Commission's 7th Framework Programme, under the projects COMBINE (Grant $\mathrm{n}^{\circ} 226520$ ) and IS-ENES (grant $\mathrm{n}^{\circ}$ 228203). This work was made possible thanks to the HPC resources of CCRT and IDRIS made available by GENCI (Grand Equipement National de Calcul Intensif), CEA (Commissariat à l'Energie Atomique et aux Energies Alternatives) and CNRS (Centre National de la Recherche Scientifique) (project 016178). The authors wish to thank Audine Laurian for the careful copy-editing of the manuscript. The authors are grateful to the two anonymous reviewers of this paper for their numerous and useful comments on the original manuscript.

Open Access This article is distributed under the terms of the Creative Commons Attribution License which permits any use, distribution, and reproduction in any medium, provided the original author(s) and the source are credited.

\section{References}

Alexander MA, Blade I, Newman M, Lanzante JR, Lau NC, Scott JD (2002) The atmospheric bridge: the influence of ENSO teleconnections on air-sea interaction over the global oceans. J Climate 15(16):2205-2231

Alkama R, Kageyama M, Ramstein G, Marti O, Ribstein P, Swingedouw D (2008) Impact of a realistic river routing in coupled ocean-atmosphere simulations of the Last Glacial Maximum climate. Clim Dyn 30(7-8):855-869. doi:10.1007/ s00382-007-0330-1 
Andrews T, Forster PM (2008) $\mathrm{CO}_{2}$ forcing induces semi-direct effects with consequences for climate feedback interpretations. Geophys Res Lett 35:L04802. doi:10.1029/2007GL032273

Arakawa A, Lamb VR (1981) A potential enstrophy and energy conserving scheme for the shallow water equations. Mon Wea Rev 109(1):18-36

Aumont O, Bopp L (2006) Globalizing results from ocean in situ iron fertilization studies. Global Biogeochem Cycles 20(2):GB2017. doi:10.1029/2005GB002591

Aumont O, Bopp L, Schulz M (2008) What does temporal variability in aeolian dust deposition contribute to sea-surface iron and chlorophyll distributions. Geophys Res Lett 35(7):L07607. doi: 10.1029/2007GL031131

Axell LB (2002) Wind-driven internal waves and langmuir circulations in a numerical ocean model of the southern Baltic sea. J Geophys Res Oce 107(C11):3204. doi:10.1029/2001JC000922

Balkanski Y (2011) L'influence des aérosols sur le climat. Thèse d'Habilitation à Diriger des Recherches. Université Versailles Saint Quentin, France

Balkanski Y, Myhre G, Gauss M, Rädel G, Highwood EJ, Shine KP (2010) Direct radiative effect of aerosols emitted by transport: from road, shipping and aviation. Atmos Chem Phys 10(10): 4477-4489. doi:10.5194/acp-10-4477-2010

Ball JT, Woodrow IE, Berry JA (1987) A model predicting stomatal conductance and its contribution to the control of photosynthesis under dierent environmental conditions. In: Biggens J (eds) Progress in photosynthesis research, vol IV. Martinus Nijho, Dordrecht, Netherlands, pp 221-224

Barnier B, Madec G, Penduff T, Molines JM, Treguier AM, Le Sommer J, Beckmann A, Biastoch A, Böning C, Dengg J, Derval C, Durand E, Gulev S, Remy E, Talandier C, Theetten S, Maltrud M, McClean J, De Cuevas B (2006) Impact of partial steps and momentum advection schemes in a global ocean circulation model at eddy-permitting resolution. Ocean Dyn 56:543-567. doi:10.1007/s10236-006-0082-1

Beckmann A, Döscher R (1997) A method for improved representation of dense water spreading over topography in geopotentialcoordinate models. J Phys Oceanogr 27(4):581-591

Bellenger H, Duvel JP, Lengaigne M, Levan P (2009) Impact of organized intraseasonal convective perturbations on the tropical circulation. Geophys Res Lett 36:L16703. doi:10.1029/2009GL 039584

Blanke B, Delecluse P (1993) Variability of the tropical Atlantic Ocean simulated by a general circulation model with two different mixed-layer physics. J Phys Oceanogr 23(7):1363-1388

Bony S, Emanuel KA (2001) A parameterization of the cloudiness associated with cumulus convection; evaluation using TOGA COARE data. J Atmos Sci 58:3158-3183

Boucher O, Lohmann U (1995) The sulfate-CCN-cloud albedo effect: a sensitivity study with two general circulation models. Tellus Ser B 47:281-300

Boucher O, Pham M (2002) History of sulfate aerosol radiative forcings. Geophys Res Lett 29(9):1308. doi:10.1029/2001GL014048

Braconnot P, Hourdin F, Bony S, Dufresne JL, Grandpeix JY, Marti O (2007) Impact of different convective cloud schemes on the simulation of the tropical seasonal cycle with a coupled oceanatmosphere model. Clim Dyn 29(5):501-520. doi:10.1007/s00, 382-007-0244-y

Brohan P, Kennedy JJ, Harris I, Tett SFB, Jones PD (2006) Uncertainty estimates in regional and global observed temperature changes: a new data set from 1850 . J Geophys Res Atm 111(D12):D12106. doi:10.1029/2005JD006548

Burchard H, Rennau H (2008) Comparative quantification of physically and numerically induced mixing in ocean models. Ocean Model 20(3):293-311. doi:10.1016/j.ocemod.2007. 10.003
Cadule P, Bopp L, Friedlingstein P (2009) A revised estimate of the processes contributing to global warming due to climate-carbon feedback. Geophys Res Lett 36:L14705. doi:10.1029/2009GL 038681

Cassou C (2008) Intraseasonal interaction between the Madden-Julian Oscillation and the North Atlantic Oscillation. Nature 455(7212): 523-527. doi:10.1038/nature07286

Cattiaux J, Quesada B, Arakelian A, Codron F, Vautard R, Yiou P (2013) North-Atlantic dynamics and European temperature extremes in the IPSL model: sensitivity to atmospheric resolution. Clim Dyn. doi:10.1007/s00382-012-1436-7

Cheruy F, Campoy A, Dupont JC, Ducharne A, Hourdin F, Haeffelin M, Chiriaco M, Idelkadi A (2013) Combined influence of atmospherice physics and soil hydrology on the simulated meteorology at the SIRTA atmospheric obervatory. Clim Dyn. doi:10.1007/s00382-012-1469-y

Chou C, Neelin JD (2004) Mechanisms of global warming impacts on regional tropical precipitation. J Climate 17(13):26882701

Chou C, Neelin JD, Chen CA, Tu JY (2009) Evaluating the "richget-richer" mechanism in tropical precipitation change under global warming. J Clim 22(8):1982-2005. doi:10.1175/2008JCL I2471.1

Cionni I, Eyring V, Lamarque JF, Randel WJ, Stevenson DS, Wu F, Bodeker GE, Shepherd TG, Shindell DT, Waugh DW (2011) Ozone database in support of cmip5 simulations: results and corresponding radiative forcing. Atmos Chem Phys 11(21): 11267-11292. doi:10.5194/acp-11-11267-2011

Clement A, DiNezio P, Deser C (2011) Rethinking the Ocean's role in the Southern Oscillation. J Clim 24(15):4056-4072. doi: 10.1175/2011JCLI3973.1

Cleveland RB, Cleveland WS, McRae J, Terpenning I (1990) STL: A seasonal-trend decomposition procedure based on loess. J Off Stat 6(1):3-73

Collatz G, Ribas-Carbo M, Berry J (1992) Coupled photosynthesisstomatal conductance model for leaves of $\mathrm{C}_{4}$ plants. Aust J Plant Physiol 19:519-538

Cravatte S, Madec G, Izumo T, Menkes C, Bozec A (2007) Progress in the 3-D circulation of the eastern equatorial Pacific in a climate ocean model. Ocean Model 17(1):28-48. doi:10.1016/ j.ocemod.2006.11.003

Déandreis C (2008) Impact des aérosols anthropiques sur le climat présent et futur. Thèse, Université Pierre et Marie Curie

Déandreis C, Balkanski Y, Dufresne JL, Cozic A (2012) Radiative forcing estimates in coupled climate-chemistry models with emphasis on the role of the temporal variability. Atmos Chem Phys 12(12):5583-5602. doi:10.5194/acp-12-5583-2012

Doherty RM, Hulme M, Jones CG (1999) A gridded reconstruction of land and ocean precipitation for the extended tropics from 1974 to 1994. Int J Climatol 19(2):119-142

d'Orgeval T, Polcher J, de Rosnay P (2008) Sensitivity of the West African hydrological cycle in ORCHIDEE to infiltration processes. Hydrol Earth Syst Sci 12(6):1387-1401. doi:10.5194/ hess-12-1387-2008

Ducoudré N, Laval K, Perrier A (1993) SECHIBA, a new set of parameterizations of the hydrologic exchanges at the landatmosphere interface within the LMD atmospheric general circulation model. Clim Dyn 6:248-273

Dufresne JL, Bony S (2008) An assessment of the primary sources of spread of global warming estimates from coupled atmosphereocean models. J Clim 21(19):5135-5144. doi:10.1175/2008JCL I2239.1

Dufresne JL, Quaas J, Boucher O, Denvil F, Fairhead L (2005) Contrasts in the effects on climate of anthropogenic sulfate aerosols between the 20th and the 21st century. Geophys Res Lett 32:L21,703. doi:10.1029/2005GL023,619 
Duvel JP, Bellenger H, Bellon G, Remaud M (2013) An event-byevent assessment of tropical intraseasonal perturbations for general circulation models. Clim Dyn. doi:10.1007/s00382012-1303-6

Emanuel KA (1991) A scheme for representing cumulus convection in large-scale models. J Atmos Sci 48:2313-2335

Emile-Geay J, Madec G (2009) Geothermal heating, diapycnal mixing and the abyssal circulation. Ocean Sci 5(2):203-217

Emori S, Brown SJ (2005) Dynamic and thermodynamic changes in mean and extreme precipitation under changed climate. Geophys Res Lett 32:L17706. doi:10.1029/2005GL023272

Escudier R, Mignot J, Swingedouw D (2013) A 20-yrs coupled oceansea ice-atmosphere variablility mode in the North Atlantic in an AOGCM. Clim Dyn. doi:10.1007/s00382-012-1402-4

Eyring V, Cionni I, Bodeker GE, Charlton-Perez AJ, Kinnison DE, Scinocca JF, Waugh DW, Akiyoshi H, Bekki S, Chipperfield MP, Dameris M, Dhomse S, Frith SM, Garny H, Gettelman A, Kubin A, Langematz U, Mancini E, Marchand M, Nakamura T, Oman LD, Pawson S, Pitari G, Plummer DA, Rozanov E, Shepherd TG, Shibata K, Tian W, Braesicke P, Hardiman SC, Lamarque JF, Morgenstern O, Pyle JA, Smale D, Yamashita Y (2010) Multi-model assessment of stratospheric ozone return dates and ozone recovery in CCMVal-2 models. Atmos Chem Phys 10(19):9451-9472. doi:10.5194/acp-10-9451-2010

Eyring V, Cionni I, Lamarque JF, Akiyoshi H, Bodeker GE, CharltonPerez AJ, Frith SM, Gettelman A, Kinnison DE, Nakamura T, Oman LD, Pawson S, Yamashita Y (2010) Sensitivity of 21st century stratospheric ozone to greenhouse gas scenarios. Geophys Res Lett 37:L16807. doi:10.1029/2010GL044443

Eyring V, Cionni I, Arblaster J, Sedlácek J, Perlwitz J, Young P, Bekki S, Bergmann D, Cameron-Smith P, Collins W, Faluvegi G, Gottschaldt KD, Horowitz L, Kinnison D, Lamarque JF, Marsh D, Saint-Martin D, Shindell D, Sudo K, Szopa S, Watanabe S (2012) Long-term changes in tropospheric and stratospheric ozone and associated climate impacts in CMIP5 simulations. J Geophys Res Atm (in review)

Farquhar G, von Caemmener S, Berry J (1980) A biochemical model of photosynthesis $\mathrm{CO}_{2}$ fixation in leaves of $\mathrm{C}_{3}$ species. Planta 49:78-90

Fichefet T, Morales Maqueda MA (1997) Sensitivity of a global sea ice model to the treatment of ice thermodynamics and dynamics. J Geophys Res 102(C6):12609-12646. doi:10.1029/97JC00480

Fichefet T, Morales Maqueda MA (1999) Modelling the influence of snow accumulation and snow-ice formation on the seasonal cycle of the Antarctic sea-ice cover. Clim Dyn 15(4):251-268. doi: $10.1007 / \mathrm{s} 003820050280$

Folberth GA, Hauglustaine DA, Lathiere J, Brocheton F (2006) Interactive chemistry in the Laboratoire de Meteorologie Dynamique general circulation model: model description and impact analysis of biogenic hydrocarbons on tropospheric chemistry. Atmos Chem Phys 6:2273-2319. doi:10.5194/acp-6-2273-2006

Forster P, Ramaswamy V, Artaxo P, Berntsen T, Betts R, Fahey DW, Haywood J, LeanDC Jand Lowe, Myhre G, Nganga J, Prinn R, Raga G, Schulz M, Van Dorland R (2007) Changes in atmospheric constituents and in radiative forcing. In: Solomon S, Qin D, Manning M, Chen Z, Marquis M, Averyt KB, Tignor M, Miller HL (eds) Climate change 2007: the scientific basis. Contribution of working group I to the fourth assessment report of the intergovernmental panel on climate change, chap 2. Cambridge University Press, Cambridge, pp 129-234

Fouquart Y, Bonnel B (1980) Computations of solar heating of the Earth's atmosphere: a new parametrization. Contrib Atmos Phys 53:35-62

Friedlingstein P, Cox P, Betts R, Bopp L, von Bloh W, Brovkin V, Cadule P, Doney S, Eby M, Fung I, Bala G, John J, Jones C, Joos F, Kato T, Kawamiya M, Knorr W, Lindsay K, Matthews HD,
Raddatz T, Rayner P, Reick C, Roeckner E, Schnitzler KG, Schnur R, Strassmann K, Weaver AJ, Yoshikawa C, Zeng N (2006) Climate-carbon cycle feedback analysis: Results from the C4MIP model intercomparison. J Clim 19(14):3337-3353. doi: 10.1175/JCLI3800.1

Fröhlich C, Lean J (2004) Solar radiative output and its variability: evidence and mechanisms. Astron Astrophys Rev 12(4):273320. doi:10.1007/s00159-004-0024-1

Gastineau G, D'Andrea F, Frankignoul C (2013) Atmospheric response to the north atlantic ocean variability on seasonal to decadal time scales. Clim Dyn. doi:10.1007/s00382-012-1333-0

Gent PR, Mcwilliams JC (1990) Isopycnal mixing in ocean circulation models. J Phys Oceanogr 20(1):150-155

Goulet L, Duvel JP (2000) A new approach to detect and characterize intermittent atmospheric oscillations: application to the intraseasonal oscillation. J Atmos Sci 57(15):2397-2416. doi: 10.1175/1520-0469(2000)057<2397:ANATDA > 2.0.CO;2

Grandpeix JY, Lafore JP (2010) A density current parameterization coupled with emanuel's convection scheme. Part I: the models. J Atmos Sci 67(4):881-897. doi:10.1175/2009JAS3045.1

Grandpeix JY, Lafore JP, Cheruy F (2010) A density current parameterization coupled with emanuel's convection scheme. Part II: 1D simulations. J Atmos Sci 67(4):898-922. doi:10.1175/ 2009JAS3045.1

Gregory J, Webb M (2008) Tropospheric adjustment induces a cloud component in $\mathrm{CO}_{2}$ forcing. J Clim 21(1):58-71. doi:10.1175/ 2007JCLI1834.1

Gregory JM, Ingram WJ, Palmer MA, Jones GS, Stott PA, Thorpe RB, Lowe JA, Johns TC, Williams KD (2004) A new method for diagnosing radiative forcing and climate sensitivity. Geophys Res Lett 31(3):L03205. doi:10.1029/2003GL018747

Guemas V, Codron F (2011) Differing impacts of resolution changes in latitude and longitude on the midlatitudes in the LMDZ atmospheric GCM. J Clim 24(22):5831-5849. doi:10.1175/ 2011JCLI4093.1

Guilyardi E, Wittenberg A, Fedorov A, Collins M, Wang C, Capotondi A, van Oldenborgh GJ, Stockdale T (2009) Understanding El Nino in ocean-atmosphere general circulation models: progress and challenges. Bull Am Meteorol Soc 90(3):325-340. doi:10.1175/2008BAMS2387.1

Hall A (2004) The role of surface albedo feedback in climate. J Climate 17(7):1550-1568

Hansen J, Sato M, Kharecha P, von Schuckmann K (2011) Earth's energy imbalance and implications. Atmos Chem Phys 11(24): 13421-13449. doi:10.5194/acp-11-13421-2011. http://www. atmos-chem-phys.net/11/13421/2011/

Hansen J, Sato M, Ruedy R, Nazarenko L, Lacis A, Schmidt G, Russell G, Aleinov I, Bauer M, Bauer S, Bell N, Cairns B, Canuto V, Chandler M, Cheng Y, Del Genio A, Faluvegi G, Fleming E, Friend A, Hall T, Jackman C, Kelley M, Kiang N, Koch D, Lean J, Lerner J, Lo K, Menon S, Miller R, Minnis P, Novakov T, Oinas V, Perlwitz J, Perlwitz J, Rind D, Romanou A, Shindell D, Stone P, Sun S, Tausnev N, Thresher D, Wielicki B, Wong T, Yao M, Zhang S (2005) Efficacy of climate forcings. J Geophys Res Atm 110(D18):D18104. doi:10.1029/2005JD 005776

Hauglustaine D, Hourdin F, Jourdain L, Filiberti M, Walters S, Lamarque J, Holland E (2004) Interactive chemistry in the Laboratoire de Meteorologie Dynamique general circulation model: description and background tropospheric chemistry evaluation. J Geophys Res Atm 109(D4):D04314. doi:10.1029/ 2003JD003957

Held IM, Soden BJ (2006) Robust responses of the hydrological cycle to global warming. J Clim 19:5686-5699

Hibler WD (1979) A dynamic thermodynamic sea ice model. J Phys Oceanogr 9(4):815-846 
Hourdin F, Armengaud A (1999) The use of finite-volume methods for atmospheric advection of trace species. Part I: test of vairious formulations in a general circulation model. Mon Wea Rev 127:822-837

Hourdin F, Couvreux F, Menut L (2002) Parameterisation of the dry convective boundary layer based on a mass flux representation of thermals. J Atmos Sci 59:1105-1123

Hourdin F, Musat I, Bony S, Braconnot P, Codron F, Dufresne JL, Fairhead L, Filiberti MA, Friedlingstein P, Grandpeix JY, Krinner G, LeVan P, Lott F (2006) The LMDZ4 general circulation model: climate performance and sensitivity to parametrized physics with emphasis on tropical convection. Clim Dyn 27(7-8):787-813. doi:10.1007/s00,382-006-0158-0

Hourdin F, Foujols MA, Codron F, Guemas V, Dufresne JL, Bony S, Denvil S, Guez L, Lott F, Gatthas J, Braconnot P, Marti O, Meurdesoif Y, Bopp L (2013a) Impact of the LMDZ atmospheric grid configuration on the climate and sensitivity of the IPSL-CM5A coupled model. Submited Clim Dyn. doi: 10.1007/s00382-012-1411-3

Hourdin F, Grandpeix JY, Rio C, Bony S, Jam A, Cheruy F, Rochetin N, Fairhead L, Idelkadi A, Musat I, Dufresne JL, Lefebvre MP, Lahellec A, Roehrig R (2013b) From LMDZ5A to LMDZ5B: revisiting the parameterizations of clouds and convection in the atmosperic component of the IPSL-CM5 climate model. Clim Dyn. doi:10.1007/s00382-012-1343-y

Huffman G, Adler R, Morrissey M, Bolvin D, Curtis S, Joyce R, McGavock B, Susskind J (2001) Global precipitation at onedegree daily resolution from multisatellite observations. J Hydrometeor 2(1):36-50

Hurtt G, Chini L, Frolking S, Betts R, Feddema J, Fischer G, Fisk J, Hibbard K, Houghton R, Janetos A, Jones C, Kindermann G, Kinoshita T, Klein Goldewijk K, Riahi K, Shevliakova E, Smith S, Stehfest E, Thomson A, Thornton P, van Vuuren D, Wang Y (2011) Harmonization of land-use scenarios for the period 1500-2100: 600 years of global gridded annual land-use transitions, wood harvest, and resulting secondary lands. Climatic Change 109:117-161. doi:10.1007/s10584-011-0153-2

IPCC (2007) In: Solomon S, Qin D, Manning M, Chen Z, Marquis M, Averyt KB, Tignor M, Miller HL (eds) Climate change 2007: the scientific basis. Contribution of working group I to the fourth assessment report of the intergovernmental panel on climate change. Cambridge University Press, Cambridge, p 996

Jam A, Hourdin F, Rio C, Couvreux F (2013) Resolved versus parametrized boundary-layer plumes. Part III: a diagnostic boundary-layer cloud parameterization derived from large eddy simulations. Boundary-Layer Meteorol. doi:10.1007/s10546012-9789-3

Johns T, Royer JF, Höschel I, Huebener H, Roeckner E, Manzini E, May W, Dufresne JL, Otterå O, van Vuuren D, Salasy Melia D, Giorgetta M, Denvil S, Yang S, Fogli P, Körper J, Tjiputra J, Stehfest E, Hewitt C (2011) Climate change under aggressive mitigation: The ENSEMBLES multi-model experiment. Clim Dyn 37(8-10):1975-2003. doi:10.1007/s00382-011-1005-5

Jones PD, New M, Parker DE, Martin S, Rigor IG (1999) Surface air temperature and its changes over the past 150 years. Rev Geophys 37(2):173-199. doi:10.1029/1999RG900002

Jourdain L, Bekki S, Lott F, Lefevre F (2008) The coupled chemistryclimate model LMDz-REPROBUS: description and evaluation of a transient simulation of the period 1980-1999. Ann Geophys 26(6):1391-1413. doi:10.5194/angeo-26-1391-2008

Kageyama M, Braconnot P, Bopp L, Caubel A, Foujols MA, Guilyardi E, Khodri M, Lloyd J, Lombard F, Mariotti V, Marti O, Roy T, Woillez MN (2013a) Mid-Holocene and Last Glacial Maximum climate simulations with the IPSL model. Part I: comparing IPSL CM5A to IPSL CM4. Clim Dyn. doi: 10.1007/s00382-012-1488-8
Kageyama M, Braconnot P, Bopp L, Caubel A, Foujols MA, Guilyardi E, Khodri M, Lloyd J, Lombard F, Mariotti V, Marti O, Roy T, Woillez MN (2013b) Mid-Holocene and Last Glacial Maximum climate simulations with the IPSL model. Part II: model-data comparisons. Clim Dyn. doi:10.1007/s00382-012-1499-5

Kanzow T, Cunningham SA, Johns WE, Hirschi JJM, Marotzke J, Baringer MO, Meinen CS, Chidichimo MP, Atkinson C, Beal LM, Bryden HL, Collins J (2010) Seasonal variability of the atlantic meridional overturning circulation at 26.5 degrees $n$. J Clim 23(21):5678-5698. doi:10.1175/2010JCLI3389.1

Kim ST, Jin FF (2011) An ENSO stability analysis. Part II: results from the twentieth and twenty-first century simulations of the CMIP3 models. Clim Dyn 36(7-8):1609-1627. doi:10.1007/ s00382-010-0872-5

Koch-Larrouy A, Madec G, Bouruet-Aubertot P, Gerkema T, Bessieres L, Molcard R (2007) On the transformation of Pacific water into Indonesian throughflow water by internal tidal mixing. Geophys Res Lett 34(4):L04604. doi:10.1029/2006 GL028405

Koch-Larrouy A, Lengaigne M, Terray P, Madec G, Masson S (2010) Tidal mixing in the Indonesian Seas and its effect on the tropical climate system. Clim Dyn 34(6):891-904. doi:10.1007/s00382009-0642-4

Konsta D, Chepfer H, Dufresne JL, Idelkadi A, Cesana G (2013) Evaluation of clouds simulated by the LMDZ5 GCM using A-train satellite observations (CALIPSO-PARASOL-CERES). Clim Dyn (submitted)

Krinner G, Viovy N, de Noblet-Ducoudré N, Ogée J, Polcher J, Friedlingstein P, Ciais P, Sitch S, Prentice IC (2005) A dynamic global vegetation model for studies of the coupled atmospherebiosphere system. Global Biogeochem Cycles 19(1):GB1015. doi:10.1029/2003GB002199

Lamarque JF, Bond TC, Eyring V, Granier C, Heil A, Klimont Z, Lee D, Liousse C, Mieville A, Owen B, Schultz MG, Shindell D, Smith SJ, Stehfest E, Van Aardenne J, Cooper OR, Kainuma M, Mahowald N, McConnell JR, Naik V, Riahi K, van Vuuren DP (2010) Historical (1850-2000) gridded anthropogenic and biomass burning emissions of reactive gases and aerosols: methodology and application. Atmos Chem Phys 10(15):7017-7039. doi:10.5194/acp-10-7017-2010

Lamarque JF, Kyle G, Meinshausen M, Riahi K, Smith S, van Vuuren D, Conley A, Vitt F (2011) Global and regional evolution of short-lived radiatively-active gases and aerosols in the representative concentration pathways. Climatic Change 109(1-2): 191-212. doi:10.1007/s10584-011-0155-0

Large W, Yeager S (2009) The global climatology of an interannually varying air-sea flux data set. Clim Dyn 33:341-364. doi: 10.1007/s00382-008-0441-3

Lathière J, Hauglustaine D, de Noblet-Ducoudré N, Krinner G, Folberth GA (2005) Past and future changes in biogenic volatile organic compound emissions simulated with a global dynamic vegetation model. Geophys Res Lett 32:L20818. doi:10.1029/ 2005GL024164

Laval K, Sadourny R, Serafini Y (1981) Land surface processes in a simplified general circulation model. Geophys Astrophys Fluid Dyn 17:129-150

Le Quéré C, Raupach MR, Canadell JG, Marland G, Bopp L, Ciais P, Conway TJ, Doney SC, Feely RA, Foster P, Friedlingstein P, Gurney K, Houghton RA, House JI, Huntingford C, Levy PE, Lomas MR, Majkut J, Metzl N, Ometto JP, Peters GP, Prentice IC, Randerson JT, Running SW, Sarmiento JL, Schuster U, Sitch $\mathrm{S}$, Takahashi T, Viovy N, van der Werf GR, Woodward FI (2009) Trends in the sources and sinks of carbon dioxide. Nat Geosci 2(12):831-836. doi:10.1038/ngeo689

Le Sommer J, Penduff T, Theetten S, Madec G, Barnier B (2009) How momentum advection schemes influence current- 
topography interactions at eddy permitting resolution. Ocean Model 29(1):1-14. doi:10.1016/j.ocemod.2008.11.007

Lean J (2009) Calculations of solar irradiance: monthly means from 1882 to 2008, annual means from 1610 to 2008. http://www. geo.fu-berlin.de/en/met/ag/strat/forschung/SOLARIS/Input_data/ Calculations_of_Solar_Irradiance.pdf

Lean J, Rottman G, Harder J, Kopp G (2005) SORCE contributions to new understanding of global change and solar variability. Solar Phys 230:27-53. doi:10.1007/s11207-005-1527-2

Lefevre F, Brasseur GP, Folkins I, Smith AK, Simon P (1994) Chemistry of the 1991-1992 stratospheric winter: three-dimensional model simulations. J Geophys Res Atm 99(D4):81838195. doi:10.1029/93JD03476

Lefevre F, Figarol F, Carslaw KS, Peter T (1998) The 1997 Arctic ozone depletion quantified from three-dimensional model simulations. Geophys Res Lett 25(13):2425-2428. doi:10.1029/ 98GL51812

Lengaigne M, Menkes C, Aumont O, Gorgues T, Bopp L, Andre JM, Madec G (2007) Influence of the oceanic biology on the tropical Pacific climate in a coupled general circulation model. Clim Dyn 28(5):503-516. doi:10.1007/s00382-006-0200-2

Lengaigne M, Madec G, Bopp L, Menkes C, Aumont O, Cadule P (2009) Bio-physical feedbacks in the Arctic Ocean using an Earth system model. Geophys Res Lett 36:L21602. doi: 10.1029/2009GL040145

Lenton A, Codron F, Bopp L, Metzl N, Cadule P, Tagliabue A, Sommer JL (2009) Stratospheric ozone depletion reduces ocean carbon uptake and enhances ocean acidification. Geophys Res Lett 36:L12606. doi:10.1029/2009GL038227

Liebmann B, Smith CA (1996) Description of a complete (interpolated) outgoing longwave radiation dataset. Bull Am Meteorol Soc 77(6): 1275-1277

Lloyd J, Guilyardi E, Weller H (2011) The role of atmosphere feedbacks during ENSO in the CMIP3 models. Part II: using AMIP runs to understand the heat flux feedback mechanisms. Clim Dyn 37(7-8):1271-1292. doi:10.1007/s00382-010-0895-y

Lloyd J, Guilyardi E, Weller H (2012) The role of atmosphere feedbacks during ENSO in the CMIP3 models. Part III: the shortwave flux feedback. J Clim 25(12):4275-4293. doi: 10.1175/JCLI-D-11-00178.1

Lott F (1999) Alleviation of stationary Biases in a GCM through a mountain drag parameterization scheme and a simple representation of mountain lift forces. Mon Wea Rev 127:788-801

Lott F, Fairhead L, Hourdin F, Levan P (2005) The stratospheric version of LMDz: dynamical climatologies, arctic oscillation, and impact on the surface climate. Clim Dyn 25(7-8):851-868. doi:10.1007/s00382-005-0064-x

Louis JF (1979) A parametric model of vertical eddy fluxes in the atmosphere. Boundary Layer Meteorol 17:187-202

Loveland TR, Reed BC, Brown JF, Ohlen DO, Zhu Z, Yang L, Merchant JW (2000) Development of a global land cover characteristics database and IGBP DISCover from $1 \mathrm{~km} \mathrm{AV}$ HRR data. Int J Remote Sens 21(6-7):1303-1330. doi:10.1080/ 014311600210191

Ludwig W, Probst J, Kempe S (1996) Predicting the oceanic input of organic carbon by continental erosion. Global Biogeochemical Cycles 10(1):23-41. doi:10.1029/95GB02925

Lyman JM, Good SA, Gouretski VV, Ishii M, Johnson GC, Palmer MD, Smith DM, Willis JK (2010) Robust warming of the global upper ocean. Nature 465(7296):334-337. doi:10.1038/nature 09043

Lévy M, Estublier A, Madec G (2001) Choice of an advection scheme for biogeochemical models. Geophys Res Lett 28(19):37253728. doi:10.1029/2001GL012947
Madec G (2008) NEMO ocean engine. Technical note, IPSL, available at http://www.nemo-ocean.eu/content/download/ 11245/56055/file/NEMO_book_v3_2.pdf

Madec G, Imbard M (1996) A global ocean mesh to overcome the North Pole singularity. Clim Dyn 12(6):381-388. doi:10.1007/ BF00211684

Madronich S, Flocke S (1998) The role of solar radiation in atmospheric chemistry. In: Boule P (eds) Handbook of environmental chemistry. Springer, Heidelberg, pp 1-26

Manabe S, Stouffer RJ (1980) Sensitivity of a global climate model to an increase of $\mathrm{CO}_{2}$ concentration in the atmosphere. J Geophys Res Oce 85(C10):5529-5554. doi:10.1029/JC085iC10p05529

Marti O, Braconnot P, Dufresne JL, Bellier J, Benshila R, Bony S, Brockmann P, Cadule P, Caubel A, Codron F, de Noblet N, Denvil S, Fairhead L, Fichefet T, Foujols MA, Friedlingstein P, Goosse H, Grandpeix JY, Guilyardi E, Hourdin F, Krinner G, Lévy C, Madec G, Mignot J, Musat I, Swingedouw D, J, Talandier C (2010) Key features of the IPSL ocean atmosphere model and its sensitivity to atmospheric resolution. Clim Dyn 34:1-26. doi:10.1007/s00382-009-0640-6

Martin GM, Bellouin N, Collins WJ, Culverwell ID, Halloran PR, Hardiman SC, Hinton TJ, Jones CD, McDonald RE, McLaren AJ, O'Connor FM, Roberts MJ, Rodriguez JM, Woodward S, Best MJ, Brooks ME, Brown AR, Butchart N, Dearden C, Derbyshire SH, Dharssi I, Doutriaux-Boucher M, Edwards JM, Falloon PD, Gedney N, Gray LJ, Hewitt HT, Hobson M, Huddleston MR, Hughes J, Ineson S, Ingram WJ, James PM, Johns TC, Johnson CE, Jones A, Jones CP, Joshi MM, Keen AB, Liddicoat S, Lock AP, Maidens AV, Manners JC, Milton SF, Rae JGL, Ridley JK, Sellar A, Senior CA, Totterdell IJ, Verhoef A, Vidale PL, Wiltshire A (2011) The HadGEM2 family of met office unified model climate configurations. Geosci Model Dev 4(3):723-757. doi:10.5194/gmd-4-723-2011

Marzin C, Braconnot P (2009) Variations of Indian and African monsoons induced by insolation changes at 6 and $9.5 \mathrm{kyr}$ BP. Clim Dyn 33(2-3):215-231. doi:10.1007/s00382-009-0538-3

Maury P, Lott F, Guez L, Duvel JP (2013) Tropical variability and stratospheric equatorial waves in the IPSLCM5 model. Clim Dyn. doi: 10.1007/s00382-011-1273-0

Meehl GA, Covey C, McAvaney B, Latif M, Stouffer RJ (2005) Overview of the coupled model intercomparison project. Bull Am Meteorol Soc 86(1):89-93

Meehl GA, Covey C, Delworth T, Latif M, McAvaney B, Mitchell JFB, Stouffer RJ (2007) The WCRP CMIP3 multi-model dataset: a new era in climate change research. Bull Am Meteorol Soc 88(9):1383-1394. doi:10.1175/BAMS-88-9-1383

Meehl GA, Stocker TF, Collins WD, Friedlingstein P, Gaye AT, Gregory JM, Kitoh A, Knutti R, Murphy JM, Noda A, Raper SCB, Watterson IG, Weaver AJ, Zhao ZC (2007) Global climate projections. In: Solomon S, Qin D, Manning M, Chen Z, Marquis M, Averyt KB, Tignor M, Miller HL (eds) Climate change 2007: the scientific basis. Contribution of working group I to the fourth assessment report of the intergovernmental panel on climate change, chap 10. Cambridge University Press, Cambridge, pp 747-846

Meinshausen M, Smith SJ, Calvin KV, Daniel JS, Kainuma, JF M Lamarque, Matsumoto K, Montzka SA, Raper SCB, Riahi K, Thomson AM, Velders GJM, van Vuuren D (2011) The RCP greenhouse gas concentrations and their extension from 1765 to 2300. Climatic Change 109:213-241. doi:10.1007/s10584-0110156-Z

Mellor G, Blumberg A (2004) Wave breaking and ocean surface layer thermal response. J Phys Oceanogr 34(3):693-698. doi:10.1175/ 2517.1 
Menut L, PTripathi O, Colette A, Vautard R, Flaounas E, Bessagnet B (2013) Evaluation of regional climate simulations for air quality modelling purposes. Clim Dyn. doi:10.1007/s00382-012-1345-9

Merryfield WJ, Holloway G, Gargett AE (1999) A global ocean model with double-diffusive mixing. J Phys Oceanogr 29(6):1124-1142

Mitchell JFB, Johns TC, Eagles M, Ingram WJ, Davis RA (1999) Towards the construction of climate change scenarios. Climatic Change 41(3-4):547-581. doi:10.1023/A:1005466909820

Morcrette JJ, Smith L, Fouquart Y (1986) Pressure and temperature dependence of the absorption in longwave radiation parametrizations. Contrib Atmos Phys 59(4):455-469

Morgenstern O, Giorgetta MA, Shibata K, Eyring V, Waugh DW, Shepherd TG, Akiyoshi H, Austin J, Baumgaertner AJG, Bekki S, Braesicke P, Bruehl C, Chipperfield MP, Cugnet D, Dameris M, Dhomse S, Frith SM, Garny H, Gettelman A, Hardiman SC, Hegglin MI, Joeckel P, Kinnison DE, Lamarque JF, Mancini E, Manzini E, Marchand M, Michou M, Nakamura T, Nielsen JE, Olivie D, Pitari G, Plummer DA, Rozanov E, Scinocca JF, Smale D, Teyssedre H, Toohey M, Tian W, Yamashita Y (2010) Review of the formulation of present-generation stratospheric chemistry-climate models and associated external forcings. J Geophys Res Atm 115:D00M02. doi:10.1029/2009JD013728

Morissey ML (1990) An evaluation of ship data in the equatorial western Pacific. J Clim 3(1):99-112

Moss RH, Edmonds JA, Hibbard KA, Manning MR, Rose SK, van Vuuren DP, Carter TR, Emori S, Kainuma M, Kram T, Meehl GA, Mitchell JFB, Nakicenovic N, Riahi K, Smith SJ, Stouffer RJ, Thomson AM, Weyant JP, Wilbanks TJ (2010) The next generation of scenarios for climate change research and assessment. Nature 463(7282):747-756. doi:10.1038/nature08823

Najjar RG, Jin X, Louanchi F, Aumont O, Caldeira K, Doney SC, Dutay JC, Follows M, Gruber N, Joos F, Lindsay K, MaierReimer E, Matear RJ, Matsumoto K, Monfray P, Mouchet A, Orr JC, Plattner GK, Sarmiento JL, Schlitzer R, Slater RD, Weirig MF, Yamanaka Y, Yool A (2007) Impact of circulation on export production, dissolved organic matter, and dissolved oxygen in the ocean: results from phase II of the Ocean carbon-cycle model intercomparison project (OCMIP-2). Global Biogeochem Cycles 21(3):GB3007. doi:10.1029/2006GB002857

Persechino A, Mignot J, Swingedouw D, Labetoulle S, Guilyardi E (2013) Decadal predictability of the atlantic meridional overturning circulation and climate in the IPSLCM5A-LR model. Clim Dyn. doi:10.1007/s00382-012-1466-1

Pham M, Boucher O, Hauglustaine D (2005) Changes in atmospheric sulfur burdens and concentrations and resulting radiative forcings under IPCC SRES emission scenarios for 1990-2100. J Geophys Res Atm 110:D06112. doi:10.1029/2004JD005125

Piao S, Ciais P, Friedlingstein P, de Noblet-Ducoudre N, Cadule P, Viovy N, Wang T (2009) Spatiotemporal patterns of terrestrial carbon cycle during the 20th century. Global Biogeochem Cycles 23:GB4026. doi:10.1029/2008GB003339

Quaas J, Boucher O (2005) Constraining the first aerosol indirect radiative forcing in the LMDZ GCM using POLDER and MODIS satellite data. Geophys Res Lett 32:L17814. doi: 10.1029/2005GL023850

Ramaswamy V, Boucher O, Haigh J, Hauglustaine D, Haywood J, Myhre G, Nakajima T, Shi G, Solomon S (2001) Radiative forcing of climate change. In: Houghton JT, Ding Y, Griggs DJ, Noguer M, Linden PJ, Dai X, Maskell K, Johnson CA (eds) Climate change 2001: the scientific basis. Contribution of working group I to the third assessment report of the intergovernmental panel on climate change, chap 6. Cambridge University Press, Cambridge, pp 349-416

Rayner NA, Parker DE, Horton EB, Folland CK, Alexander LV, Rowell DP, Kent EC, Kaplan A (2003) Global analyses of sea surface temperature, sea ice, and night marine air temperature since the late nineteenth century. J Geophys Res Atm 108(D14): 4407. doi:10.1029/2002JD002670

Rio C, Hourdin F (2008) A thermal plume model for the convective boundary layer: representation of cumulus clouds. J Atmos Sci 65:407-425

Rio C, Hourdin F, Couvreux F, Jam A (2010) Resolved versus parametrized boundary-layer plumes. Part II: continuous formulations of mixing rates for mass-flux schemes. Boundary Layer Meteorol 135:469-483. doi:10.1007/s10546-010-9478-Z

Rogelj J, Meinshausen M, Knutti R (2012) Global warming under old and new scenarios using IPCC climate sensitivity range estimates. Nat Clim Change 2(4):248-253. doi:10.1038/nclimate1385

de Rosnay P, Polcher J (1998) Modelling root water uptake in a complex land surface scheme coupled to a GCM. Hydrol Earth Syst Sci 2(2-3):239-255. doi:10.5194/hess-2-239-1998

de Rosnay P, Polcher J, Laval K, Sabre M (2003) Integrated parameterization of irrigation in the land surface model ORCHIDEE. Validation over Indian Peninsula. Geophys Res Lett 30(19):1986. doi:10.1029/2003GL018024

Sadourny R, Laval K (1984) January and July performance of the LMD general circulation model. In: New perspectives in climate modelling. Elsevier Science Publishers, Amsterdam, pp 173-198

Sander SP, Friedl RR, Golden DM, Kurylo MJ, Moortgat GK, KellerRudek H, Wine PH, Ravishankara AR, Kolb CE, Molina MJ, Finlayson-Pitts BJ, Huie RE, Orkin VL (2006) Chemical kinetics and photochemical data for use in atmospheric studies, evaluation no. 15. JPL Publication 06-2, Jet Propulsion Laboratory, Pasadena (CA), USA, http://jpldataeval.jpl.nasa.gov

Sato M, Hansen JE, McCormick MP, Pollack JB (1993) Stratospheric aerosol optical depths, 1850-1990. J Geophys Res Atm 98(D12):22987-22994. doi:10.1029/93JD02553

Schulz M (2007) Constraining model estimates of the aerosol radiative forcing. Thèse d'Habilitation à Diriger des Recherches, Université Pierre et Marie Curie, Paris, France

Schulz M, Balkanski Y, Guelle W, Dulac F (1998) Role of aerosol size distribution and source location in a three-dimensional simulation of a saharan dust episode tested against satellitederived optical thickness. J Geophys Res Atm 103(D9):10579_ 10592. doi:10.1029/97JD02779

Simmons HL, Jayne SR, Laurent LCS, Weaver AJ (2004) Tidally driven mixing in a numerical model of the ocean general circulation. Ocean Modelling 6(3-4):245-263. doi:10.1016/ S1463-5003(03)00011-8

Son SW, Gerber EP, Perlwitz J, Polvani LM, Gillett NP, Seo KH, Eyring V, Shepherd TG, Waugh D, Akiyoshi H, Austin J, Baumgaertner A, Bekki S, Braesicke P, Bruehl C, Butchart N, Chipperfield MP, Cugnet D, Dameris M, Dhomse S, Frith S, Garny H, Garcia R, Hardiman SC, Joeckel P, Lamarque JF, Mancini E, Marchand M, Michou M, Nakamura T, Morgenstern O, Pitari G, Plummer DA, Pyle J, Rozanov E, Scinocca JF, Shibata K, Smale D, Teyssedre H, Tian W, Yamashita Y (2010) Impact of stratospheric ozone on Southern Hemisphere circulation change: a multimodel assessment. J Geophys Res Atm 115:D00M07. doi:10.1029/2010JD014271

Stevens B, Schwartz SE (2012) Observing and modeling Earth's energy flows. Surv Geophys 33(3-4):779-816. doi:10.1007/ s10712-012-9184-0

Stommel H (1961) Thermohaline convection with two stable regimes of flow. Tellus 13(2):224-230. doi:10.1111/j.2153-3490.1961. tb00079.x

Swart NC, Fyfe JC (2012) Ocean carbon uptake and storage influenced by wind bias in global climate models. Nat Clim Change 2(1):47-52. doi:10.1038/NCLIMATE1289

Swingedouw D, Braconnot P, Delecluse P, Guilyardi E, Marti O (2007) The impact of global freshwater forcing on the 
thermohaline circulation: adjustment of North Atlantic convection sites in a CGCM. Clim Dyn 28(2):291-305. doi:10.1007/ s00382-006-0171-3

Swingedouw D, Braconnot P, Delecluse P, Guilyardi E, Marti O (2007) Quantifying the AMOC feedbacks during a 2xCO2 stabilization experiment with land-ice melting. Clim Dyn 29(5):521-534. doi:10.1007/s00382-007-0250-0

Swingedouw D, Mignot J, Braconnot P, Mosquet E, Kageyama M, Alkama R (2009) Impact of freshwater release in the North Atlantic under different climate conditions in an OAGCM. J Clim 22(23):6377-6403. doi:10.1175/2009JCLI3028.1

Swingedouw D, Mignot J, Labetoule S, Guilyardi E, Madec G (2013) Initialisation and predictability of the AMOC over the last 50 years in a climate model. Clim Dyn. doi:10.1007/s00382012-1516-8

Szopa S, Balkanski Y, Schulz M, Bekki S, Cugnet D, FortemsCheiney A, Turquety S, Cozic A, Déandreis C, Hauglustaine D, Idelkadi A, Lathière J, Marchand M, Yan N, Dufresne JL (2013) Aerosol and ozone changes as forcing for climate evolution between 1850 and 2100. Clim Dyn. doi:10.1007/s00382-0121408-y

Taylor KE, Stouffer RJ, Meehl GA (2012) An overview of CMIP5 and the experiment design. Bull Am Meteorol Soc 93(4):485498. doi:10.1175/BAMS-D-11-00094.1

Terray P (2011) Southern Hemisphere extra-tropical forcing: a new paradigm for El Niño-Southern Oscillation. Clim Dyn 36(11-12): 2171-2199. doi:10.1007/s00382-010-0825-Z

Tiedtke M (1989) A comprehensive mass flux scheme for cumulus parameterization in large-scale models. Mon Wea Rev 117: $1179-1800$
Trenberth KE, Fasullo JT (2012) Tracking Earth's energy: From El Niño to global warming. Surv Geophys 33(3-4):413-426. doi: 10.1007/s10712-011-9150-2

Valcke S (2006) OASIS3 user's guide (prism-2-5). Tech. Rep. TR/ CMGC/06/73, PRISM Report No 3, CERFACS, Toulouse, France

Van Leer B (1977) Towards the ultimate conservative difference scheme: IV. A new approach to numerical convection. J Computat Phys 23:276-299

Vial J, Osborn TJ, Lott F (2013) Sudden stratospheric warmings and tropospheric blockings in a multi-century simulation of the IPSL-CM5A coupled climate model. Clim Dyn doi:10.1007/ s00382-013-1675-2

van Vuuren D, Edmonds J, Kainuma M, Riahi K, Thomson A, Hibbard K, Hurtt G, Kram T, Krey V, Lamarque JF, Masui T, Meinshausen M, Nakicenovic N, Smith S, Rose S (2011) The representative concentration pathways: an overview. Climatic Change, 1-27. 10.1007/s10584-011-0148-z

Wang YM, Lean JL, Sheeley NR (2005) Modeling the sun's magnetic field and irradiance since 1713. Astrophys J 625(1):522-538. doi: $10.1086 / 429689$

Wanninkhof R (1992) Relationship between wind-speed and gasexchange over the ocean. J Geophys Res Oce 97(C5):73737382. doi:10.1029/92JC00188

Wittenberg AT (2009) Are historical records sufficient to constrain ENSO simulations? Geophys Res Lett 36. doi:10.1029/2009GL 038710

Xavier PK, Duvel JP, Braconnot P, Doblas-Reyes FJ (2010) An evaluation metric for intraseasonal variability and its application to CMIP3 twentieth-century simulations. J Clim 23(13):34973508. doi:10.1175/2010JCLI3260a.1 